\title{
LUMINESCENCE METHODS FOR STUDY AND DETERMINATION OF POLLUTANTS IN THE ENVIRONMENT
}

\author{
Tanausú Vega Morales ${ }^{1}$, Sarah Montesdeoca Esponda ${ }^{1}$, José Juan Santana Rodríguez ${ }^{1}$, \\ Snezhana Efremova Aaron ${ }^{2}$, Jean-Jacques Aaron ${ }^{3,4}$ \\ ${ }^{1}$ Department of Chemistry, Faculty of Marine Sciences, University of Las Palmas de G.C., \\ 35017 Las Palmas de G.C., Spain \\ ${ }^{2}$ Department of Medical and Experimental Biochemistry, Faculty of Medicine, \\ "SS Cyril and Methodius" University of Skopje, 50. Divizja 6, MK-1000 Skopje, Republic of Macedonia \\ ${ }^{3}$ Université Paris-Est- Marne la Vallée, Laboratoire Géomatériaux et Environnement (LGE), \\ 5 boulevard Descartes, 77454 Champs-sur-Marne Cedex 2, France \\ ${ }^{4}$ ITODYS, Université Paris 7-Denis Diderot-CNRS-UMR 7086, Bâtiment Lavoisier - 15 rue Jean de Baïf, \\ 75205 Paris Cedex 13, France \\ jeanjacquesaaron@yahoo.fr (J.J.Aaron)
}

\begin{abstract}
The analytical performances and applications of various luminescence spectrometric methods to the study and determination of pollutants present at low levels in the environment are reviewed for the last two decades (1990 2010). The first part concerns luminescence stationary systems, including fluorescence, photochemically-induced fluorescence, phosphorescence and related luminescence methods. In the second part, the combination of these luminescence methods with flow techniques such as high performance liquid chromatography (HPLC), capillary electrophoresis (CE) and flow injection analysis (FIA) for the detection and determination of environmental pollutants is investigated. A part of the review is also devoted to the usefulness of organized supramolecular systems, such as micellar media, cyclodextrins and calixarenes, for improving the efficiency of luminescence methods.
\end{abstract}

Key words: luminescence; fluorescence; phosphorescence; bioluminescence; HPLC; CE; FIA; micellar media; cyclodextrins; pollutants

\section{ЛУМИНЕСЦЕНТНИ МЕТОДИ ЗА ПРОУЧУВАЊЕ И ОПРЕДЕЛУВАЊЕ ЗАГАДУВАЧКИ СУПСТАНЦИИ ВО ЖИВОТНАТА СРЕДИНА}

\footnotetext{
Направен е преглед на аналитичките перформанси и примена на различни луминесцентни спектрометриски методи за проучување и определување загадувачки супстанции присутни со ниски нивоа во животната средина, кој се однесува на последните две децении (1990-2010). Првиот дел се однесува на луминесцентните стационарни системи, вклучувајќи ги флуоресценцијата, фотохемиски индуцираната флуоресценција, фосфоресценцијата и сродните луминесцентни методи. Во вториот дел е проучувана комбинацијата на овие луминесцентни методи со проточните техники како што се високоефикасната течна хроматографија (HPLC), капиларната електрофореза (CE) и анализата на проточно инјектирање (FIA) за детекција и определување на загадувачките супстанции во животната средина. Дел од прегледот е посветен и на искористувањето на организираните супрамолекуларни системи, на пример мицелните медиуми, циклодекстрините и каликсарените, за подобрување на ефикасноста на луминесцентните методи.
}

Клучни зборови: луминесценција; флуоресценција: фосфоресценција; биолуминесценција; HPLC; CE; FIA; мицелни медуими; циклодекстрини; загадувачки супстанции 


\section{INTRODUCTION}

The presence of a variety of organic and inorganic pollutants at very low concentrations in various compartments of the environment constitutes nowadays a very serious problem, because of their potential adverse effects and possible toxicity. Indeed, since several decades it is well known that the atmosphere, natural waters and soils are polluted worldwide by a number of polycyclic aromatic hydrocarbons (PAHs), organo-chlorinated compounds, pesticides and heavy metals at trace levels $[1,2]$. For example, pesticide residues and other organic micropollutants have been recently found in the air and rainwater of rural as well as urban regions of developed countries [3, 4], as well as in the natural waters of many rivers and lakes $[5$, 6]. Therefore, it is very important to establish and improve sensitive and selective analytical methods and procedures for identifying, detecting and determining pollutants in the environment.

Chromatographic, multi-residues methods remain one of the preferred tools for the characterization and determination of low levels of pollutants in the environment $[3,5,6]$. However, luminescence spectrometry has also been proposed for the study and determination of chemical species, and several improved luminescence analytical methods and procedures have been developed in recent years [7-14]. For instance, fluorescence spectrometry has been extensively applied to the quantitative analysis of many organic compounds in the biological, biomedical, food and environmental fields [7, 8]. Indeed, from the analytical standpoint, fluorescence, phosphorescence and related luminescence techniques present the interest to be very sensitive, relatively selective and simple methods, and, in particular, can be easily applied to environmental samples, generally without further purification [7-10]. For this reason, a number of luminescence methods have been developed for the determination of many chemical families, such as PAHs, pesticides, organo-chlorinated compounds, pharmaceuticals and heavy toxic metals, possibly present at low concentration levels in the atmosphere, waters, soils and living organisms.

In addition, several organized media, including micelles and cyclodextrins, have been extensively applied to luminescence methods and other related analytical techniques, and have generally permitted to enhance their sensitivity and selectivity [15-24]. On the one hand, micelles are prepared by adding appropriate amounts of surfac- tants in water or water-organic mixtures. Surfactants present an amphiphilic character and possess two parts, the head, polar and hydrophilic, and the so-called tail, hydrophobic, which consists in general of a long hydrocarbon chain, linear or branched, with different numbers of carbon atoms. The surfactants are classified as anionic, cationic, nonionic and zwitterionic, according to the nature of the hydrophilic group. The surfactant molecules will aggregate in aqueous or partially-aqueous solution to form micelles of a colloidal size, when the surfactant concentration exceeds a certain threshold value, called critical micelle concentration (CMC), at temperature higher than its Kraft temperature [25]. By using micellar media, it is possible to modify the solubility and microenvironment of analytes, and to increase their luminescence signal [24]. On the other hand, cyclodextrins (CDs) are water-soluble, cyclic oligosaccharides, and, depending on their size, they can form inclusion complexes with appropriate organic molecules, producing changes in their photophysical properties. The three most used CDs are known as $\alpha, \beta$ and $\gamma$, and they contain six, seven and eight units of glucopyranose, respectively. Since most analytes, upon forming complexes with cyclodextrins, yield an enhancement of their luminescence quantum yield relative to aqueous medium, CDs have extensively been used in luminescence analytical techniques [22, 23, 24].

Two distinct types of luminescence systems, namely in the stationary mode and in combination with several flow techniques (liquid chromatography, capillary electrophoresis and flow injection analysis), have been proposed for environmental analyses.

The goal of our review is to examine the recent literature (period 1990-2010), concerning the use of different types of luminescent spectrometric methods, for investigating and determining organic and inorganic pollutants and other compounds of environmental interest at the trace level. In this article we will study successively the performances, results and environmental applications of luminescence methods in the stationary mode (fluorescence, phosphorescence and related luminescence methods such as luminescent and chemiluminescent (CL) immunosensors and bioluminescent biosensors), and of dynamic systems (high performance liquid chromatography [HPLC], capillary electrophoresis $[\mathrm{CE}]$, and flow injection analysis, [FIA], in various modes) with luminescence detection. The interest of using various organized molecular media for improving the performances 
of luminescence methods in environmental analyses will also be particularly emphasized.

\section{STATIONARY LUMINESCENCE METHODS: STUDY AND DETERMINATION OF POLLUTANTS IN THE ENVIRONMENT}

In this section, we will describe the basis, performances and analytical applications of various luminescence spectrometric methods in the stationary mode, utilized to study and determine several groups of organic and inorganic pollutants generally present at low concentration levels in the environment.

\section{Generalities on the analytical interest of luminescence spectrometric methods}

Two main luminescence spectrometric methods of analytical interest exist, namely fluorescence and phosphorescence.

As already stated, conventional fluorescence spectrometry has been widely utilized for the quantitative analysis of a variety of organic compounds [7-10]. In the case of complex, environmental samples, the scope of application of fluorimetric analysis can be extended to mixtures by using synchronous fluorescence (SF) spectrometry [26]. In the SF spectrometric technique, a fluorescence signal is recorded by simultaneously scanning both excitation and emission wavelengths ( $\lambda_{\mathrm{EX}}$ and $\lambda_{\mathrm{EM}}$ ), using an optimized, fixed wavelength interval $\left(\Delta \lambda=\lambda_{\mathrm{EM}}-\lambda_{\mathrm{EX}}\right)$. The SF spectra measured on the basis of the selection of a suitable $\Delta \lambda$ are generally simpler, with narrower peaks, and hence much more selective than the corresponding, conventional fluorescence spectra.

In case the analytes under study present a too low fluorescence quantum yield, indirect fluorescence methods have been developed. One of the most efficient and easy-to-use indirect fluorimetric methods is photochemically-induced fluorescence (PIF), which is based on the ultraviolet (UV) irradiation of a non-fluorescent or weakly-fluorescent analyte, resulting into the photochemical formation of strongly fluorescent photoproduct(s) [27]. PIF can be applied either in the stationary mode (liquid solution or solid surface) or in a dynamic flow containing the analytes, in combination with HPLC or FIA [27-29]. After the photochemical reaction of the analyte has taken place, the formed photoproduct(s) is (are) fluorimetrically detected and quantified. Since a number of years, PIF has been demonstrated to be a versatile, simple, very sensitive and selective analytical tool for the determination of many compounds at low concentration levels, and has been applied in pharmaceutical, clinical and environmental analyses [27-29].

Phosphorescence spectrometry in conventional, room-temperature liquid solutions lacks sensitivity, because of the forbidden character of the phosphorescence triplet-to-singlet transition. For analytical purposes, phosphorescence must be used in special, experimental conditions, including frozen solutions at low temperature (low-temperature phosphorescence, LTP), solid substrates at room temperature (solid-state room-temperature phosphorescence, SS-RTP), liquid solutions at room temperature (room temperature phosphorescence in the liquid state, RTPL) in the presence of oxygen scavengers and heavy atoms, micellar media or CDs $[30,31]$. The role of frozen solutions, solid substrates, micellar media and CDs is to rigidify the analytical medium of interest, and to decrease the non-radiative, inverse intersystem crossing process, whereas that of oxygen scavengers and heavy atoms is to increase the probability of the singlet-to-triplet intersystem crossing process. In these particular conditions, phosphorescence spectrometry constitutes a useful analytical technique for the determination of a number of pharmaceuticals, and of biomedical and environmental compounds, because of the improved sensitivity and selectivity of the method, and of the small volume of sample required [30, 31]. As shown by Kuijt et al. [31], the RTPL methods, have been recently developed as convenient, relatively sensitive and simple analytical tools.

\section{Polycyclic aromatic hydrocarbons (PAHs)}

Because PAHs generally present strong fluorescence quantum yield values, room temperature fluorescence spectroscopy is a very useful method for their determination in the environment, with several important advantages, including large linear dynamic ranges and very low limit of quantification (LOQ) and limit of detection (LOD) values at $\mathrm{ng} \mathrm{ml}^{-1}$ concentration levels. Several types of media, such as solid surfaces and organized systems (micelles, cyclodextrins, nanotubes, nanospheres) have been proposed to increase the PAH fluorescence and/or phosphorescence signal and 
therefore, to improve the sensitivity of luminescence methods. Various environmental applications of luminescence spectrometry obtained in different media are summarized in Table 1, in which we have provided the types of utilized matrices and media, the detection modes and excitation/emission wavelengths, and the available LOD values.

Bortolato et al. [32] suggested the use of nylon membranes as a solid surface for the roomtemperature fluorescent and phosphorescent determination of benzo $[a]$ pyrene, one of the most carcinogenic PAHs, at ultra trace levels in water samples. This approach was based on the solidphase extraction of the analyte on a nylon membrane via a syringe procedure, and its luminescent determination on the nylon surface. It permitted to detect benzo[a]pyrene at the sub-ppt (sub-ng L ${ }^{-1}$ ) level. The method was successfully applied to determine benzo $[a]$ pyrene in real samples, including spiked tap, underground and mineral waters [32]. The characterization of several important PAHs was also studied by fluorescence on five types of solid surface as the first step for developing new optical sensors for PAH screening in environmental samples [33]. Filter paper coated with poly(hydrogenmethylsiloxane) and dichlorodimethylsilane solutions were applied to the extraction and solid-matrix fluorescence and phosphorescence measurement of $\mathrm{PAH}$ aqueous solutions by Ackerman and Hurtubise [34], leading to very small LOD values (for example, $29 \mathrm{fmol} / \mathrm{mL}$ for benzo[e]pyrene). Whitcomb et al. [35] investigated the potential of solid-phase extraction (SPE) timeresolved laser-induced fluorimetry (TRLIF) for screening PAHs in aqueous samples. The authors used octadecyl membranes for the dual purpose of extracting PAHs from water samples, and serving as the solid substrate for TRLIF detection. Comparing to SPE solid-matrix conventional luminescence, they found that SPE-TRLIF yielded an LOD improvement of one order of magnitude, reaching the ppt level, and allowing the direct determination of benzo[a]pyrene in a spiked river water sample [35]. Polyurethane foams (PUFs) were also proposed for the extraction of several PAHs in water and their determination in solid phase by luminescence spectroscopy [36]. By this method, a benzo $[a]$ pyrene concentration of $0.02 \mathrm{ng}$ $\mathrm{mL}^{-1}$ could be determined. In another study, Djachuk et al. [37, 38] examined the adsorption of PAHs on a cellulose matrix from aqueous micellar media and the feasibility of their luminescence determination.
Synchronous fluorescence (SF) spectrometric methods were also developed by various groups to improve the selectivity of the quantitative analysis of PAHs in complex mixtures [39-47]. For example, Vasquez-Troche et al. [39] were able to determine benzo $[a]$ pyrene, benzo $[b]$ fluoranthene and benzo[ $k]$ fluoranthene in a mixture of 16 PAHs by constant- wavelength mode SF. The procedure was simple and fast and permitted their routine quantification at the $\mu \mathrm{g} \mathrm{L}^{-1}$ level. Another study described significant improvements in selectivity and sensitivity obtained, in spite of some practical problems, by using the constant-energy synchronous luminescence (CESL) method instead of the more classical constant-wavelength SF, and demonstrated the advantage of applying optimized CESL in the case of complex mixtures of PAHs [40]. The simultaneous SF determination of various binary and ternary mixtures of PAHs in sea water was also reported by Santana Rodriguez et al. [42-45], using micellar media, containing various surfactants. For instance, these authors were able to resolve mixtures of benzo[ $a]$ pyrene and perylene in the presence of Triton X-100 [42], benzo[a]pyrene, perylene and chrysene using polyoxyethylene10-lauryl ether (POLE) [42], dibenz[a,c]anthracene and coronene, and chrysene, perylene and coronene with hexadecyltrimethylammonium bromide (HDTAB) [44]. The selected $\Delta \lambda$ values ranged between 16 and $140 \mathrm{~nm}$, according to the mixture. Also the determination of perylene and benzo$[g h i]$ perylene was carried out in sea water samples, using HDTAB as a surfactant [45], with LODs of 0.12 and $0.21 \mathrm{ng} \mathrm{mL}^{-1}$, respectively. SF spectrometry can also be improved by combining it with chemometric techniques and mathematical treatment of the spectral data. For example, Guiteras et al. [46] compared different multivariate calibration methods (classical least squares [CLS], principal component regression [PCR] and partial least squares regression [PLSR]), for the determination of multicomponent PAHs in water samples, in the presence of the surfactant polyoxyethylene-23dodecyl ether (Brij-35). The best predictive performances were achieved with PLSR, although PCR gave also good results. In a related study, the quantitative analysis of mixtures of PAHs, containing six to ten components, was performed by combining SF spectrometry with a multivariate method in the presence of cetyltrimethylammonium bromide (CTAB) as a surfactant [47]. LOD values were in the $0.005-32.0 \mathrm{ng} \mathrm{mL}^{-1}$ range. 
Table 1

Fluorescence and phosphorescence analysis of PAHs: environmental applications

\begin{tabular}{|c|c|c|c|c|c|}
\hline PAH & Matrix & Medium & $\begin{array}{l}\text { Technique } \\
\lambda[\mathrm{nm}]\end{array}$ & $\begin{array}{c}\mathrm{LOD}^{\mathrm{a}} \\
\left(\mathrm{ng} \mathrm{mL}^{-1}\right) \\
\end{array}$ & Ref. \\
\hline Benzo $[a]$ pyrene & $\begin{array}{l}\text { Tap, underground \& } \\
\text { mineral water }\end{array}$ & Solid surface (nylon) & $\mathrm{F}^{\mathrm{b}} \& \mathrm{RTP}^{\mathrm{c}}$ & - & [32] \\
\hline Benzo[e]pyrene & Water & Coated filter paper & $\mathrm{F}^{\mathrm{b}} \& \mathrm{RTP}^{\mathrm{c}}$ & $29 \mathrm{fmol} \mathrm{mL}^{-1}$ & [34] \\
\hline Benzo $[a]$ pyrene & River water & Octadecyl membrane & SPE-TRLIF & A few ppt & [35] \\
\hline Benzo $[a]$ pyrene & Water & $\begin{array}{l}\text { Polyurethane foams } \\
\text { (PUFs) }\end{array}$ & Solid-state $\mathrm{F}^{\mathrm{b}}$ & 0.02 & [36] \\
\hline $\operatorname{Benzo}[a]$ pyrene & \multirow{6}{*}{ Tap and sea water } & \multirow[t]{6}{*}{ POLE $^{\mathrm{e}}$} & $\begin{array}{c}\mathrm{LVAF}^{\mathrm{f}} \\
\lambda_{\mathrm{EX}} 264, \lambda_{\mathrm{EM}} 408\end{array}$ & - & \multirow{6}{*}{ [48] } \\
\hline Benzo $[e]$ pyrene & & & $\begin{array}{c}\mathrm{LVAF}^{\mathrm{f}} \\
\lambda_{\mathrm{EX}} 289, \lambda_{\mathrm{EM}} 392\end{array}$ & - & \\
\hline Benzo[ghi]perylene & & & $\begin{array}{c}\mathrm{LVAF}^{\mathrm{f}} \\
\lambda_{\mathrm{EX}} 300, \lambda_{\mathrm{EM}} 417\end{array}$ & - & \\
\hline Coronene & & & $\begin{array}{c}\mathrm{LVAF} \\
\lambda_{\mathrm{EX}} 303, \lambda_{\mathrm{EM}} 449\end{array}$ & - & \\
\hline Dibenzo $[a, h]$ anthracene & & & $\begin{array}{c}\mathrm{LVAF}^{\mathrm{f}} \\
\lambda_{\mathrm{EX}} 298, \lambda_{\mathrm{EM}} 398\end{array}$ & - & \\
\hline Indene $[1,2,3-c d]$ pyrene & & & $\begin{array}{c}\mathrm{LVAF}^{\mathrm{f}} \\
\lambda_{\mathrm{EX}} 256, \lambda_{\mathrm{EM}} 360\end{array}$ & - & \\
\hline Acenaphtene & \multirow{5}{*}{ Tap and river water } & \multirow[t]{5}{*}{$\operatorname{SDS}^{\mathrm{g}}$} & $\lambda_{\mathrm{EX}} 227.6, \lambda_{\mathrm{EM}} 339.8$ & 1.8 & \multirow{5}{*}{ [49] } \\
\hline Phenanthrene & & & $\begin{array}{c}\mathrm{F}^{\mathrm{b}} \\
\lambda_{\mathrm{EX}} 253.1, \lambda_{\mathrm{EM}} 368.2\end{array}$ & 3.8 & \\
\hline Fluorene & & & $\begin{array}{c}\mathrm{F}^{\mathrm{b}} \\
\lambda_{\mathrm{EX}} 264.9, \lambda_{\mathrm{EM}} 610.0\end{array}$ & 1.7 & \\
\hline Pyrene & & & $\begin{array}{c}F^{b} \\
\lambda_{\mathrm{EX}} 336.3, \lambda_{\mathrm{EM}} 376.5\end{array}$ & 2.0 & \\
\hline Benzo $[a]$ pyrene & & & $\begin{array}{c}\mathrm{F}^{\mathrm{b}} \\
\lambda_{\mathrm{EX}} 297.8, \lambda_{\mathrm{EM}} 432.3\end{array}$ & 0.8 & \\
\hline Benzo $[a]$ pyrene & \multirow{3}{*}{ Particulate air } & \multirow[t]{3}{*}{$\operatorname{SDS}^{\mathrm{g}}$} & $\begin{array}{c}\mathrm{F}^{\mathrm{b}} \\
\lambda_{\mathrm{EX}} 294, \lambda_{\mathrm{EM}} 405\end{array}$ & 0.002 & \multirow{6}{*}{ [51] } \\
\hline Pyrene & & & $\lambda_{\mathrm{EX}} 335, \lambda_{\mathrm{EM}} 390$ & 0.003 & \\
\hline Benzo $[a]$ anthracene & & & $\begin{array}{c}F^{\mathrm{b}} \\
\lambda_{\mathrm{EX}} 288, \lambda_{\mathrm{EM}} 388\end{array}$ & 0.01 & \\
\hline Pyrene & \multirow{3}{*}{ Particulate air } & \multirow{3}{*}{$\mathrm{CTAB}^{\mathrm{h}}$} & $\lambda_{\mathrm{EX}} 335, \lambda_{\mathrm{EM}} 392$ & 0.17 & \\
\hline $\operatorname{Benzo}[a]$ pyrene & & & $\lambda_{\mathrm{EX}} 290, \lambda_{\mathrm{EM}} 390$ & 0.10 & \\
\hline Benzo[ghi]perylene & & & $\lambda_{\mathrm{EX}} 290, \lambda_{\mathrm{EM}} 420$ & 0.08 & \\
\hline Pyrene & \multirow{3}{*}{ Particulate air } & Brij 35 & $\begin{array}{c}\mathrm{F}^{\mathrm{b}} \\
\lambda_{\mathrm{EX}} 338, \lambda_{\mathrm{EM}} 391\end{array}$ & 0.02 & \multirow{3}{*}{ [52] } \\
\hline Benzo $[a]$ pyrene & & & $\begin{array}{c}F^{b} \\
\lambda_{E X} 297, \lambda_{E M} 410\end{array}$ & 0.004 & \\
\hline Benzo[ghi]perylene & & & $\lambda_{\mathrm{EX}} 300, \lambda_{\mathrm{EM}} 420$ & 0.02 & \\
\hline $\begin{array}{l}\text { Benzo }[a] \text { pyrene, } \\
\text { benzo[ }[b] \text { fluoranthene, } \\
\text { benzo }[k] \text { fluoranthene }\end{array}$ & Mixture of 16 PAHs & - & $\mathrm{SF}^{\mathrm{i}}$ & $0.09-0.3 \mu \mathrm{g} \mathrm{L}^{-1}$ & [39] \\
\hline $\begin{array}{l}\text { Benzo }[a] \text { pyrene } \\
\text { Perylene }\end{array}$ & Sea water & Triton $\mathrm{X}-100$ & $\begin{array}{c}\mathrm{SF}^{\mathrm{i}} \\
\Delta \lambda 18\end{array}$ & $\begin{array}{l}0.27 \\
0.30 \\
\end{array}$ & [42] \\
\hline Benzo $[a]$ pyrene & Sea water & POLE $^{\mathrm{e}}$ & $\begin{array}{c}\mathrm{SF}^{\mathrm{i}} \\
\Delta \lambda 17.5\end{array}$ & $\begin{array}{l}0.05 \\
0.28\end{array}$ & [42] \\
\hline
\end{tabular}




\begin{tabular}{|c|c|c|c|c|c|}
\hline PAH & Matrix & Medium & $\begin{array}{c}\text { Technique } \\
\lambda[\mathrm{nm}]\end{array}$ & $\begin{array}{c}\mathrm{LOD}^{\mathrm{a}} \\
\left(\mathrm{ng} \mathrm{mL}^{-1}\right)\end{array}$ & Ref. \\
\hline $\begin{array}{l}\text { Perylene } \\
\text { Chrysene }\end{array}$ & & & $\begin{array}{c}\mathrm{SF}^{\mathrm{i}} \\
\Delta \lambda 17.5 \\
\mathrm{SF} \\
\Delta \lambda 42\end{array}$ & 0.64 & \\
\hline $\begin{array}{l}\text { Dibenz }[a, c] \text { anthracene } \\
\text { Coronene }\end{array}$ & Sea water & HDTAB $^{\mathrm{j}}$ & $\begin{array}{c}\mathrm{SF}^{\mathrm{i}} \\
\Delta \lambda 89\end{array}$ & $\begin{array}{l}0.20 \\
0.22\end{array}$ & [44] \\
\hline $\begin{array}{l}\text { Dibenz }[a, c] \text { anthracene } \\
\text { Coronene }\end{array}$ & Sea water & HDTAB $^{j}$ & $\begin{array}{c}\mathrm{SF}^{\mathrm{i}} \\
\Delta \lambda 89\end{array}$ & $\begin{array}{l}0.20 \\
0.22\end{array}$ & [44] \\
\hline $\begin{array}{l}\text { Chrysene } \\
\text { Perylene } \\
\text { Coronene }\end{array}$ & Sea water & $\operatorname{HDTAB}^{\mathrm{j}}$ & $\begin{array}{c}\mathrm{SF}^{\mathrm{i}} \\
\Delta \lambda 41 \\
\mathrm{SF}^{\mathrm{i}} \\
\Delta \lambda 3 \\
\mathrm{SF}^{\mathrm{i}} \\
\Delta \lambda 140\end{array}$ & $\begin{array}{l}0.17 \\
0.13 \\
0.14\end{array}$ & [44] \\
\hline $\begin{array}{l}\text { Dibenz }[a, c] \text { anthracene } \\
\text { Coronene }\end{array}$ & Sea water & $\operatorname{HDTAB}^{\mathrm{j}}$ & $\begin{array}{c}\text { SF } \\
\Delta \lambda 89\end{array}$ & $\begin{array}{l}0.20 \\
0.22\end{array}$ & [44] \\
\hline $\begin{array}{l}\text { Chrysen } \\
\text { Perylene } \\
\text { Coronene }\end{array}$ & Sea water & HDTAB $^{\mathrm{j}}$ & $\begin{array}{c}\mathrm{SF}^{1} \\
\Delta \lambda 41 \\
\mathrm{SF}^{\mathrm{i}} \\
\Delta \lambda 3 \\
\mathrm{SF}^{\mathrm{i}} \\
\Delta \lambda 140\end{array}$ & $\begin{array}{l}0.17 \\
0.13 \\
0.14\end{array}$ & [44] \\
\hline $\begin{array}{l}\text { Perylene } \\
\text { Benzo[ghi]perylene }\end{array}$ & Sea water & $\operatorname{HDTAB}^{\mathrm{j}}$ & $\begin{array}{c}\mathrm{SF}^{\mathrm{i}} \\
\Delta \lambda 16\end{array}$ & $\begin{array}{l}0.12 \\
0.21\end{array}$ & [45] \\
\hline Fluorene & Sea water & $\beta-C D^{k}$ & $\begin{array}{c}\mathrm{RTP}^{\mathrm{c}} \\
\lambda_{\mathrm{EX}} 304, \lambda_{\mathrm{EM}} 460\end{array}$ & 4.5 & [55] \\
\hline Benzo $[a]$ pyrene & $\begin{array}{l}\text { Road dust and } \\
\text { particles on cypress } \\
\text { leaves }\end{array}$ & $\operatorname{SDS}^{\mathrm{g}}$ & $\begin{array}{c}\text { ME-RTP }{ }^{1} \\
\lambda_{\mathrm{EX}} 380, \lambda_{\mathrm{EM}} 690\end{array}$ & 3.9 & [56] \\
\hline Anthracene, pyrene & Water & $\mathrm{CA}[\mathrm{n}] / \mathrm{SiO}_{2} / \mathrm{CdTe}^{\mathrm{m}}$ & $\mathrm{F}^{\mathrm{b}}$ & $2.45-2.94 \times 10^{-8} \mathrm{~mol} \mathrm{~L}^{-1}$ & [58] \\
\hline
\end{tabular}

${ }^{\mathrm{a}} \mathrm{LOD}=$ limit of detection, expressed in $\mathrm{ng} \mathrm{mL} \mathrm{L}^{-1}$, unless otherwise noted in this column; ${ }^{\mathrm{b}} \mathrm{F}=$ fluorescence; ${ }^{\mathrm{c}} \mathrm{RTP}=\mathrm{room}-$ temperature phosphorescence; ${ }^{\mathrm{d}} \mathrm{SPE}-\mathrm{TRLIF}=$ solid-phase extraction - time-resolved laser-induced fluorimetry; ${ }^{\mathrm{e}} \mathrm{POLE}=\mathrm{Polyoxy}-$ ethylene-10-lauryl ether; ${ }^{\mathrm{f}} \mathrm{LVAF}=$ Linear variable angle fluorescence; ${ }^{\mathrm{g}} \mathrm{SDS}=$ Sodium dodecyl sulphate; ${ }^{\mathrm{h}} \mathrm{CTAB}=\mathrm{Cetyltrimethyl-}$ ammonium bromide; ${ }^{i} \mathrm{SF}=$ Synchronous fluorescence; ${ }^{\mathrm{j}} \mathrm{HDTAB}=$ Hexadecyltrimethylammonium bromide; ${ }^{\mathrm{k}} \beta$-CD $=\beta$-cyclodextrin; ${ }^{1} \mathrm{ME}-\mathrm{RTP}=$ micellar enhanced room-temperature phosphorescence; ${ }^{\mathrm{m}} \mathrm{CA}[n] / \mathrm{SiO}_{2} / \mathrm{CdTe}=$ calixarene $(\mathrm{CA}(\mathrm{n}), n=4,7)$ coated silica nanospheres englobed with CdTe nanocrystals.

Generally, the use of organized media, such as micelles, cyclodextrins (CDs), calixarenes, was found to increase the luminescence quantum yields of PAHs, resulting into an improvement of analytical sensitivity. The increase of luminescence signals of PAHs can be attributed to the existence of physicochemical interactions occurring between the hydrophobic part (hydrocarbon tails) of the surfactant molecules and PAHs, in the case of micelles, and to the formation of host-guest inclusion complexes of PAHs with CDs or calixarenes. These interactions and complex formation improved the solubility of PAHs in aqueous media, and diminished the vibrational motions of $\mathrm{PAH}$ molecules, which increased their luminescence yield values. It was also observed that the fluorescence enhancement factor values varied consid- erably with the organized media and PAHs under study, from about 1.5 to 186 , for different PAHs [43, 44, 48-50].

Using linear variable angle fluorescence (LVAF), and a micellar medium containing POLE (2.5 mmol L $\left.{ }^{-1}\right)$, Amador-Hernandez et al. [48] were able to determine a multi-component mixture of six PAHs (benzo[a]pyrene, benzo[e]pyrene, benzo $[g h i]$ perylene, coronene, dibenzo $[a, h]$ anthracene and indeno[1,2,3-cd]pyrene) in natural, fresh and marine waters (Table 1). The authors applied several known algorithms, including multiple linear regression, PLSR type-1, and artificial neural networks, which avoided spectral interference problems, allowing to resolve the PAH mixtures without the need of preliminary separation [48]. 
Lázaro et al. [49] studied the influence of several aqueous micellar systems, including HDTAB, SDS, bis-2-ethylhexylsulfosuccinate sodium salt and polyoxyethylene-23-lauryl ether, on the fluorimetic determination of pyrene, phenanthrene, benzo $[a]$ pyrene, acenaphthene and fluorene, and applied their method to tap and river water samples spiked with these PAHs.

The effect of $\beta$-cyclodextrin $(\beta-C D)$ and of the non-ionic surfactant Pluronic-F-68 on the fluorescent characteristics of several PAHs was investigated by Rubio et al. [50], which permitted to establish a rather selective method to determine benzo $[g h i]$ perylene in the presence of $\beta-C D$. The same group determined different PAHs in particulate air samples, using micellar solutions containing ionic and non-ionic surfactants, namely sodium dodecyl sulphate (SDS), CTAB and Brij-35 [51, 52] (Table 1). LOD values were obtained at the sub-ng $\mathrm{mL}^{-1}$ level, the detection being more sensitive for pyrene and benzo[a]pyrene when Brij-35 was employed, which can be attributed to the nonionic nature of this surfactant.

Micelles and CDs were also used in RTPL techniques, namely micelle-stabilized (MS)-RTP and cyclodextrin-induced (CD)-RTP, and were applied to the environmental analysis of HAPs [31, 53-56]. In the MS-RTP method, phosphorescent PAHs were incorporated into a micellar assembly, which provoked a dramatic enhancement of the RTP signal [31]. Jin and Liu [53] investigated the effect of the triplet energy on the MS-RTP of PAHs, and found that a triplet energy larger than $14000 \mathrm{~cm}^{-1}$ is necessary for inducing MS-RTP of PAHs. The same authors [54] studied five PAHs by chemical deoxygenation MS-RTP, with sodium sulfite as $\mathrm{O}_{2}$ scavenger and with thallium nitrate as a heavy atom in SDS micellar media. LOD values were $1.7 \times 10^{-7}-3.4 \times 10^{-7} \mathrm{~mol} \mathrm{~L}^{-1}$. In the CD-RTP method, inclusion complexes were formed between PAHs and CDs in aqueous solution, yielding a strong HAP phosphorescence signal. Using CD-RTP, Algarra and Hernandez [55] successfully determined fluorene in sea-water samples. The phosphorescence study was performed in optimum conditions at $15^{\circ} \mathrm{C}$ in a $8 \times 10^{-3} \mathrm{~mol} \mathrm{~L}^{-1} \beta$-CD solution of $\mathrm{pH}=6.65$, containing 3-bromopropan-1-ol as heavy atom and sodium sulfite-sulfurous acid as oxygen scavenger. A LOD value of $4.5 \mathrm{ng} \mathrm{mL} \mathrm{m}^{-1}$ was obtained for fluorene. However, a drawback of this method was because it had a moderate selectivity against other PAHs and aromatic mole- cules, normally present in real samples, although an increase in selectivity was observed relative to fluorimetric measurements. Segura et al. [56] optimized a microemulsion room-temperature phosphorescence (ME-RTP) method to determine benzo $[a]$ pyrene in road dust samples and in particles deposited on cypress leaves. The method, based on the effect of the hexane/n-pentanol/SDS/water microemulsion on the phosphorescence of this $\mathrm{PAH}$, was rapid, easy-to-apply and led to a LOD of $3.9 \mathrm{ng} \mathrm{mL}^{-1}$ (Table 1).

Recently, the interactions between singlewalled carbon nanotubes (SWNTs) or calixarene nanoparticles and PAHs have been investigated by fluorescence spectroscopy $[57,58]$. Debnath et al. [57] modeled fluorescence quenching as a function of PAH concentration, revealing concentration regions where the interactions caused a debundling of the carbon nanotubes, and obtained a linear correlation between the binding energy of PAHsSWNTs and the molecular weight of PAHs. Li and $\mathrm{Qu}$ [58] studied the selective inclusion of PAHs on highly luminescent and stable calixarene (CA (n), $n=4,7$ ) coated silica nanospheres englobed with CdTe nanocrystals $\left(\mathrm{CA}[\mathrm{n}] / \mathrm{SiO}_{2} / \mathrm{CdTe}\right)$, and found a linear relationship of the $\mathrm{CA}[4] / \mathrm{SiO}_{2} / \mathrm{CdTe}$ and $\mathrm{CA}[7] / \mathrm{SiO}_{2} / \mathrm{CdTe}$ fluorescence intensities with increasing anthracene and pyrene concentration, respectively, corresponding to a linear dynamic range (LDR) of $0.1-50 \mu \mathrm{M}$. LOD values were respectively $2.45 \times 10^{-8}$ and $2.94 \times 10^{-8} \mathrm{~mol} \mathrm{~L}^{-1}$, while the fluorescence of $\mathrm{CA}[n] / \mathrm{SiO}_{2} / \mathrm{CdTe}$ in response to other PAHs was negligible. These calixarene naoparticles thus afforded a very selective and sensitive detection system for PAHs [58].

A distinct and important method to identify and quantify trace amounts of PAHs in complex environmental samples, including soils, sediments, crude oils and biota, is constituted by Shpol'skii spectrometry, based on low-temperature fluorescence or phosphorescence of PAHs embedded in a polycrystalline n-alkane matrix [59]. In these particular conditions, the fluorescence or phosphorescence spectra showed a remarkable vibrational resolution so that even very similar isomers can be distinguished by this method. Several groups developed and applied Shpol'skii spectrometry to a variety of PAHs in several environmental samples, such as crude oils, sediments and fish tissues [59, 60], marine sediments [61], river natural waters and sediments [62], and lake sediments [63]. The possibility of utilizing Shpol'skii fluorescence and phosphorescence spectrometry for determination 
of mutagenic amino- and nitro-substituted PAHs in environmental samples was also critically investigated by Kozin et al. [64].

The development and application of different fluorescence methods to the study and quantitative analysis of various PAH-contaminated environmental matrices, including soils and sediments [63, $65,66,67]$, living organisms [68] and air [69], have been reported. For example, Hawthorne et al. [66] developed a simple field-portable method based on in situ sampling with solid-phase microextraction (SPME) coupled with laser-induced fluorescence (LIF) for determining the total dissolved PAHs in sediment pore water. The LOD in pore water was about $2 \mathrm{ng} \mathrm{mL}$, as total PAHs. Also, the identification and determination of PAHs in petroleum contaminated soils were performed by fluorescence and synchronous luminescence spectrometry [67]. Hanson and Larson [68] established and optimized fixed-wavelength fluorescence of the fish bile as a simple screening method for monitoring $\mathrm{PAH}$ exposure to fish. In another study, Oliveira et al. [69] tested ground-state diffuse reflectance and LIF techniques on the evaluation for total PAHs in un-extracted and unfractionated airborne particulate matter, obtained from air particulate samples collected in Rio de Janeiro.

\section{Organo-chlorinated compounds}

A great variety of organo-chlorinated compounds exists, including polychlorinated biphenyls (PCBs), their mixtures (Aroclors, trade name), and polychlorinated dibenzofurans (PCDFs), which are considered as important and toxic persistent organic pollutants (POP) of the environment. Although, because of the presence of several chlorine atoms (heavy atoms) in their structure, organochlorinated compounds are generally less fluorescent than PAHs, it has been possible to analyze them at low concentration levels, using several luminescence methods, generally improved by organized media and solid surfaces. The most important literature data relative to luminescence techniques applied to environmental analysis of organo-chlorinated compounds are summarized in Table 2.

Hernández Garcia et al. [70-73] investigated the fluorescence properties of several PCBs, Arochlors and PCDFs, in micellar media with cationic, anionic or non-ionic surfactants, and in cyclodextrins $(\alpha-C D$ and $\beta-C D)$. Among different surfac- tants, POLE yielded the highest fluorescent enhancement for PCBs. Significant changes in fluorescence intensity resulting from the presence of chlorine atoms in the analyte molecules were observed in all micelles under study. In the case of PCBs, the fluorescence enhancement factor due to the presence of POLE increased proportionally with the number of chlorine atoms in the biphenyl molecule, up to tetrachlorobiphenyl, then decreased proportionally for more than four chlorine atoms. This variation in PCB fluorescence with the number of chlorine atoms is a complex phenomenon which depends on several factors, such as the chlorine heavy atom effect on the singlet-to-triplet intersystem crossing rate and chlorine-substitution related changes in the symmetry and vibronic coupling between singlet states [24]. A similar behavior was also noted for PCDFs. Using a micellar medium containing POLE $\left(0.025 \mathrm{~mol} \mathrm{~L}^{-1}\right)$, this fluorimetric method was successfully applied to the determination of 3,4,4'-trichlorobiphenyl [70], 3,3',4,4'-tetrachlorobiphenyl [73], 2,8-dichlorodibenzofuran [72], and 2,3,7,8-tetrachlorodibenzofuran [71] at the $\mathrm{ng} \mathrm{mL}^{-1}$ level, in spiked sea waters samples, even in the presence of PCBs congeners, dioxins and Arochlors (Table 2).

Santana Rodriguez et al. [74] established two spectrofluorimetric methods based on the fluorescence quenching effect of Aroclor 1221 and 4chlorobiphenyl by cetylpyridinium bromide (CPB) in order to quantify these compounds in spiked sea water samples. The same group [75] also applied derivative synchronous fluorescence (D-SF) spectrometry $(\Delta \lambda=48 \mathrm{~nm})$ to determine simultaneously 3,3',4,4'-tetrachlorobiphenyl (TTCB) and 2,3,7,8tetrachlorodibenzofuran (TTCDF) in spiked sea water from Canary Islands. In this D-SF method, POLE was used as surfactant, and the LOD values were $2.7 \mathrm{ng} \mathrm{mL}^{-1}$ for TTCDF and $5.3 \mathrm{ng} \mathrm{mL}^{-1}$ for TTCB.

Two types of specially-designed instruments, namely a battery-operated portable synchronous luminescence spectrofluorometer and a portable synchronous scanning luminoscope, were developed for on-site analysis of soils, waste sites and ground water contaminated by PCBs and other aromatic pollutants $[76,77]$. Also, a simple, enhanced photoactivated fluorescence method on solid substrates was described by Vo-Dinh et al. $[78,79]$ for rapid screening of PCB congeners and Aroclor mixtures. This method combined several steps, including photoactivation by UV irradiation, excitation and fluorescence of the formed photo- 
product, and led to LODs in the ppb range for

PCBs.

Table 2

Fluorescence and phosphorescence analysis of organo-chlorinated compounds: environmental applications

\begin{tabular}{|c|c|c|c|c|c|}
\hline Analyte & Matrix & Medium & $\begin{array}{l}\text { Technique } \\
\lambda[\mathrm{nm}]\end{array}$ & $\begin{array}{c}\mathrm{LOD}^{\mathrm{a}} \\
\left(\mathrm{ng} \mathrm{mL}^{-1}\right)\end{array}$ & Ref. \\
\hline $3,4,4$ '-Trichlorobiphenyl & Sea water & POLE $^{b}$ & $\begin{array}{c}\mathrm{F}^{\mathrm{c}} \\
\lambda_{\mathrm{EX}} 260, \lambda_{\mathrm{EM}} 328\end{array}$ & 4.9 & {$[70]$} \\
\hline 2,3,7,8-Tetrachlorodibenzofuran & Sea water & POLE $^{\mathrm{b}}$ & $\lambda_{\mathrm{EX}} 304, \lambda_{\mathrm{EM}} 336$ & 1.3 & {$[71]$} \\
\hline 2,8-Dichlorodibenzofuran & Sea water & POLE $^{\mathrm{b}}$ & $\begin{array}{c}\mathrm{F}^{\mathrm{c}} \\
\lambda_{\mathrm{EX}} 293, \lambda_{\mathrm{EM}} 333\end{array}$ & 1.1 & {$[72]$} \\
\hline $3,3^{\prime}, 4,4^{\prime}$-Tetrachlorobiphenyl & Sea water & POLE $^{b}$ & $\begin{array}{c}\mathrm{F}^{\mathrm{c}} \\
\lambda_{\mathrm{EX}} 293, \lambda_{\mathrm{EM}} 333\end{array}$ & 1.4 & {$[73]$} \\
\hline 4-Chlorobiphenyl & Sea water & $\mathrm{CPB}^{\mathrm{d}}$ & $\begin{array}{c}\mathrm{F}^{\mathrm{c}} \\
\lambda_{\mathrm{EX}} 253, \lambda_{\mathrm{EM}} 320\end{array}$ & - & {$[74]$} \\
\hline Arochlor 1221 & Sea water & $\mathrm{CPB}^{\mathrm{d}}$ & $\lambda_{\mathrm{EX}} 247, \lambda_{\mathrm{EM}} 247$ & - & {$[74]$} \\
\hline $\begin{array}{l}3,3,4,4 \text { '-Tetrachlorobiphenyl } \\
\text { 2,3,7,8-Tetrachlorodibenzofuran }\end{array}$ & Sea water & POLE $^{\mathrm{b}}$ & $\begin{array}{l}\mathrm{D}^{\mathrm{SF}}{ }^{\mathrm{e}} \\
\Delta \lambda 48\end{array}$ & $\begin{array}{l}5.3 \\
2.7\end{array}$ & {$[75]$} \\
\hline PCBs and Arochlor mixtures & - & Solid substrate & $\mathrm{PAF}^{\mathrm{f}}$ & ppb level & {$[78,79]$} \\
\hline Aroclor 1242 & Soil & $\mathrm{NaLS}{ }^{\mathrm{g}}$-treated filter paper & $\begin{array}{c}\text { SS-RTP }^{\mathrm{h}} \\
\lambda_{\mathrm{EX}} 280, \lambda_{\mathrm{EM}} 460\end{array}$ & $5.6 \mathrm{mg} \mathrm{mL}^{-1}$ & {$[80]$} \\
\hline Dibenzofuran and PCDFs & - & $\mathrm{NaLS}^{\mathrm{g}}$-treated filter paper & SS-RTP ${ }^{\mathrm{h}}$ & $4.6-34 \mathrm{ng}$ & {$[81]$} \\
\hline
\end{tabular}

${ }^{\mathrm{a}} \mathrm{LOD}=$ limit of detection, expressed in $\mathrm{n} \mathrm{mL}^{-1}$, except otherwise mentioned in this column; ${ }^{\mathrm{b}} \mathrm{POLE}=$ Polyoxyethylene-10lauryl ether; ${ }^{\mathrm{c}} \mathrm{F}=$ Conventional fluorescence; ${ }^{\mathrm{d}} \mathrm{CPB}=$ Cetylpyridinium bromide. In these methods, $\mathrm{CPB}$ was used as a fluorescence quencher; ${ }^{\mathrm{e}} \mathrm{D}-\mathrm{SF}=$ Derivative synchronous fluorescence; ${ }^{\mathrm{f}} \mathrm{PAF}=$ Photoactivated fluorescence; ${ }^{\mathrm{g}} \mathrm{NaLS}=$ Sodium lauryl sulfate; ${ }^{\mathrm{h}} \mathrm{SS}-$ TRP $=$ solid surface room-temperature fluorescence.

Solid surface-room temperature phosphorescence (SS-RTP) was also developed for the determination of organo-chlorinated compounds. For example, Pal et al. [80] investigated the SS-RTP properties of several Arochlors on filter paper treated with sodium lauryl sulfate (NaLS), using thallium acetate as heavy atom salt. They obtained enhancement factors of SS-RTP signal of about 24 in the presence of SDS. In these optimal conditions, the method was applied to the determination of Arochlors in spiked soil extracts. Moreover, Santana Rodriguez et al. [81] studied dibenzofuran and PCDFs by SS-RTP on filter paper treated with $\mathrm{NaLS}$, selecting thallium nitrate as heavy atom salt. The authors optimized various experimental conditions, such as the type of filter paper, irradiation time, and heavy atom salt and surfactant concentrations, and obtained rather low absolute LOD values, ranging from $4.6 \mathrm{ng}$ for dibenzofuran to 34 ng for 2,4,6-trichlorodibenzofuran.

\section{Pesticides}

Most pesticides display a relatively weak native fluorescence. For this reason, the use of organized media (micelles, CDs, calixarene nanomaterials), have been frequently proposed to improve the analytical sensitivity of spectrofluorimetry for these compounds. Other various luminescent techniques, such as photochemically-induced fluorescence, phosphorescence, luminescent and bioluminescent biosensors, have been actively developed in recent years. We have presented in Table 3 the most important literature data of luminescence techniques applied to environmental analysis of pesticides. 
Márquez et al. [82] determined the rodenticide Warfarin (3-( $\alpha$-4-acetonylbenzyl)-4-hydroxycoumarin) by fluorimetry in a $\beta$-CD $\left(0.012 \mathrm{~mol} \mathrm{~L}^{-1}\right)$ solution with a LOD value of $0.059 \mu \mathrm{g} \mathrm{mL}^{-1}$ and a relative standard deviation (RSD) of $3.5 \%$. The authors were able to apply this method to irrigation water samples without preliminary extraction procedure. In a related study, Pacioni and Veglia [83] used a $\beta$-CD-enhanced spectrofluorimetric method to quantify the insecticides carbaryl (1-napthyl- $N$ methyl-carbamate) and carbofuran (2,2-dimethyl, 2,3-dihydro-7-benzofuranyl- $N$-methylcarbamate), reaching respective LOD values of 1.94 and 14.5 $\mathrm{ng} \mathrm{mL} \mathrm{m}^{-1}$. After optimization, this technique was successfully applied to determine both pesticides in fruits and tap water. Ayala et al. [84] also developed a fluorimetric method in aqueous micellar media, using HDTAB as a surfactant, for the determination of carbaryl and its degradation product, 1-naphtol, in natural waters. Carbaryl was analyzed either directly in a moderately acidic medium with a LOD of $6.2 \mathrm{ng} \mathrm{mL} \mathrm{m}^{-1}$, or indirectly, after its complete, baso-catalysed or acidocatalysed hydrolysis into 1-naphtol, at $\mathrm{pH} 11.0$ or $\mathrm{pH} 3.0$ values, with LOD values of, respectively,

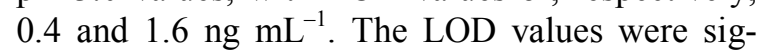
nificantly lower in strongly acidic or basic micellar media because 1-naphthol possessed a higher fluorescence quantum yield than carbaryl itself. Maggio et al. [85] reappraised the fluorescence enhancement of the pesticide carbendazim in the presence of micellar media and CDs. The authors concluded that the carbendazim fluorescence intensity was significantly increased by micelles formed by SDS, HDTAB, HDTAC and decyltrimethylammonium bromide (DTAB) and (2hydroxy)-propyl- $\beta-C D$ (HP- $\beta-C D)$. Among the organized media under study, the cationic surfactant HDTAB produced the largest fluorescence signal and its use should be considered for the spectrofluorimetric analysis of carbendazim [85].

Kunsági-Máté et al. [86, 87] investigated by spectrofluorimetry the host-guest interactions of calix[4]arene and 4-tert-butylcalix[4]arene molecules with different neutral pesticide-related benzotrifluoride molecules. The photoluminescence signal reflected the supramolecular interactions, which makes calixarenes promising candidates as host molecules to be used in chemical sensors for pesticide molecules. More recently, $\mathrm{Li}$ and $\mathrm{Qu}$ [88] synthesized highly luminescent and stable CdTe quantum dots (QDs) in sol-gel derived composite silica nanospheres coated with calix[4]arene $\left(\mathrm{CA}[4] / \mathrm{SiO}_{2} / \mathrm{CdTe}\right)$ which were found to allow a very sensitive determination of methomyl, a carbamate insecticide, via a significant fluorescence signal enhancement. Under optimal conditions, the $\mathrm{CA}[4] / \mathrm{SiO}_{2} / \mathrm{CdTe}$ relative fluorescence intensity increased linearly with methomyl concentration, with a LDR of $0.1-50 \mu \mathrm{M}$, and a LOD of $0.08 \mu \mathrm{M}$, while the change of fluorescence intensity of $\mathrm{CA}[4] / \mathrm{SiO}_{2} / \mathrm{CdTe}$ in the presence of other pesticides, including parathion-methyl, fenamithion, optunal (isocarbophos) and acetamiprid, was negligible [88].

Photochemically-induced fluorescence (PIF) methods have been widely utilized in the case of a number of non- or weakly-fluorescent pesticides [89-95]. For example, Coly and Aaron [89] determined by cyclodextrin-enhanced (CDE)-fluorimetry and/or CDE-PIF several weakly-fluorescent aromatic pesticides, including coumatetralyl, pirimiphos-methyl, chlorpyriphos, deltamethrin and fenvalerate. They showed the formation of 1:1 inclusion complexes between $\beta-C D$ or HP- $\beta-C D$ and the pesticide molecules. Linear dynamic ranges were over two orders of magnitude, and LOD values ranged between 0.2 and $54 \mathrm{ng} \mathrm{mL}$, according to the pesticide. Application to the analysis of spiked tap water and river water samples yielded satisfactory recoveries $(88-116 \%)$. A very sensitive micelle-enhanced (ME)-PIF method was developed by the same authors [90] for the quantitative analysis of non-fluorescent sulfonylurea herbicides in river water samples. Chlorsulfuron, metsulfuron methyl, 3-rimsulfuron and sulfometuron methyl, were determined in the presence of SDS and CTAC micellar media, with LOD values ranging from 0.2 to $6 \mathrm{ng} \mathrm{mL}^{-1}$, according to the compound. Mahedero et al. [91] applied a CDE-PIF technique, based on the formation of inclusion complexes between $\beta-C D$ or HP- $\beta-C D$ and phenylurea herbicides, including linuron, diuron, isoproturon and neburon. The reported LOD values were higher than the previous ones, in the range of 580-700 $\mathrm{ng}$ $\mathrm{mL}^{-1}$ [91]. Clearly, pre-concentration steps would be needed for the CDE-PIF analysis of complex, real environmental samples containing very low herbicide amounts (Table 3 ). 
Table 3

Fluorescence and phosphorescence analysis of pesticides: environmental applications

\begin{tabular}{|c|c|c|c|c|c|}
\hline Analyte & Matrix & Medium & $\begin{array}{c}\text { Detection method } \\
\lambda[\mathrm{nm}]\end{array}$ & $\begin{array}{c}\mathrm{LOD}^{\mathrm{a}} \\
\left(\mathrm{ng} \mathrm{mL}^{-1}\right)\end{array}$ & Ref. \\
\hline Warfarin & Irrigation water & $\beta-C D^{b}$ & $\begin{array}{c}\mathrm{F}^{\mathrm{c}} \\
\lambda_{\mathrm{EX}} 310, \lambda_{\mathrm{EM}} 386\end{array}$ & 0.059 & [82] \\
\hline Carbaryl & Tap water & $\beta-\mathrm{CD}^{\mathrm{b}}$ & $\lambda_{\mathrm{EX}} 281, \lambda_{\mathrm{EM}} 336$ & 1.94 & [83] \\
\hline Carbofuran & Tap water & $\beta-C D^{b}$ & $\begin{array}{c}\mathrm{F}^{\mathrm{c}} \\
\lambda_{\mathrm{EX}} 273, \lambda_{\mathrm{EM}} 307\end{array}$ & 14.5 & [83] \\
\hline Carbaryl & Well waters & HDTAB $^{\mathrm{d}}$ & $\begin{array}{c}\mathrm{F}^{\mathrm{c}} \\
\lambda_{\mathrm{EX}} 285, \lambda_{\mathrm{EM}} 337\end{array}$ & 6.22 & {$[84]$} \\
\hline Methomyl & - & $\mathrm{CA}[4] / \mathrm{SiO}_{2} / \mathrm{CdTe}^{\mathrm{e}}$ & $\mathrm{F}^{\mathrm{c}}$ & $0.08 \mu \mathrm{M}$ & {$[88]$} \\
\hline Coumatetralyl & \multirow{5}{*}{$\begin{array}{l}\text { Tap water, river } \\
\text { water }\end{array}$} & $H P-\beta-C D^{f}$ & $\begin{array}{c}\mathrm{CDE}^{\mathrm{g}}-\mathrm{F}^{\mathrm{c}} \\
\lambda_{\mathrm{EX}} 314, \lambda_{\mathrm{EM}} 380\end{array}$ & 1.0 & \multirow{5}{*}{ [89] } \\
\hline Pirimiphos-methyl & & $\beta-C D^{b}$ & $\begin{array}{c}\mathrm{CDE}^{\mathrm{g}}-\mathrm{F}^{\mathrm{c}} \\
\lambda_{\mathrm{EX}} 305, \lambda_{\mathrm{EM}} 366\end{array}$ & 2.8 & \\
\hline Chlorpyriphos & & $\beta-C D^{b}$ & $\begin{array}{c}\mathrm{CDE}^{\mathrm{g}}-\mathrm{PIF}^{\mathrm{h}} \\
\lambda_{\mathrm{EX}} 378, \lambda_{\mathrm{EM}} 428\end{array}$ & 4.3 & \\
\hline Deltamethrin & & $H P-\beta-C D^{f}$ & $\begin{array}{c}\mathrm{CDE}^{\mathrm{g}}-\mathrm{PIF}^{\mathrm{h}} \\
\lambda_{\mathrm{EX}} 291, \lambda_{\mathrm{EM}} 312\end{array}$ & 4.4 & \\
\hline Fenvalerate & & $\beta-C D^{b}$ & $\begin{array}{c}\mathrm{CDE}^{\mathrm{g}}-\mathrm{PIF}^{\mathrm{h}} \\
\lambda_{\mathrm{EX}} 320, \lambda_{\mathrm{EM}} 362\end{array}$ & 2.6 & \\
\hline Chlorsulfuron & \multirow{4}{*}{ River water } & CTAC $^{\mathrm{i}}$ & $\lambda_{\mathrm{EX}} 314, \lambda_{\mathrm{EM}} 380$ & 0.5 & \multirow{4}{*}{ [90] } \\
\hline Metsulfuron methyl & & $\mathrm{SDS}^{\mathrm{k}}$ & $\begin{array}{c}\text { ME }^{\mathrm{j}}-\mathrm{PIF}^{\mathrm{h}} \\
\lambda_{\mathrm{EX}} 322, \lambda_{\mathrm{EM}} 378\end{array}$ & 0.2 & \\
\hline 3-rimsulfuron & & CTAC $^{\mathrm{i}}$ & $\lambda_{\mathrm{EX}} 317, \lambda_{\mathrm{EM}} 365$ & 0.8 & \\
\hline Sulfometuron methyl & & CTAC $^{\mathrm{i}}$ & $\begin{array}{c}\mathrm{ME}^{\mathrm{J}}-\mathrm{PIF}^{\mathrm{h}} \\
\lambda_{\mathrm{EX}} 290, \lambda_{\mathrm{EM}} 341\end{array}$ & 6 & \\
\hline Diuron & \multirow{3}{*}{ River water } & $H P-\beta-C D{ }^{f}$ & $\begin{array}{c}\mathrm{CDE}^{\mathrm{g}}-\mathrm{PIF}^{\mathrm{h}} \\
\lambda_{\mathrm{EX}} 317, \lambda_{\mathrm{EM}} 356\end{array}$ & 770 & \multirow{3}{*}{ [91] } \\
\hline Neburon & & $\beta-C D^{b}$ & $\begin{array}{c}\mathrm{CDE}^{\mathrm{g}}-\mathrm{PIF}^{\mathrm{h}} \\
\lambda_{\mathrm{EX}} 319, \lambda_{\mathrm{EM}} 359\end{array}$ & 800 & \\
\hline Linuron & & $\beta-\mathrm{CD}^{\mathrm{b}}$ & $\begin{array}{c}\mathrm{CDE}^{\mathrm{g}}-\text { PIF }^{\mathrm{h}} \\
\lambda_{\mathrm{EX}} 321, \lambda_{\mathrm{EM}} 356\end{array}$ & 660 & \\
\hline Sulfometuron-methyl & \multirow{2}{*}{ Tap water } & \multirow{2}{*}{$\mathrm{CTAC}^{\mathrm{i}}$} & $\begin{array}{c}\text { D-ME-PIF }^{1} \\
\lambda_{\text {EX }} 290, \lambda_{\text {EM }} 341\end{array}$ & 21 & \multirow{2}{*}[92]{} \\
\hline 3-Rimsulfuron & & & $\begin{array}{c}\text { D-ME-PIF } \\
\lambda_{\mathrm{EX}} 317, \lambda_{\mathrm{EM}} 365\end{array}$ & 3.2 & \\
\hline$\alpha$-Cypermethrin & $\begin{array}{l}\text { Tap water, natural } \\
\text { water }\end{array}$ & $\begin{array}{l}\text { Organic solutions, } \beta-C D{ }^{b} \text {, } \\
\text { HP- } \beta-C D^{f}\end{array}$ & $\mathrm{PIF}^{\mathrm{h}}$ & 6.0 & {$[95]$} \\
\hline $\begin{array}{l}\text { Aminocarb, carbendazin, } \\
\text { coumatetralyl }\end{array}$ & Water & $\beta-C D^{b}$ & SF-VASS ${ }^{\mathrm{m}}$ & - & [96] \\
\hline Carbaryl & Soil & $\mathrm{SDS}^{\mathrm{k}}$-microemulsion & $\begin{array}{c}\text { ME-RTP } \\
\lambda_{\text {EX }} 292, \lambda_{\text {EM }} 490 \\
\end{array}$ & 25 & [99] \\
\hline Carbaryl & Irrigation water & $\begin{array}{l}\text { Various heavy atoms + } \\
\text { oxygen scavenger }\end{array}$ & HAI-RTP ${ }^{\circ}$ & 2.8 & [101] \\
\hline Napropamide & Soil, vegetables & $\mathrm{SDS}^{\mathrm{k}}+\mathrm{TINO}_{3}$ & $\begin{array}{c}\text { MS-RTP }^{\mathrm{p}} \\
\lambda_{\mathrm{EX}} 282, \lambda_{\mathrm{EM}} 528\end{array}$ & 16 & [104] \\
\hline Napropamide & Natural water, soil & $\begin{array}{l}\text { KI + sodium sulfite } \\
\text { aqueous solution }\end{array}$ & HAI-RTP ${ }^{\circ}$ & 3.2 & [105] \\
\hline Thiabendazole, carbaryl & Natural waters & $\begin{array}{l}\text { KI + sodium sulfite } \\
\text { aqueous solution }\end{array}$ & $\begin{array}{l}\text { DVASS-RTP } \\
\text { SS HAI-RTP }^{\mathrm{r}} \\
\end{array}$ & $1.4-1.7$ & [106] \\
\hline
\end{tabular}

${ }^{\mathrm{a}} \mathrm{LOD}=$ limit of detection, expressed in $\mathrm{ng} \mathrm{mL}^{-1}$, unless otherwise noted in this column; ${ }^{\mathrm{b}} \beta-\mathrm{CD}=\beta$-cyclodextrin; ${ }^{\mathrm{c}} \mathrm{F}=$ fluorescence; ${ }^{\mathrm{d}} \mathrm{HDTAB}=$ hexadecyltrimethylammonium bromide; ${ }^{\mathrm{e}} \mathrm{CA}[4] / \mathrm{SiO}_{2} / \mathrm{CdTe}=$ calixarene $(\mathrm{CA}[4])$ coated silica nanospheres englobed with CdTe nanocrystals; ${ }^{\mathrm{f}} \mathrm{HP}-\beta-\mathrm{CD}=$ hydroxypropyl- $\beta$-cyclodextrin; ${ }^{\mathrm{g}} \mathrm{CDE}=$ cyclodextrin-enhanced; ${ }^{\mathrm{h}} \mathrm{PIF}=\mathrm{Photoche}-$ mically induced fluorescence. ${ }^{\mathrm{i}} \mathrm{CTAC}=$ Cetyltrimethylammonium chloride; ${ }^{\mathrm{j}} \mathrm{ME}=$ micelle-enhanced; ${ }^{\mathrm{k}} \mathrm{SDS}=\mathrm{Sodium}$ dodecyl 
sulphate $;{ }^{1} \mathrm{D}-\mathrm{ME}-\mathrm{PIF}=$ first derivative micelle-enhanced PIF $;{ }^{\mathrm{m}} \mathrm{SF}-\mathrm{VASS}=$ Synchronous fluorescence with variable angle scanning; ${ }^{\mathrm{n}}$ ME-RTP $=$ micelle-enhanced room-temperature phosphorescence; ${ }^{\circ} \mathrm{HAI}-\mathrm{RTP}=$ heavy-atom induced RTP; ${ }^{\mathrm{p}} \mathrm{MS}-\mathrm{RTP}=$ micellestabilized RTP; ${ }^{\mathrm{q}}$ DVASS-RTP $=$ three-dimensional derivative variable-angle synchronous scanning; ${ }^{\mathrm{r}} \mathrm{SS}$ HAI-RTP $=$ synchronous scanning heavy-atom induced RTP.

Also, Coly and Aaron [92] simultaneously determined, by the first derivative micelle-enhanced PIF (D-ME-PIF) spectrometry, binary mixtures of sulfonylurea herbicides in spiked tap water. This D-PIF method, based on the $1^{\text {st }}$-order mathematical derivation of the PIF signal with wavelength, was found by the authors to be much more selective than the classical (zero-order) method. In this micelle-enhanced D-PIF method, either SDS or CTAC was utilized according to the pesticide binary mixture under study, and short UV irradiation times $(20-60 \mathrm{~s})$ were applied. The achieved LOD values were in the range $0.5-52 \mathrm{ng} \mathrm{mL}^{-1}$ [92]. In a related study, the same authors developed a micelle-enhanced PIF method in combination with a partial least squares (PLS) algorithm, for the simultaneous quantification of sulfonylurea herbicide synthetic binary mixtures and applied it to tap water analysis [93]. Almanza Lopez et al. [94] described a sensitive and simple method for the resolution of binary mixtures of chlorophenoxyacid herbicides, based on time-resolved PIF in micellar media containing CTAC, a cationic surfactant. Critical variables, such as the surfactant concentration and the UV irradiation time, were optimised for each compound using Sequential Response Surface Methodology (SRSM) by applying Doehlert designs in order to obtain maximum fluorescence intensity. Satisfactory recoveries were obtained in the analysis of several mixtures of these herbicides at different ratios in spiked waters [94]. Recently, a study of the PIF spectral properties of $\alpha$ cypermethrin, a pyrethroid insecticide, was performed in several organic solutions and in $C D$ aqueous solutions ( $\beta-\mathrm{CD}$ and $2-\mathrm{HP}-\beta-\mathrm{CD})$ by Mbaye et al. [95]. The PIF signal was found to be significantly enhanced in the $\mathrm{CD}$ media relative to the organic solutions. The stoichiometry and formation constant values of the $\alpha$-cypermethrin : $C D$ inclusion complexes were evaluated. The best analytical performances of the CD-enhanced PIF method were obtained in the presence of HP- $\beta$ $\mathrm{CD}$, with a LDR going from 21 to $8,330 \mathrm{ng} \mathrm{mL}^{-1}$, a LOD of $6.0 \mathrm{ng} \mathrm{mL}^{-1}$ and a RSD of $1.9 \%$. Application to the analysis of spiked tap water and Senegal natural water samples collected close to agricultural areas yielded recoveries ranging from about 77 to $98 \%$. An interference study of foreign species, including other pesticides and inorganic ions, likely to be present in natural waters, was carried out [95].

SF spectrometry and related fluorimetric techniques have also been investigated to perform the simultaneous determination of pesticides in complex mixtures [96-98]. For instance, GarcíaSánchez et al. [96] reported that SF spectrometry with variable angle scanning (VASS method) permitted the CD-enhanced fluorescence determination of three pesticides, including aminocarb, carbendazin and coumatetralyl, at the $\mathrm{ng} \mathrm{mL}^{-1}$ level and resolution of their ternary mixtures. The maximum fluorescence intensity was obtained in $10^{-2} \mathrm{~mol} \mathrm{~L}^{-1} \beta-\mathrm{CD}$ aqueous solutions for the three pesticides. The recoveries from ternary mixtures by VASS were within $84-130 \%$. Hyfantis et al. [97] developed a standard field method based on synchronous scanning luminescence, for the onsite analysis of contaminated soils and ground water, and they applied it to the detection of pesticides at the ppb range. Picón Zamora et al. [98] accomplished the simultaneous determination of carbendazim, fuberidazole and thiabendazole by cross-section (CS) fluorimetry combined with multivariate calibration algorithms, such as PCR and two PLS algorithms, PLS-1 and PLS-2. The final calibration model, which used a PLS-1 method built on CS through the total fluorescence spectroscopic data, was shown to be suitable for carbendazim, fuberidazole and thiabendazole monitoring, with a RSD value of $5 \%$, in water samples at trace levels.

Since a large number of pesticides displayed relatively strong phosphorescence, several RTP methods have been applied to the environmental analysis of pesticides [99-106]. Segura et al. [99] optimized a ME-RTP method in a dichloromethane/1-pentanol/SDS microemulsion to determine the insecticide carbaryl in real soil samples. Carbaryl was also determined by the chemical deoxygenation MS-RTP method [100], and by the so-called HAI (heavy-atom induced)-RTP methodology [101]. In the later technique, several instrumental and experimental variables were optimized, 
yielding a LOD value of $2.8 \mathrm{ng} \mathrm{mL}^{-1}$, and a RSD value of $2.1 \%$ at the $150 \mathrm{ng} \mathrm{mL}^{-1}$ level. Spiked irrigation water samples taken near agricultural fields gave mean percentage recoveries of $95.7 \%$ [101]. More recently, Machicote and Bruzzone [102] determined simultaneously carbaryl and its degradation product, 1-naphtol, by $1^{\text {st }}$ derivative synchronous non-protected RTP in the presence of potassium iodide and sodium sulfite, while Alvarez-Diaz et al. [103] used halogenated molecularly imprinted polymers (MIP) for the selective determination of carbaryl by RTP. The later RTP optosensing system demonstrated high selectivity for carbaryl even in the presence of other luminophores that could be unspecifically adsorbed onto the MIP surface. Under optimal experimental conditions, the LOD was $4 \mu \mathrm{g} \mathrm{L}^{-1}$, the linear range extended up to $1 \mathrm{mg} \mathrm{L}^{-1}$ of the analyte, and a RSD of $3 \%$ was obtained at the $150 \mu \mathrm{g} \mathrm{L}^{-1}$ level [103]. Another pesticide, napropamide, was analyzed by Murillo et al. [104] in spiked soil, pepper and tomato samples using the MS-RTP method. The anionic surfactant SDS was utilized for the micellar medium, with thallium nitrate as a heavy atom and sodium sulfite to remove oxygen. The method was applicable on a LDR of $50-600 \mathrm{ng} \mathrm{mL}^{-1}$, and a LOD of $16 \mathrm{ng} \mathrm{mL}^{-1}$ was obtained. Napropamide was also determined by HAI-RTP, a simple and rapid method, performed in the presence of heavy atom salt (1 M KI ) and of sodium sulfite $(6 \mathrm{mM})$ used as an oxygen scavenger [105]. This method led to a LDR of 3.2-600 ng mL $\mathrm{m}^{-1}$ and a LOD of 3.2 $\mathrm{ng} \mathrm{mL}^{-1}$, and was successfully applied to the analysis of napropamide in water and soil samples. A three-dimensional derivative variable-angle synchronous scanning (DVASS) and a synchronous scanning (SS) HAI-RTP method were reported by Diaz et al. [106] to identify and quantify the spectral overlapping of phosphorescent pesticides thiabendazole and carbaryl, in the presence of sodium sulfite and external heavy atom salt. The increase of selectivity afforded by the DVASS and SS RTP methodology permitted to demonstrate its applicability to simultaneous determination of the phosphorescence signals of both pesticides with overlapping spectral profiles. LOD values were in the range of 1.4 to $1.7 \mathrm{ng} \mathrm{mL}^{-1}$. The proposed method was satisfactorily applied to the analysis of both pesticides in different types of water samples [106] (Table 3).

In recent years, luminescent and chemiluminescent (CL) immunosensors and bioluminescent biosensors have been developed for the detection and determination of toxic pesticides and other pollutants in the environment [107-118].

In the field of immunosensors, GonzálezMartinez et al. [107] studied enzymatic and nonenzymatic labels combined with luminescence detection for immunosensing pesticide residues (carbaryl, 1-naphthol, irgarol 1051) in organic media. The enzymes peroxidase and alkaline phosphatase enzymes, with fluorogenic (3-p-hydroxyphenylpropanoic acid) and luminogenic (AMPPD derivative) substrates, respectively, were assessed as enzymatic markers, while terbium(III) chelate, with timeresolved fluorescence detection, was evaluated as a non-enzymatic label. The best sensitivity was achieved by using alkaline phosphatase in an immunocomplex capture assay format $\left(\mathrm{I}_{50}\right.$ parameter values at the low $\mu \mathrm{g} \mathrm{L}^{-1}$ level). The method was applied to the measurement of carbaryl (100 $\mathrm{ng} \mathrm{L}^{-}$ ${ }^{1}$ ) in different spiked river water samples, after solid-phase extraction and analyte elution with an ethyl acetate-methanol mixture, resulting in recoveries in the range of 81 to $98 \%$ [107]. Also, a new, versatile, portable miniaturized flow-injection system, permitting to measure immunoluminescence reactions, was designed for the field analysis of pesticides and other environmental pollutants by Ciumasu et al. [108]. The competition between the enzyme-tracer and the analyte for the antigenbinding sites of the antibodies immobilized on a gold surface yielded a CL signal that was inversely proportional to the analyte concentration. The detection limits $\left(\mathrm{LOD} ; \mathrm{IC}_{20}\right)$ reached with the field prototype in the laboratory were about $0.2 \mu \mathrm{g} \mathrm{L}^{-1}$ for the herbicides diuron and atrazine [108]. A CL immunoassay with two types of a multi-spot membrane strip was developed by Rubtsova et al. [109] for the simultaneous determination of several pesticides in water samples. The immunoassay allowed the authors to estimate semi-quantitatively the concentration for a particular analyte, making possible to differentiate between atrazine, simazine and terbutylazine in ternary mixtures of pesticides. Katmeh et al. [110] demonstrated the feasibility of using an enhanced CL immunoassay, adapted to a camera luminometer, for screening pesticide-containing water samples, and providing a semi-quantitative assay based on a photographic record of the CL end-point. This CL immunoassay was applied to the herbicide chlortoluron, and showed considerable potential as a rapid, simple and portable means of monitoring multiple samples for the presence of this herbicide. A satisfactory accuracy was obtained in the analysis of sam- 
ples containing chlortoluron at concentrations above the range of 0.07 to $0.12 \mu \mathrm{g} \mathrm{L}{ }^{-1}$ [110].

Also, luminescent and bioluminescent biosensors have been the object of numerous environmental developments, in order to detect and determine pesticides, to distinguish between their bioavailable and inert forms, and to evaluate their toxicity. For example, Orellana et al. [111] designed, synthesized and performed the spectroscopic characterization of the novel luminescent indicator (4acetoxy-1,10-phenanthroline)bis(1,10-phenanthroline) ruthenium(II) dichloride $\left(\left[\mathrm{Ru}(\mathrm{phen})_{2}(4-\right.\right.$ AOp) $\left.]^{2+} 2 \mathrm{Cl}^{-}\right)$, which led to the development of a flow-through catalytic biosensor system for determination of carbamate pesticides in water. The feasibility of using the novel indicator dye with the enzymatic biosensor was successfully tested with 2-isopropoxy-phenyl $\mathrm{N}$-methylcarbamate [111].

Several types of bioluminescent (BL) biosensor systems have been investigated. Lux-marked bacteria led to the development of geneticallyengineered whole-cell BL biosensors that have been applied for detection of pesticides and other contaminants and measurement of their toxicity [112-115]. For instance, Hay et al. [114] built a bioluminescent whole-cell reporter for detection of the herbicide 2,4-dichlorophenoxyacetic acid (2,4D) and its degradation product, 2,4-dichlorophenol, in soil, permitting to obtain a linear bioluminescent response to 2,4-D in the concentration range of $2.0 \mu \mathrm{M}$ to $1.1 \times 10^{2} \mu \mathrm{M}$. Using another $\mathrm{BL}$ approach, Trajkovska et al. [116] evaluated the effect of different concentrations of three pesticides, including fenoxaprop- $p$-ethyl, diclofopmethyl and metsulfuron methyl, on the firefly luciferase (FL) activity by measuring the variation of BL intensity $v s$. time during the ATP bioluminescent reaction. The authors found that the FL activity was maximally inhibited (79-100\%, depending on the compound) at a pesticide concentration of $2.4 \times 10^{-4} \mathrm{~mol} \mathrm{~L}^{-1}$, and was partially inhibited (5.3-26\%, according to the compound) at pesticide concentrations of $2.4 \times 10^{-5}-2.4 \times 10^{-8} \mathrm{~mol}$ $\mathrm{L}^{-1}$. Also, biosensors based on natural-BL bacteria were described. Vetrova et al. [117] proposed prototype technologies of a BL signal system (BSS), based on the luminous bacterium Photobacterium phosphoreum, and three enzymatic BL systems for detecting and signalling the presence of toxic pesticides in water. The effect of several pesticides, including organophosphates, dithiocarbamide acid derivatives, and pyrethroids, on the $\mathrm{BL}$ signal of the four systems under study was analysed. $\mathrm{EC}_{50}$ and $\mathrm{EC}_{80}$ values were determined and compared to the maximum permissible concentration for each of the analysed substances. The triple-enzyme systems luciferase - NADH:FMN oxidoreductase with alcohol dehydrogenase or trypsin were shown to be more sensitive to organophosphorous compounds $\left(0.13-11 \mathrm{mg} \mathrm{L}^{-1}\right)$, while the triple-enzyme system luciferase-NADH:FMN oxidoreductase with trypsin was highly sensitive to lipotropic poison, a dithiocarbamine acid derivative $\left(0.03 \mathrm{mg} \mathrm{L}^{-1}\right)$. Sensitivities of the triple-enzyme systems to pyrethroid preparations were similar to those of luminous bacteria $\left(0.9-5 \mathrm{mg} \mathrm{L}^{-1}\right)$. The results can be applied to construct an alarm-test BL system for detecting toxic pesticides, based on intact bacteria or enzyme systems [117]. A combined analytical and toxicological study of several pesticides, including chlorothalonil, cyprodynil, dichlobénil, pendimethaline, trifluraline and $\alpha$-endosulfan, present at the trace level in the air and total atmospheric precipitations of Paris, was performed by Trajkovska et al. [118]. Using the Microtox ${ }^{\circledR}$ BL method, based on the evaluation of the BL inhibition of the Vibrio fischeri marine bacteria at two exposure times to the pesticide solutions, the authors were able to evaluate the $\mathrm{EC}_{50}$ values of these pesticides as well as the global toxicity of the atmospheric samples. The respective contribution of the toxic potency of the various pesticides contained in these samples was discussed [118].

\section{Metals}

Luminescence methods have also been used for the determination of several toxic metals and metallic ions present at the trace level in the environment. These methods are generally based on the formation of complexes (chelates) between the metallic ion under study and a fluorescent (or phosphorescent) organic reagent (ligand), resulting into either an increase of luminescence or a fluorescence (or phosphorescence) quenching, and measurement of the change in luminescence intensity with the metal concentration [119-126]. In recent years, a number of selective crown ethers, cryptands and calixarene derivatives combined with fluorophores, so-called fluoroionophores, have also been described for molecular recognition of various metallic cations [14].

An improvement of the fluorimetric method applied to the quantification of dissolved aluminum in natural waters was reported by Ren et al. 
[119]. The method was based on the increase of the fluorescence of a $\mathrm{Al}(\mathrm{III})-$ lumogallin complex by Triton X-100, yielding a 5-fold enhancement of the fluorescence signal relative to an aqueous medium, which led to obtaining a LOD value of 0.7 $\mathrm{nmol} \mathrm{L}{ }^{-1}$. for aluminium. It was possible to avoid the interferences due to the possible presence of $\mathrm{Fe}(\mathrm{III})$ and $\mathrm{F}^{-}$by using $o$-phenanthroline and $\mathrm{Be}(\mathrm{II})$ for metallic complexation. Also, Wie et al. [120] determined $\mathrm{Sb}(\mathrm{III})$ in natural and industrial water samples using a microemulsion system, by the fluorescence quenching method with $\mathrm{CTAB}$ as a quencher. The $\mathrm{Sb}$ (III) determination was based on the formation of a complex between antimony and a fluorescent reagent, namely 2,6,7-trihydroxy-9(3,5-dibromo-4-hydroxyphenyl)fluorine, in a buffer medium at $\mathrm{pH} 5.33$. The LOD was $0.15 \mathrm{ng} \mathrm{mL}^{-1}$, and foreign ions were eliminated by pre-concentration and separation steps with a sulfhydryl dextrose gel at $\mathrm{pH}$ 1.0. Recently, several new synthesized, fluorescent oligothiophène-8-hydroxyquinoline (Th-8-HQ) derivatives were found to form complexes with heavy metal ions, including $\mathrm{Hg}^{2+}$, $\mathrm{Ca}^{2+}, \mathrm{Mg}^{2+}$ and $\mathrm{Zn}^{2+}$, which provoked a partial fluorescence quenching of the Th-8-HQ derivative, proportional to the metallic ion concentration present in the medium under study [121]. Using this method, the authors were able to measure very small concentrations of $\mathrm{Hg}^{2+}$, at the $\mu \mathrm{mol} \mathrm{L}{ }^{-1}$ level, which might lead to the development of selective and very sensitive fluorescent chemical sensors for the determination of traces of mercury and other toxic heavy metals in the environment [121].

A MS-RTP method, based on the reaction of $\mathrm{Ga}$ (III) with 7-iodo-8-hydroquinoline-5-sulfonic acid (Ferron), was proposed by the Sanz-Medel group [122] for the gallium determination. CTAB was employed as enhancing agent, giving a LOD of $5 \mathrm{ng} \mathrm{mL} \mathrm{m}^{-1}$ for gallium. The authors also demonstrated the applicability of their method to the multi-component analysis of the group-III elements, such as $\mathrm{Al}(\mathrm{III}), \mathrm{Ga}(\mathrm{III})$ and In(III). Kalman filtering was used to deconvolute the emission phosphorescence spectra of mixtures of aluminum and gallium, allowing the simultaneous determination of both metals with satisfactory results. A novel RTP method to determine mercury in natural water samples was developed by San Vicente et al. [123]. The principle of the measurement, performed in liquid solution, consisted in an energy transfer occurring from a phosphor molecule $(\alpha-$ bromonaphthalene), in the presence of $\beta-C D$, which acted as a donor, to an Hg-sensitive dye (Hg-dithizonate), which acted as an acceptor. The method resulted in a more than five times improvement of the sensitivity of $\mathrm{Hg}(\mathrm{II})$ detection as compared to the conventional absorption spectrophotometric method, using dithizone as an $\mathrm{Hg}$ indicator [123]. In a related study, the same group described two luminescence methods which were based on the formation of chelates between different sulphonic-hydroxyquinolines and heavy metals, such as lead, and between purines and mercury, exhibiting, respectively, strong RTP and fluorescence [124]. After optimization, these methods led to LOD values of 0.1 and $1.4 \mathrm{ng} \mathrm{mL}^{-1}$ for lead and mercury, respectively, and a RSD of the order of $4 \%$ at $100 \mathrm{ng} \mathrm{mL}^{-1}$ of $\mathrm{Pb}$ (II) and $\mathrm{Hg}$ (II). Both methods were successfully applied to the determination of mercury and lead in seawater samples, and possible interferences present in seawater, including seawater cations and anions, were evaluated in detail.

Bioluminescent biosensors using bacteria were also used for detecting bioavailable toxic metals $[125,126]$. For example, Tauriainen et al. [125] developed microbial sensors for analyzing the presence of various metals or metalloids, including lead, arsenic, mercury and cadmium, by recombinant DNA technology. The strains were based on strictly regulated promoters controlling the expression of the firefly luciferase gene in microbial cells. The developed sensors were realtime indicators of metal responsive gene expression, giving results in approximately $30 \mathrm{~min}$, with optimal induction time in the range of 60 to 240 min. The authors described the performance of these metal-sensing bacteria for the assessment of different water samples spiked with lead, arsenic, mercury or cadmium, and showed that these bacteria are sensitive detectors of metal bioavailability, which is difficult or even impossible to evaluate by traditional analytical chemistry methods [125]. In another study, Fu et al. [126] constructed two $\mathrm{Hg}^{2+}$-specific biosensors, using bacterial luciferase as a reporter gene, and plasmid-free Pseudomonas putida X4 and Enterobacter aerogenes NTG-01 as host strains. The performances of the $\mathrm{X} 4$ and NTG-01 biosensors were compared in the same assay conditions. The shortest induction time of both biosensors was $30 \mathrm{~min}$. The maximum BL signal output for NTG-01 and X4 sensors was observed at incubation time of 5 and $4 \mathrm{~h}$, respectively. The lowest detectable concentration of 
mercury by both biosensors was only $100 \mathrm{pM}$ at $28^{\circ} \mathrm{C}, \mathrm{pH} 7$ and for an initial cell number of $10^{6}$ CFU mL ${ }^{-1}$. The $\mathrm{Cd}^{2+}, \mathrm{Zn}^{2+}, \mathrm{Co}^{2+}, \mathrm{Cu}^{2+}$, and $\mathrm{Pb}^{2+}$ ions at the nanomolar level did not interfere with the biosensor measurements. These results show that the sensitivity of both biosensors is sufficient for the detection of $\mathrm{Hg}^{2+}$ in the most contaminated environments [126].

\section{LUMINESCENCE METHODS COMBINED WITH DYNAMIC SYSTEMS: IDENTIFICATION AND DETERMINATION OF POLLUTANTS}

\section{HPLC methods with luminescence detection}

Among the dynamic systems that can be combined with luminescence, high performance liquid chromatography (HPLC) is probably the most employed in environmental studies because a good separation method is needed for characterization of complex matrices. Indeed, the HPLC techniques allow one to identify specifically very similar compounds in complex environmental samples by using the retention time values. It is important to stress that fluorescence detection (FD) coupled with HPLC, is generally 20-30 times more sensitive than UV-visible absorption detection, and is sometimes even more sensitive than mass spectrometry (MS). Gas chromatography (GC) is also currently used in environmental analyses, but its application is limited due to the lack of volatility of many pollutants and their thermal instability. Moreover, HPLC-FD requires no high-pressure carrier gas cylinders, and its maintenance is easier than GC/MS [127]. Other advantages are that HPLC allows to inject a sample on-line, and that it can be coupled with several extraction methods, providing less manipulation and less loss or contamination of analytes, as well as a faster and easier analysis [128-132].

Although fluorescence detection combined with HPLC generally offers a high sensitivity and selectivity, a derivatization step is sometimes required to convert a non-fluorescent compound into a fluorescent product. In these conditions, HPLCFD has been used for a large number of environmentally-important compounds. Table 4 summarizes some analytical performances and applications of HPLC-FD for different samples and matrices.
Usually, prior to detection, extraction and concentration steps are needed, since the contaminants are generally present at low concentrations in the environment. Depending on the type of sample and analyte and according to the concentration levels to be detected, a large number of extraction techniques are available. In the case of liquid samples, liquid-liquid extraction (LLE) and solid-phase extraction (SPE) are the most utilized [128-132]. Other more recent techniques, including solid-phase microextraction (SPME), stir bar sorptive extraction (SBSE), liquid-phase microextraction (LPME), single-drop microextraction (SDME), hollow fiber membrane-protected LPME (HFM-LPME), dispersive liquid-liquid microextraction (DLLME) and ionic liquid based dispersive liquid-liquid microextraction (IL-DLLME), are employed to a lesser extent. For solid samples, the most conventional procedure is constituted by the Soxhlet extraction. Other very much used extraction techniques are sonication and automated Soxhlet. Some more recent methods also exist such as supercritical fluid extraction (SFE), accelerated solvent extraction (ASE, or pressurised solvent extraction [PSE]), pressurised fluid extraction (PFE), microwave-assisted extraction (MAE) and focused microwave-assisted Soxhlet extraction. Many of these techniques are detailed below.

\section{Polycyclic aromatic hydrocarbons (PAHs)}

Many analytical studies have concerned a list of $16 \mathrm{PAHs}$, designated as priority pollutants by the US Environmental Protection Agency (US EPA), because of their toxicity, mutagenicity, carcinogenicity, and endocrine-disrupting potential $[133,134]$. The official method proposed for PAHs determination is $\mathrm{GC}$ with a flame ionization detector (GC-FID). However, because of the absence of selectivity and sensitivity, this method requires an intermediate clean-up step by thin layer chromatography. Another possibility is the use of mass spectrometry-selected ion monitoring (MS-SIM), but the latter technique is not selective for isomers with identical mass spectra. HPLC-UV provides good selectivity, but lower sensitivity. In contrast, HPLC-FD has the advantage to yield at the same time high selectivity and sensitivity without any preliminary clean-up step [136] (Table 4). 
Table 4 .

Environmental analysis by HPLC with luminescence detection

\begin{tabular}{|c|c|c|c|c|c|c|}
\hline Analyte & Matrix & $\begin{array}{l}\lambda_{\mathrm{EX}} \lambda_{\mathrm{EM}} \\
(\mathrm{nm})\end{array}$ & Remarks & $\operatorname{LOD}^{a}$ & $\begin{array}{l}\text { Maximum concentration } \\
\text { found }\end{array}$ & Ref. \\
\hline $\mathrm{PAHs}^{\mathrm{b}}$ & Aerosol & $\begin{array}{l}\text { F progra- } \\
\text { mming. }\end{array}$ & $\mathrm{ASE}^{\mathrm{c}}$ & $5 \mathrm{pg}$ & $46.8 \mathrm{ng} \cdot \mathrm{m}^{-3}$ & [127] \\
\hline $\mathrm{PAHs}^{\mathrm{b}}$ & Aerosol & $\begin{array}{l}\text { F progra- } \\
\text { mming. }\end{array}$ & $\begin{array}{l}\text { Soxhlet-Warm } \\
\text { Automated } \\
\text { column }\end{array}$ & $5 \mathrm{pg}$ & $61.2 \mathrm{ng} \cdot \mathrm{m}^{-3}$ & [133] \\
\hline Nitro-PAHs ${ }^{b}$ & Aerosol & $\begin{array}{l}\text { F progra- } \\
\text { mming. }\end{array}$ & $\begin{array}{l}\text { Soxhlet } \\
\text { On-line reduction }\end{array}$ & $0.06-1.25 \mu \mathrm{g} \cdot \mathrm{L}^{-1}$ & $492 \mathrm{pg} \cdot \mathrm{m}^{-3}$ & [136] \\
\hline $\mathrm{PAHs}^{\mathrm{b}}$ & Rainfall water & $\begin{array}{l}\text { F progra- } \\
\text { mming. }\end{array}$ & SBSE $^{d}$ & $0.2-1.5 \mathrm{ng} \cdot \mathrm{L}^{-1}$ & $105.1 \mathrm{ng} \cdot \mathrm{L}^{-1+}$ & [141] \\
\hline $\mathrm{PAHs}^{\mathrm{b}}$ & Sediments & $\begin{array}{l}\text { F progra- } \\
\text { mming. }\end{array}$ & Soxhlet & $0.03-0.37 \mu \mathrm{g} / \mathrm{kg}$ & $3766 \mu \mathrm{g} / \mathrm{kg}$ & [143] \\
\hline $\mathrm{PAHs}^{\mathrm{b}}$ & Waters & $\begin{array}{l}\text { F progra- } \\
\text { mming. }\end{array}$ & IL-DLLME $^{\mathrm{e}}$ & $0.04-2 \mathrm{ng} \cdot \mathrm{L}^{-1}$ & $606.1 \mathrm{ng} \cdot \mathrm{L}^{-1}$ & [149] \\
\hline $\begin{array}{l}\text { Carbaryl, } \\
\text { Triazophos }\end{array}$ & $\begin{array}{l}\text { River, sea and } \\
\text { tap water }\end{array}$ & $274 / 335$ & $\operatorname{DLLME}^{\mathrm{f}}$ & $\begin{array}{l}12.3 \mathrm{pg} \cdot \mathrm{mL}^{-1} \\
16.0 \mathrm{pg} \cdot \mathrm{mL}^{-1}\end{array}$ & $\begin{array}{l}0.093 \mathrm{pg} \cdot \mathrm{mL}^{-1} \\
0.075 \mathrm{pg} \cdot \mathrm{mL}^{-1}\end{array}$ & [154] \\
\hline Carbamates & $\begin{array}{l}\text { Air of } \\
\text { manufactory }\end{array}$ & $330 / 460$ & $\begin{array}{l}\text { Sorbent tubes } \\
\text { Derivatization }\end{array}$ & $3 \mu \mathrm{g} \cdot \mathrm{m}^{-3}$ & $7 \mathrm{mg} \cdot \mathrm{m}^{-3}$ & [156] \\
\hline $\begin{array}{l}\text { Glyphosate, } \\
\text { AMPA }^{\mathrm{g}}\end{array}$ & River water & $260 / 310$ & Derivatization & $\begin{array}{l}0.025 \mu \mathrm{g} \cdot \mathrm{L}^{-1} \\
0.05 \mu \mathrm{g} \cdot \mathrm{L}^{-1}\end{array}$ & $\begin{array}{l}0.17 \mu \mathrm{g} \cdot \mathrm{L}^{-1} \\
0.76 \mu \mathrm{g} \cdot \mathrm{L}^{-1}\end{array}$ & [158] \\
\hline Benzimidazole & $\begin{array}{l}\text { Sea, waste and } \\
\text { groundwater }\end{array}$ & $\begin{array}{l}280 / 320 \\
300 / 350\end{array}$ & SPME $^{h}$ & $0.03-1.30 \mathrm{ng} \cdot \mathrm{mL}^{-1}$ & - & [159] \\
\hline Aluminium & Drinking water & $418 / 490$ & $\begin{array}{l}\text { Reaction pre- } \\
\text { column with } \\
\text { morin }\end{array}$ & $2 \cdot 10^{-9} \mathrm{M}$ & $1.02 \cdot 10^{-6} \mathrm{M}$ & {$[160]$} \\
\hline Aluminium & Soil & $360 / 513$ & $\begin{array}{l}\text { Reaction post- } \\
\text { column with HQS }\end{array}$ & & $\begin{array}{l}150 \mu \mathrm{M} \text { (free Al) } \\
50 \mu \mathrm{M} \text { (inert Al) }\end{array}$ & [161] \\
\hline Ibuprofen & WWTPs & $\begin{array}{l}254 / 290 \\
230 / 420\end{array}$ & $\mathrm{SPE}^{\mathrm{j}}$ & $\begin{array}{l}0.25 \mu \mathrm{g} \cdot \mathrm{L}^{-1} \text { (influent) } \\
0.12 \mu \mathrm{g} \cdot \mathrm{L}^{-1} \text { (effluent) } \\
0.06 \mu \mathrm{g} \cdot \mathrm{L}^{-1} \text { (influent) } \\
0.03 \mu \mathrm{g} \cdot \mathrm{L}^{-1} \text { (effluent) }\end{array}$ & $\begin{array}{l}143.0 \mu \mathrm{g} \cdot \mathrm{L}^{-1} \text { (influent) } \\
10.1 \mu \mathrm{g} \cdot \mathrm{L}^{-1} \text { (effluent) } \\
11.4 \mu \mathrm{g} \cdot \mathrm{L}^{-1} \text { (influent) } \\
3.12 \mu \mathrm{g} \cdot \mathrm{L}^{-1} \text { (effluent) }\end{array}$ & [162] \\
\hline $\begin{array}{l}\text { Marbofloxacin } \\
\text { Enrofloxacin }\end{array}$ & Surface water & $\begin{array}{l}297 / 507 \\
280 / 450\end{array}$ & $\mathrm{SPE}^{\mathrm{j}}$ & $\begin{array}{l}2 \mathrm{ng} \cdot \mathrm{L}^{-1} \\
0.7 \mathrm{ng} \cdot \mathrm{L}^{-1}\end{array}$ & $\begin{array}{l}9 \mathrm{ng} \cdot \mathrm{L}^{-1} \\
37 \mathrm{ng} \cdot \mathrm{L}^{-1}\end{array}$ & [163] \\
\hline Ibuprofen & WWTPs ${ }^{\mathrm{k}}$ & $\begin{array}{l}254 / 290 \\
230 / 420\end{array}$ & $\mathrm{SPE}^{\mathrm{j}}$ & $\begin{array}{l}0.25 \mu \mathrm{g} \cdot \mathrm{L}^{-1} \text { (influent) } \\
0.12 \mu \mathrm{g} \cdot \mathrm{L}^{-1} \text { (effluent) } \\
0.06 \mu \mathrm{g} \cdot \mathrm{L}^{-1} \text { (influent) } \\
0.03 \mu \mathrm{g} \cdot \mathrm{L}^{-1} \text { (effluent) }\end{array}$ & $\begin{array}{l}373.1 \mu \mathrm{g} \cdot \mathrm{L}^{-1} \text { (influent) } \\
48.24 \mu \mathrm{g} \cdot \mathrm{L}^{-1} \text { (effluent) } \\
27.40 \mu \mathrm{g} \cdot \mathrm{L}^{-1} \text { (influent) } \\
4.28 \mu \mathrm{g} \cdot \mathrm{L}^{-1} \text { (effluent) }\end{array}$ & {$[165]$} \\
\hline Ofloxacin & WWTPs & $278 / 500$ & $\mathrm{SPE}^{\mathrm{j}}$ & $\begin{array}{l}0.3 \mu \mathrm{g} \cdot \mathrm{L}^{-1} \text { (influent) } \\
0.08 \mu \mathrm{g} \cdot \mathrm{L}^{-1} \text { (effluent) }\end{array}$ & $\begin{array}{l}3.52 \mu \mathrm{g} \cdot \mathrm{L}^{-1} \text { (influent) } \\
5.70 \mu \mathrm{g} \cdot \mathrm{L}^{-1} \text { (effluent) }\end{array}$ & [166] \\
\hline $\begin{array}{l}\text { Ofloxacin/ } \\
\text { Norfloxacin } \\
\text { Ciprofloxacin }\end{array}$ & $\begin{array}{l}\text { WWTPs and } \\
\text { river water }\end{array}$ & $278 / 445$ & $\mathrm{SPE}^{\mathrm{j}}$ & $\begin{array}{l}0.120 \mu \mathrm{g} \cdot \mathrm{L}^{-1} \text { (influent) } \\
0.035 \mu \mathrm{g} \cdot \mathrm{L}^{-1} \text { (effluent/river) } \\
0.100 \mu \mathrm{g} \cdot \mathrm{L}^{-1} \text { (influent) } \\
0.035 \mu \mathrm{g} \cdot \mathrm{L}^{-1} \text { (effluent/river) }\end{array}$ & $0.459 \mu \mathrm{g} \cdot \mathrm{L}^{-1}$ (river) & [168] \\
\hline $\begin{array}{l}\text { Ofloxacin } \\
\text { Norfloxacin } \\
\text { Ciprofloxacin } \\
\text { Enrofloxacin } \\
\end{array}$ & $\begin{array}{l}\text { Hospital and } \\
\text { municipal } \\
\text { wastewater }\end{array}$ & $278 / 450$ & $\mathrm{SPE}^{\mathrm{j}}$ & $\begin{array}{l}85 \mathrm{ng} \cdot \mathrm{L}^{-1} \\
8.5 \mathrm{ng} \cdot \mathrm{L}^{-1} \\
8.5 \mathrm{ng} \cdot \mathrm{L}^{-1} \\
17 \mathrm{ng} \cdot \mathrm{L}^{-1}\end{array}$ & $\begin{array}{l}9451.9 \mathrm{ng} \cdot \mathrm{L}^{-1} \text { (hospital) } \\
455.0 \mathrm{ng} \cdot \mathrm{L}^{-1} \text { (influent) } \\
2927.2 \mathrm{ng} \cdot \mathrm{L}^{-1} \text { (hospital) } \\
121.8 \mathrm{ng} \cdot \mathrm{L}^{-1} \text { (WWTP } \text { (WW }^{\mathrm{k}} \text { ) }\end{array}$ & {$[169]$} \\
\hline $\begin{array}{l}\text { Fluoroquinolones } \\
\text { Sulfonamides }\end{array}$ & Manure feedlot & $\begin{array}{l}278 / 445 \\
420 / 485\end{array}$ & $\begin{array}{l}\text { Ultrasonic } \\
\text { extraction }\end{array}$ & $\begin{array}{l}0.046-0.099 \mathrm{mg} \cdot \mathrm{L}^{-1} \\
0.025-0.058 \mathrm{mg} \cdot \mathrm{L}^{-1}\end{array}$ & $\begin{array}{l}1420.76 \mathrm{mg} \cdot \mathrm{kg}^{-1} \\
6.04 \mathrm{mg} \cdot \mathrm{kg}^{-1}\end{array}$ & [172] \\
\hline $\begin{array}{l}\text { Enrofloxacin } \\
\text { Ciprofloxacin }\end{array}$ & $\begin{array}{l}\text { Sandy, loamy } \\
\text { sand, sandy } \\
\text { loam }\end{array}$ & $280 / 450$ & $\begin{array}{l}\text { Vortex Ultrasonic } \\
\text { extraction }\end{array}$ & 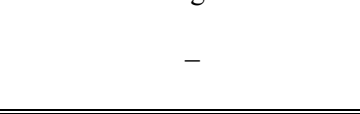 & $\begin{array}{l}0.204 \mathrm{mg} \cdot \mathrm{kg}^{-1} \\
0.053 \mathrm{mg} \cdot \mathrm{kg}^{-1}\end{array}$ & {$[175]$} \\
\hline
\end{tabular}

${ }^{\mathrm{a}} \mathrm{LOD}=$ limit of detection. ${ }^{\mathrm{b}} \mathrm{PAHs}=$ polycyclic aromatic hydrocarbons. ${ }^{\mathrm{c}} \mathrm{ASE}=$ accelerated solvent extraction. ${ }^{\mathrm{d}} \mathrm{SBSE}=$ stir bar sorptive extraction. ${ }^{\mathrm{e}}$ IL-DLLME $=$ ionic liquid based dispersive liquid-liquid microextraction. ${ }^{\mathrm{f}}$ DLLME $=$ dispersive liquid-liquid microextraction. ${ }^{\mathrm{g}}$ AMPA $=$ Aminomethylphosphoric acid. ${ }^{\mathrm{h}} \mathrm{SPME}=$ solid-phase microextraction. ${ }^{\mathrm{i}} \mathrm{HQS}=8$-hydroxyquinoline-5sulfonic acid; ${ }^{\mathrm{j}} \mathrm{SPE}=$ solid-phase extraction. ${ }^{\mathrm{k}} \mathrm{WWWTP}=$ Wastewater treatment plant. ${ }^{*}$ Limit of quantification. 
Most papers on PAHs have concerned applications to aerosol samples [133-139]. Indeed, atmospheric PAHs generally originated from the incomplete combustion of organic matter (e.g., fossil-fuel combustion), and their characteristic composition permitted to identify different sources of aerosols [133]. Atmospheric particles were usually collected on quartz or glass fiber filters, using a high-volume air sampler [127, 134, 136, 138]. Regarding the extraction method of PAHs from these filters, the sonication technique was commonly utilized with organic solvents, such as benzene/ethanol or acetonitrile, and absolute LOD values between 2.5 and $95 \mathrm{pg}$ were achieved [134, 135].

The ASE technique was used for extracting the PAHs from filters. This procedure was based on organic solvents taken at high-pressure and temperature values, which improved the dissolution and diffusion rates of the analytes from the matrix and led to recovery and precision values similar to those of the standard US EPA extraction procedure [127]. Also, Okuda et al. [133] have very recently applied a modified Soxhlet extraction procedure, so-called Soxhlet-Warm, to the same PAHs. In this method, the use of a heated solvent allowed to accelerate the extraction from the samples and offered, in terms of extraction efficiency, results comparable to other methods such as ASE and SFE. In both cases, after extraction, an additional chromatographic column was utilized to separate PAHs from co-extracts that could not be removed by the conventional separation procedures, and that had negative effects on the analytical precision and accuracy. The purification method, based on an aminopropylsilane chemically-bonded stationary-phase chromatographic column, was optimized. In the early work of the same group [127], this clean-up step was manually performed and was time-consuming, whereas, in the more recent paper [133], an automated column chromatography was available. The calculated LOD values were around $5 \mathrm{pg}$. In an interesting work, Rynö et al. [137] compared different extraction procedures, including Soxhlet, ASE and ultrasonic extraction, for the determination of PAHs in aerosol samples. The authors concluded that ASE was the best extraction technique, due to its good reproducibility and the more simple and rapid handling of samples than the Soxhlet extraction.

The PAH nitrated derivatives (nitro-PAHs or NPAHs) also present a great environmental inter- est because they are produced by primary emissions such as diesel or by PAH reactions with nitrogen oxides in the gas phase and subsequent partitioning to the particulate phase $[136,138]$. Although most studies of NPAHs in environmental samples were based on GC coupled to a massselective detector with negative chemical ionization (GC-NCI-MS) or to an electron-capture detector (GC-ECD), the determination of un-derivatized NPAHs by low-temperature luminescence was applicable, too. However, since NPAHs present a very weak fluorescence, it is necessary to perform first their reduction to the corresponding aminoPAHs which generally exhibit a very strong fluorescence signal [136]. For this purpose, a second column, densely packed with Pt on $\gamma$-alumina, was placed between the HPLC column and the fluorescence detector, allowing on-line reduction and detection $[136,138]$.

Rainwater samples containing PAH traces have also been analyzed. The sampling was carried out with a wet-only rainwater sampler, and two extraction techniques, including solid-phase extraction (SPE) [140] and stir bar sorptive extraction (SBSE) [141], were used. The total concentrations detected ranges approximately between 0.15 and $1596 \mathrm{ng} \mathrm{L}^{-1}$, and between 31 and $105 \mathrm{ng} \mathrm{L}^{-1}$, respectively.

Similar methods have been applied for the extraction of PAHs from solid samples. A number of examples of analysis of PAHs in sediments [142145] and soils [146-148] were reported. The most used extraction techniques were the sonication $[142,148]$ and Soxhlet $[143,144]$, leading to LOD values in the range of 0.2 to $17.4 \mathrm{ng} \mathrm{g}^{-1}$ and 0.05 to $0.4 \mathrm{ng} \mathrm{g}^{-1}$, respectively. Several extraction solvents or mixtures, such as $n$-hexane-acetone, dichloromethane and dichloromethane-methanol, were selected. After extraction, a cleaning step was often carried out with a SPE alumina-silica [148] or a polypropylene cartridge [142]. Mechanical shaking using acetone-dichloromethane [146] and ASE with acetone-cyclohexane [147] were also utilized with satisfactory results. PAH concentrations until $650 \mu \mathrm{g} \mathrm{kg}^{-1}$ were obtained.

Few, but very interesting examples are relative to PAH-containing water samples HPLC-FD analysis $[149,150]$. For example, Gasperi et al. [149] examined the quality of the Seine River water in Paris. The extraction was performed by SPE, using an Oasis HLB column and achieving limit of

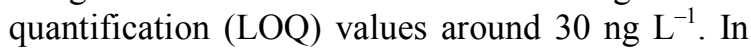


another investigation, different water samples, including tap, bottled, fountain, well, rainwater, river and treated wastewater, were analyzed, employing ionic liquid based dispersive liquid-liquid microextraction (IL-DLLME) with acetone as an extractant. The LOQ values obtained for PAHs ranged between 0.1 and $2 \mathrm{ng} \mathrm{L}^{-1}[150]$.

Several studies also concerned the biomonitoring of PAHs and other pollutants in biological samples, such as fish bile, pine tree barks or gulls [151-153].

\section{Pesticides}

As already pointed out in the first part of this review, most pesticides exhibit rather weak fluorescence. For this reason, HPLC with direct fluorescence detection has not been very much used. However, a HPLC-FD method with post-column derivatization has been developed for the analysis of carbamates, due to the thermal lability of these pesticides and the lower sensitivity of UV absorption detection [154].

Since the tolerable pesticide maximum concentrations in water, authorized by the European Union (EU), are very low, a sample preparation is generally required to extract and concentrate the pollutants before their analysis. For pesticides, the most employed extraction techniques are LLE and SPE, but they present some disadvantages, such as the large amounts of required solvent and extraction time, and they are costly. Therefore, an alternative technique, namely dispersive liquid-liquid microextraction (DLLME) was proposed for the determination of carbaryl and triazophos, an organophosphorus pesticide [154]. DLLME is based on the rapid injection of a mixture of extraction and dispersive solvents into an aqueous sample, resulting in the formation of a cloudy solution. Using acetonitrile and tetrachloroethane as extractant and dispersive solvents, respectively, the method was validated for both compounds in different water samples (tap water, river water and seawater), obtaining recoveries between 80.4 and $114.2 \%$. The LOD values were $12.3 \mathrm{pg} \mathrm{mL}^{-1}$ for carbaryl and $16 \mathrm{pg} \mathrm{mL}^{-1}$ for triazophos. Moreover, the authors compared this technique with other literature extraction methods employing hollow fiber liquid-phase microextraction with gas chromatography combined to flame photometric or mass spectrometry detection (HFM-LPME-GCFPD and HFM-LPME-GC-MS), and they obtained by their technique lower LOD and RSD values, as well as shorter extraction time [154].

Some examples of the analysis of carbamate pesticides in soil and in air have also been reported. Focused microwave assisted Soxhlet extraction was chosen to extract $N$-methyl carbamates from soil [155]. This technique was developed in order to avoid the disadvantages of Soxhlet extraction, such as the long extraction time and large solvent volume required, and to exploit its benefits (easy manipulation, sample fresh solvent contact during the whole extraction step, and no filtration was needed after extraction). Microwave power, irradiation time and number of cycles were optimized by means of a two-level full factorial design. After extraction, $\mathrm{N}$-methylcarbamates were hydrolysed by $\mathrm{NaOH}$ at high temperature to yield methylamine, which subsequently reacted with $o$ phthalaldehyde (OPA) at high $\mathrm{pH}$ to produce a strongly fluorescent isoindole, which could be measured at excitation and emission wavelength values of 340 and $445 \mathrm{~nm}$, respectively [155]. Recovery values were similar to those obtained by the US EPA method. In the case of the analysis of airborne carbamates in the workplace, a XAD-2 sorbent tube was used for separation purposes [156]. The sampling was performed by passing the air from five manufactories of carbamate pesticides through the sorbents about three hours. The instrument possessed an auto-sampler and two pumps for delivering the OPA and $\mathrm{NaOH}$ solutions needed for the post-column reaction, and a $\mathrm{C} 18$ HPLC column was utilized. The excitation and emission wavelengths for fluorescence detection were set at 330 and $460 \mathrm{~nm}$, respectively. A LOD value of $3 \mu \mathrm{g} \mathrm{m}^{-3}$ was obtained for all pesticides under study, and the measured real concentrations ranged between 0.001 and $7.41 \mathrm{mg} \mathrm{m}^{-3}$ (Table 4).

In the case of organophosporus pesticides (OPs), GC is the traditional technique used for their analysis, but it presents some drawbacks because of the lack of volatility of these compounds. Thus, HPLC constitutes a good alternative for nonvolatile and thermally unstable OPs. The method was based on the post-column photolysis of OPs, followed by fluorescence detection [157]. The photolysis of OPs aqueous solutions was performed by the UV irradiation with a low-pressure mercury lamp in the presence of peroxydisulfate. The obtained photoproduct reacted with molybdate to form molybdophosphoric acid, and then reacted with thiamine to generate fluorescent thiochrome, 
which was finally measured at $\lambda_{\mathrm{EM}}=440 \mathrm{~nm}$ with an excitation wavelength set at $375 \mathrm{~nm}$. The LOD

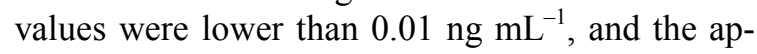
plication to real samples (tap and runoff waters) provided recovery values ranging between 95 and $101 \%$ [157]. In a related study on the HPLC analysis of OPs, 9-fluorenymethylchloroformate (FMOC-Cl) was used for derivatization [158]. In this case, the excitation and emission wavelengths were 260 and $310 \mathrm{~nm}$, respectively, for the determination of glyphosate and its main metabolite, aminomethyl-phosphoric acid (AMPA).

Benzimidazole fungicides which are strongly fluorescent can be easily measured by HPLC with direct fluorescence detection [159]. LOD values between 0.03 and $1.3 \mathrm{ng} \mathrm{mL}^{-1}$ were achieved and recovery values ranged from 80.6 to $119.6 \%$ for seawater, groundwater and wastewater applications. This method also involved solid-phase microextraction (SPME), using a carboxen-polydimethylsiloxane fibre, and several parameters, including the ionic strength, extraction time, temperature and desorption time, were optimized. Direct fluorescence detection was carried out after desorption of the benzimidazoles from the fibre.

\section{Metals}

Relatively few studies have reported on the HPLC-FD determination of metals at the trace level in the environment. Indeed, metals at the trace level in the environment are generally determined by various atomic spectrometric methods, more specific, sensitive and efficient than HPLCFD. Nevertheless, HPLC with fluorescence detection is also used because atomic spectrometry requires more expensive and sophisticated instrumentation. HPLC-FD is based on the formation of complexes (chelates) between the metallic ion under study and a fluorescent organic reagent. The formed chelates can be easily separated by HPLC.

Several examples of aluminium determination in liquid and solid samples using HPLC-FD have been described $[160,161]$. Aluminium was determined in environmental and biological samples by reversed-phase HPLC via pre-column formation of a strongly fluorescent complex with morin $\left(3,5,7,2^{\prime}, 4^{\prime}\right.$-pentahydroxyflavone) [160]. Chromatographic conditions were optimized with both UV-VIS and fluorescence detection to clarify the behaviour of the aluminium-morin complex, and two peaks were observed, indicating the formation of two species. Different drinking water samples were analyzed, and the recovery values ranged between 96.2 and $119.4 \%$. The concentrations measured in real samples were about $1.02 \times 10^{-6}$ and $5.30 \times 10^{-7} \mathrm{M}$, with $\mathrm{RSD}$ values lower than $7 \%$ [160]. In another study, Umemuraa et al. [161] determined aluminium in soil, by forming a complex between 8-hydroxyquinoline-5-sulfonic acid (8-HQS) and $\mathrm{Al}^{3+}$. A strong cation-exchange column was used for the separation of the free and inert aluminium fractions. Then, these fractions were mixed with the post-column reagent (PCR), containing 8-HQS, cethyltrimethylammonium bromide (CTAB) and $\mathrm{NaF}$ in a $0.1 \mathrm{M}$ acetate buffer solution ( $\mathrm{pH} 4.7)$. The stable complex of 8HQS with $\mathrm{Al}^{3+}$ was measured by fluorescence detection ( $\lambda_{\mathrm{EX}}$ and $\lambda_{\mathrm{EM}}$ set at 360 and $513 \mathrm{~nm}$, respectively). The inert aluminium fraction could be determined by inductively coupled plasma- atomic emission spectrometry (ICP-AES). When the aluminium annual monitoring was investigated, a clear tendency to an increase in spring and summer was observed for the free aluminium fraction. The measured aluminium concentrations could reach $150 \mu \mathrm{M}[161]$.

\section{Pharmaceutical compounds}

HPLC with mass spectrometry detection (HPLC-MS) is very suitable for achieving more sensitivity in the determination of pharmaceuticals in water samples. However, when examining strongly contaminated samples, such as wastewater, a suppression of the electrospray ionization is likely to occur. In these conditions, HPLC-FD can be considered as a preferable analytical tool for analysis of pharmaceuticals in the environment [162].

As a consequence, in recent years, the pharmaceuticals as well as the personal care products (PPCPs) probably constitute the emergent compounds that appear most frequently in the scientific papers concerning HPLC-FD for the environmental analysis. Indeed, several methods based on this combination have been developed for the determination of pharmaceutical compounds in different water samples (seawater, river water, groundwater, wastewater) [163-171] and solid samples (soils, sediments, sludge) [172-178]. This is due to two reasons. Firstly, the continuous growth of knowledge about these pharmaceutical compounds and their dangerous effects on the environment results in a very large volume of analytical studies, 
which requires the use of more usual and simple techniques. Secondly, the major cause of contamination by pharmaceuticals is due to the effluents of wastewater treatment plants (WWTPs) which are not able to eliminate completely these pharmaceuticals. Therefore, the most important analysis should be performed on this type of a very complex matrix, and requires an efficient separation and detection method. HPLC-FD provides at once a good separation and a satisfactory identification, since it is very unlikely that sample interferences would present the same excitation and emission wavelength values as the pharmaceutical under study. Usually, the separation is achieved by passing the sample through a reverse-phase HPLC column (of C 18 type, in most cases) and using a gradient elution in the separation step.

Numerous studies concerning both the influents and effluents of WWTPs are found in the literature [165-169]. In these kinds of samples, an extraction and a clean-up step are essential. The most utilised extraction technique is SPE, the Oasis HLB cartridge (hydrophilic and lipophilic balance type) being often the most appropriate system. SPE allows one to separate the target analyte from possible interferences of the matrix, besides providing an important pre-concentration factor of the sample.

For example, two anti-inflammatory drugs, namely ibuprofen and naproxen, were measured with HPLC-FD by Santos et al. [165] at concentrations of about 48.2 and $4.3 \mu \mathrm{g} \mathrm{L}^{-1}$, respectively, in effluent samples of four WWTPs from Sevilla (Spain). Using an identical methodology, the same group compared the seasonal concentration changes of these compounds in summer and autumn [162]. The mean concentration of ibuprofen was major in autumn (in both influents and effluents), while that of naproxen was lesser.

Antibiotics, particularly the fluoroquinolones (FQs) were also frequently found in the WWTP effluents or influents. Indeed, FQs have been detected in various wastewater treatment plants worldwide in Switzerland [167], China [166, 168], Portugal [169]) (Table 4). In all cases, SPE was used in the procedure, and the obtained LOD values were between 0.0085 and $0.3 \mu \mathrm{g} \mathrm{L}^{-1}$, for influents and effluents, respectively.

Surface and groundwater samples have also been investigated. For instance, two FQs, namely enrofloxacin and marblofloxacine, were measured in surface waters located close to swine and cattle farms in Pavia (Italy) at concentrations of about 37 and $9 \mathrm{ng} \cdot \mathrm{L}^{-1}$, respectively [163]. Moreover, in this work, the efficiency of the materials used for sample filtration, including cellulose esters, cellulose nitrate, nylon and glass fiber, were compared in term of their recovery values. The lowest recovery percentages of FQs retained in the filters were obtained with nylon. In the case of cellulose filters, the recovery values obtained for river water samples were found to be higher than for ultra-pure water, which can be attributed to a more important association of FQs with the natural organic matter (present in river water) than with filters [163]. In another study, twenty-two water samples were taken in the Mondego River (Portugal) for the determination of FQ antibiotics, using SPE and a monolithic column [171]. The recovery values ranged between 76.5 and $98.0 \%$. In addition, a comparison of inter-day and intra-day measurements was carried out, resulting in RSD values lower than $12 \%$.

As already mentioned, HPLC-FD does not exclusively concern the fluorescent compounds, but can be also applied to non-fluorescent or weakly fluorescent analytes, after performing a post-column derivatization. For example, tetracyclines were determined by HPLC-FD in seawater samples [164], after complexation in a $0.1 \mathrm{~mol} \mathrm{~L}^{-1}$ $\mathrm{Mg}$ (II) reagent solution. A strongly fluorescent $\mathrm{Mg}(\mathrm{II})$-tetracycline chelate was detected at $\lambda_{\mathrm{ex}}=$ $374 \mathrm{~nm}$ and $\lambda_{\mathrm{em}}=499 \mathrm{~nm}$, and LOD values in the low $\mu \mathrm{g} \cdot \mathrm{L}^{-1}$ level were obtained.

A number of examples of HPLC-FD applications to various solid samples, also exists such as soils, sediments, and even livestock manure. Generally, before determining pharmaceuticals in solid samples an efficient extraction procedure had to be applied, because stronger interactions of the analytes occurred with the solid matrix than with the liquid samples, which required more complex pretreatments [178]. Extraction was usually achieved by means of centrifugation or ultrasonic treatment with an organic solvent. Veterinary antibiotics such as FQs and sulfonamides were detected at concentrations of about 1421 and $6 \mathrm{mg} \mathrm{kg}^{-1}$, respectively, in manure samples from China, using ultrasonic extraction [172]. In some cases, SPE was applied as clean-up step [174, 175, 177]. For example, oxolinic acid was extracted from marine sediments with sodium hydroxide and dimethyl sulfoxide and determined by HPLC-FD, the extract being passed through an Oasis HLB cartridge with phosphoric acid for the elution [177]. In another study, Blackwell et al. [174] extracted sul- 
fachloropyridazine and other veterinary antibiotics from soils and pig slurry by performing a combination of ultrasonic agitation and vortex mixing. Then, the extract was passed through by means of a tandem SPE procedure with an Isolute SAX anion exchange cartridge to remove natural organic matter, and an Oasis HLB polymeric cartridge to retain the antibiotics under study. A fluorescence analysis was achieved using fluorescamine for the derivatization reaction, and recovery values were obtained in the range of 68 to $85 \%$ [174].

Microwave assisted extraction (MAE) was also convenient for the extraction from solid samples. For instance, Prat et al. [176] determined flumequine and oxolinic acid in sediments and agricultural soils by using mechanical shaking and MAE with dichloromethane for extraction, and HPLC-FD. The LOD values were in the low $\mu \mathrm{g} \cdot \mathrm{kg}^{-1}$ level.

More generally, it is interesting to stress that HPLC-FD has been used not only for quantitative analysis of pharmaceuticals present in environment samples, but also for studies of the pharmaceutical biodegradation, toxicity and/or bioaccumulation in the environment $[173,179,180]$.

\section{Capillary electrophoresis (CE) with luminescence detection}

In the early 1980s, the availability of special fused-silica capillaries $(<100 \mu \mathrm{m}$ I.D. $)$ has allowed the development of modern capillary electrophoresis (CE). However, it was not until the late 1980s that commercial instruments appeared [181, 182]. Since then, $C E$ has been transformed from a research technique to a routine technology for a wide variety of chemicals in several application areas, including pharmaceutical, biomedical, biochemical and environmental analyses. Nowadays, $\mathrm{CE}$ constitutes a very important separation and analysis methodology, due to its capacity to determine simultaneously various compounds with high efficiency, high resolution, low consumption of samples and electrolytes, and short analysis time [183]. Moreover, CE can even surpass HPLC in terms of simplicity, resolution and economy [184].

However, the main disadvantage of this technique lies in the lack of sensitivity of the UV-VIS photometric detectors, generally used, mainly resulting from the required small sample volumes (e.g., 2-10 nL) and short light paths (e.g., 25-100 $\mathrm{mm})$ [183]. As a consequence, several attempts have been made to improve the CE sensitivity, and various types of $\mathrm{CE}$ detectors have been tested in order to enhance sensitivity without reducing the CE resolution [184]. During the last twenty years, both fluorescence and laser-induced fluorescence (LIF) detectors have been developed and have been found to be much more sensitive than classical UV/VIS absorption detectors. For example, it has been reported that LIF detectors could increase sensitivity more than 1000 -fold relative to the conventional UV/VIS detectors [185].

Regarding the use of $\mathrm{CE}$ in the environmental analysis, different $\mathrm{CE}$ modes, such as capillary zone electrophoresis (CZE) with buffer modifiers and pseudo-stationary phases, micellar electrokinetic capillary chromatography (MEKC) with various micelles, and capillary electrochromatography (CEC) have been proposed, which has considerably increased the applicability of this technique [24]. Table 5 shows the characteristics of different CE-luminescence methods applied to the analysis of various pollutants of environmental interest.

\section{Polycyclic aromatic hydrocarbons (PAHs)}

Several types of CE have been used for the efficient separation of a wide range of PAHs and their metabolites (Table 5). Since most PAHs exhibit strong native fluorescence, their LIF detection represents a very suitable choice, improving the LOD values. However PAHs are also hydrophobic and neutral compounds, which hinders their separation by either conventional CE or MEKC.

Various separation strategies have been developed to overcome this problem. On the one hand, typical solvophobic associations between an ionic additive, such as an ionic surfactant, and neutral analytes have been described in CE. On the other hand, several approaches have been directed towards introducing either organic additives (such as organic amines) or modifiers (such as CDs) into the aqueous background electrolyte (BGE) in CZE or MEKC. Moreover, the incorporation of organic solvents in BGE has greatly extended the scope of MEKC and has provided a major variable for optimizing the separation of PAHs. Also, the use of organic solvents has permitted to improve the solubility of several sample components, and to alter the electro-osmotic flow (EOF), which modifies the electrophoretic mobility of sample ions by changing their solvation [186]. 
Table 5

Environmental analysis by CE with luminescence detection

\begin{tabular}{|c|c|c|c|c|c|c|}
\hline Analyte & Matrix & $\begin{array}{l}\text { Separation } \\
\text { mode }\end{array}$ & $\begin{array}{l}\text { Detection } \\
\lambda[\mathrm{nm}]\end{array}$ & $\operatorname{LOD}^{\mathrm{a}}$ & Remarks & Ref. \\
\hline $\begin{array}{l}\text { Mixture of } 23 \text { napht- } \\
\text { halene sulphonates }\end{array}$ & River water & $\mathrm{CE}$ & $\begin{array}{l}\text { LIF } \\
\lambda_{\mathrm{EX}} 280 \mathrm{~nm}\end{array}$ & $1-35 \mathrm{mg} \mathrm{L}^{-1}$ & Borate buffer (pH 8.75) & [192] \\
\hline $\begin{array}{l}\text { Priority pollutant } \\
\text { PAH }{ }^{\mathrm{b}} \text { mixture }\end{array}$ & Soil extracts & CEC & $\begin{array}{l}\operatorname{LIDF}^{\mathrm{c}} \\
\lambda_{\mathrm{EX}} 257 \mathrm{~nm}\end{array}$ & $0.5-96 \times 10^{-10} M$ & $\begin{array}{l}\text { Tris(hydroxymethyl)aminometha- } \\
\text { ne (TRIS); sodium tetraborate so- } \\
\text { lution (pH 9.0) }\end{array}$ & [187] \\
\hline $\begin{array}{l}\text { Benzo }[a] \text { pyrene } \\
\text { metabolite }\end{array}$ & - & $\mathrm{CE}$ & $\begin{array}{l}\text { LIF } \\
\lambda_{\mathrm{EX}} 325 \mathrm{~nm}\end{array}$ & $0.5 \mathrm{mg} \mathrm{mL}^{-1}$ & $\begin{array}{l}3 \text {-cyclohexylamino-1-propane- } \\
\text { sulfonic acid (CAPS) }\end{array}$ & {$[275]$} \\
\hline Hydroxy-PAHs & Flatfish bile & MEKC & $\begin{array}{l}\text { LIF } \\
\lambda_{\mathrm{EX}} 325 \mathrm{~nm}\end{array}$ & $0.8-5 \times 10^{-14} M$ & SDS and $\gamma-\mathrm{CD}^{\mathrm{d}}$ & [276] \\
\hline Hydroxy-PAHs & Isopods & $\mathrm{CD}^{\mathrm{d}}-\mathrm{MEKC}$ & $\begin{array}{l}\text { LIF } \\
\lambda_{\mathrm{EX}} 266 \mathrm{~nm}\end{array}$ & $2-6 \mathrm{ng} / \mathrm{mL}$ & $\begin{array}{l}\text { Borate buffer (pH 9.0); } \\
\gamma-\mathrm{CD}\end{array}$ & [277] \\
\hline $16 \mathrm{PAHs}^{\mathrm{b}}$ & - & MEKC & $\begin{array}{l}\text { LIF } \\
\lambda_{\mathrm{EX}} 266 \mathrm{~nm}\end{array}$ & $1-150 \mathrm{ng} / \mathrm{mL}$ & $\begin{array}{l}\text { Sodium dioctyl sulfosuccinate; } \\
\text { borate buffer ( } \mathrm{pH} 9.0 \text { ) }\end{array}$ & [278] \\
\hline $\begin{array}{l}\text { Aniline pesticidic } \\
\text { metabolites }\end{array}$ & $\begin{array}{l}\text { Tap and lake } \\
\text { water }\end{array}$ & $\mathrm{CE}$ & $\begin{array}{l}\text { LIF } \\
\lambda_{\mathrm{EX}} 520 \mathrm{~nm}\end{array}$ & $3.9-8.7 \times 10^{-10} M$ & $\begin{array}{l}\text { Borate buffer (pH 9.5); fluorescein } \\
\text { isothiocyanate (FITC) }\end{array}$ & [279] \\
\hline $\begin{array}{l}\text { Aminated pesticides } \\
\text { and metabolites }\end{array}$ & Groundwater & $\mathrm{CE}$ & $\begin{array}{l}\text { LIF } \\
\lambda_{\mathrm{EX}} 488 \mathrm{~nm}\end{array}$ & $0.45-3.48 \mu \mathrm{g} \mathrm{L}{ }^{-1}$ & $\begin{array}{l}\text { Fluorescein isothiocyanate (FITC); } \\
\text { borate buffer ( } \mathrm{pH} 9)\end{array}$ & [280] \\
\hline $\begin{array}{l}\text { Amino phosphonic } \\
\text { acid herbicides }\end{array}$ & - & MEKC, CZE & $\begin{array}{l}\text { LIF } \\
\lambda_{\mathrm{EX}} 488 \mathrm{~nm}\end{array}$ & $2-65 \mathrm{ng} \mathrm{mL}^{-1}$ & $\begin{array}{l}5-(4,6 \text {-dichloro- } s \text {-triazin-2- } \\
\text { ylamino)fluorescein (DTAF) }\end{array}$ & [199] \\
\hline $\begin{array}{l}\text { Aniline pesticidic } \\
\text { metabolites }\end{array}$ & Lake water & $\mathrm{CZE}$ & $\begin{array}{l}\mathrm{MEPF}^{\mathrm{f}} \\
\lambda_{\mathrm{EX}} 488 \mathrm{~nm}\end{array}$ & $1.6-2.6 \mu \mathrm{M}$ & Fluorescein isothiocyanate (FITC), & {$[209]$} \\
\hline Glyphosate & River water & SPE-MEKC & $\begin{array}{l}\text { LIF } \\
\lambda_{\mathrm{EX}} 415 \mathrm{~nm}\end{array}$ & $0.04-1.6 \mathrm{nM}$ & $\begin{array}{l}\text { Naphthalene-2,3-dicarboxaldehy- } \\
\text { de (NDA)-cyanide }\end{array}$ & [210] \\
\hline $\begin{array}{l}\text { Phenol pesticidic } \\
\text { metabolites }\end{array}$ & Tap water & $\begin{array}{l}\text { CEC, CZE and } \\
\text { SM-EKC }^{\mathrm{e}}\end{array}$ & $\begin{array}{l}\text { LIF } \\
\lambda_{\mathrm{EX}} 325 \mathrm{~nm}\end{array}$ & $10^{-7}$ to $10^{-9} M$ & $\begin{array}{l}\text { Carbazole- } 9-N \text {-acetic acid (CRA); } \\
\text { dioctyl sulfosuccinate sodium salt } \\
(\text { DOSS) }\end{array}$ & [211] \\
\hline $\mathrm{Ca}, \mathrm{Mg}, \mathrm{Zn}, \mathrm{Cd}$ & - & $\mathrm{CE}$ & $\begin{array}{l}\mathrm{FD} \\
\lambda_{\mathrm{EX}} 366 \mathrm{~nm} \\
\lambda_{\mathrm{Em}} 500 \mathrm{~nm}\end{array}$ & $\sim 0.1 \mu \mathrm{m} \mathrm{L}^{-1}$ & $\begin{array}{l}\text { 8-hydroxyquinoline-5-sulphonic } \\
\text { acid (HQS); malonic acid buffer } \\
\text { (pH 3) formate buffer (pH 3.5) } \\
\text { acetate buffer ( } \mathrm{pH} 4.4 \text { ) }\end{array}$ & [212] \\
\hline $\begin{array}{l}\text { Selenium and } \\
\text { antimony compounds }\end{array}$ & - & $\mathrm{CE}$ & $\begin{array}{l}\text { LIF } \\
\lambda_{\mathrm{EX}} 488 \mathrm{~nm}\end{array}$ & $0.9-6.2 \mu \mathrm{M}$ & Fluorescein (pH 9.5) & [213] \\
\hline $\begin{array}{l}\text { Paramagnetic and } \\
\text { heavy metal ions }\end{array}$ & $\begin{array}{l}\text { River water, } \\
\text { human serum }\end{array}$ & CZE & $\begin{array}{l}\text { LIF } \\
\lambda_{\mathrm{EX}} 493 \mathrm{~nm} \\
\lambda_{\mathrm{Em}} 523 \mathrm{~nm}\end{array}$ & $10^{-11}-10^{-10} \mathrm{~mol} \mathrm{~L}$ & $\begin{array}{l}\text { FTC (fluorescein-thiocarbamyl); } \\
\text { ABEDTA (1-(4-aminobenzyl)et- } \\
\text { hylenediamine- } N, N, N^{\prime}, N^{\prime} \text {-tetra- } \\
\text { acetic acid) }\end{array}$ & [219] \\
\hline Mercury ion & - & MEKC & $\begin{array}{l}\text { LIF } \\
\lambda_{\mathrm{EX}} 488 \mathrm{~nm}\end{array}$ & $5 \times 10^{-8} \mathrm{M}$ & Rhodamine $6 \mathrm{G}$ & [221] \\
\hline $\begin{array}{l}\text { Ephedrine and } \\
\text { pseudoephedrine }\end{array}$ & - & MEKC & $\begin{array}{l}\text { LIF } \\
\lambda_{\mathrm{EX}} 488 \mathrm{~nm} \\
\lambda_{\mathrm{Em}} 520 \mathrm{~nm}\end{array}$ & $\begin{array}{l}1.41-3.85 \times 10^{-4} \\
\operatorname{ng~mL}\end{array}$ & $\begin{array}{l}\text { 5-(4,6-dichloro-s-triazin-2- } \\
\text { ylamino) fluorescein; } 20 \mathrm{mM} \\
\text { borate }+20 \mathrm{mM} \text { SDS + } 15 \% \\
\text { acetonitrile }\end{array}$ & {$[223]$} \\
\hline $\begin{array}{l}\text { Aminoglycoside } \\
\text { antibiotics }\end{array}$ & Milk & MEKC & $\begin{array}{l}\text { LIF } \\
\lambda_{\mathrm{EX}} 635 \mathrm{~nm}\end{array}$ & $3-6 \mu \mathrm{g} \mathrm{L}^{-1}$ & $\begin{array}{l}\text { Borate buffer (pH 9.2); SDS and } \\
\text { Triton X-100 }\end{array}$ & [224] \\
\hline Pramipexole & - & $\mathrm{CE}$ & $\lambda_{\mathrm{Em}}^{L I F} 488 \mathrm{~nm}$ & $10 \mathrm{ng} \mathrm{mL}^{-1}$ & Borate buffer $(\mathrm{pH} 10.3)$ & [228] \\
\hline Duloxetine & - & $\mathrm{CE}$ & $\begin{array}{l}\text { LIF } \\
\lambda_{\mathrm{EX}} 635 \mathrm{~nm}\end{array}$ & $10 \mathrm{ng} \mathrm{mL}^{-1}$ & 5-(4,6-dichlorotriazinyl)- & [229] \\
\hline
\end{tabular}

${ }^{\mathrm{a}} \mathrm{LOD}=$ limit of detection; ${ }^{\mathrm{b}} \mathrm{PAHs}=$ polycyclic aromatic hydrocarbons $;{ }^{\mathrm{c}} \mathrm{LIDF}=$ laser-induced dispersed fluorescence; ${ }^{\mathrm{d}} \mathrm{CD}=$ cyclodextrin; ${ }^{\mathrm{e}} \mathrm{SM}-\mathrm{EKC}=$ surfactant-mediated electrokinetic capillary chromatography; ${ }^{\mathrm{f}} \mathrm{MEPF}=$ multiphoton execited fluoressence 
In an attempt to improve further the separation of PAHs by CE technique, capillary electrochromatography (CEC) has also been utilized for the separation of these compounds [187-189]. In CEC, the stationary phase was contained into the capillary and interacted with the analytes according to classical chromatographic separation mechanisms, whereas the mobile phase was driven through the capillary by the EOF [181]. In fact, CEC has rapidly grown in popularity as a separation technique able to analyze structurally-similar positional and geometrical isomers of PAHs [190]. Nevertheless, MEKC has remained the major option to solve the selectivity and solubility issues [191].

Since PAHs generally appeared in the environment at the trace and even the ultra-trace levels, besides having systems of detection and quantification sufficiently sensitive and selective, it was necessary to use multi-step sample pre-treatment techniques with the major objective of eliminating potential matrix interferences to isolate the target compounds, and finally to enrich the sample extracts. These types of preliminary procedures significantly improved the overall sensitivity of CE. From this standpoint, several extraction/pre-concentration techniques have been coupled to different CE modes. Among them, SPE is the most commonly coupled procedure with $\mathrm{CE}$, essentially for simplicity reasons [192-195]. However, other extraction techniques such as solid phase microextraction (SPME) [66], liquid-liquid-liquid microextraction (LLLME) [196], or even stir bar sorptive extraction (SBSE) [197] have been successfully used for PAHs extraction in combination with CE.

\section{Pesticides}

Determination of pesticide residues in environmental samples constitutes a complex problem because of the large number of families of compounds involved, and above all, of their remarkable physicochemical differences. In addition, the thermal instability of many pesticides makes necessary to prepare first stable derivatives, and then indirectly determine them by GC, the most frequently used technique for the determination of these compounds. However, because of the thermal instability and the low volatility of many new pesticides, the use of $\mathrm{CE}$ techniques represents nowadays a suitable alternative for the pesticide analysis [198]. Indeed, the CE methods are gener- ally able to determine simultaneously multi-component pesticide mixtures with high recovery, good reproducibility, and relatively low LOD values, [199-01]. In this sense, the prospects of CE for the pesticides analysis are very promising because of its various advantages, such as the great separation efficiency, short analysis time and very small consumption of expensive reagents and toxic solvents [202].

However, as in the case of PAHs, the main drawback of CE for the pesticide analysis remains its lack of sensitivity. Indeed, according to the EU legislation, the maximum tolerable total pesticide concentration in drinking water is $0.5 \mu \mathrm{g} \mathrm{L}^{-1}$. Thus, several analytical procedures have been developed with the major goal of lowering the pesticide LODs in CE, by means of sample preconcentration procedures, and improved detection systems and/or CE modes. Hernández-Borges et al. [198] presented an extensive review on the pesticide analysis by $\mathrm{CE}$, focusing on two main aspects of the pesticide analysis by CE, namely optimization of the sample pre-concentration procedure and improvement of the detection system. The authors concluded that the coupling of extraction techniques, such as SPE [195, 203], SPME [204] and CPE [205], with on-line pre-concentration procedures like sample stacking, and sweeping,. should be really helpful to achieve low LOD values. Moreover, other extraction techniques, such as SBSE [206] or pressurized liquid extraction [207] have been coupled to $\mathrm{CE}$ and tested in different environmental matrices for the pesticides analysis.

Referring to the detectors used in the pesticide analysis by $\mathrm{CE}$, improved luminescence detectors, such as LIF, have been used to a much lesser extent than conventional UV-VIS detectors, mainly because, as already mentioned, a large number of pesticides do not exhibit native fluorescence. However, LIF still constitutes a more sensitive and selective detector than UV absorption one and, in addition, it has nowadays the possibility of being combined with a wide range of lasers, such as Ar-ion $\left(\lambda_{\text {exc }}=488 \mathrm{~nm}\right), \mathrm{He}-\mathrm{Cd}\left(\lambda_{\text {exc }}=325 \mathrm{~nm}\right)$, He-Ne $\left(\lambda_{\text {exc }}=633 \mathrm{~nm}\right)$ or infrared diode lasers, broadening the range of pesticides that can be determined. Thus, pesticide LIF detection typically requires a preliminary derivatization step with an appropriate fluorogenic label [208], such as dichlorotriazinylamino fluorescein (DTAF), fluorescein isothiocyanate (FITC), and 7-aminonaphtalene-1,3-disulfonic acid (ANDSA), etc. 
The choice of separation strategies of pesticides in environmental samples by $\mathrm{CE}$ also depends on the nature of the mixture under study. Therefore, several CE modes, including CZE [209], MEKC [210], CEC [211] or even non aqueous CE (NACE) [203, 207], have been employed to determine pesticide mixtures. Several detailed examples of pesticide analysis by CE methodologies are highlighted in Table 5.

\section{Metals}

Among all CE applications, the use of this separation technique for the determination of metals has been far lesser than for organic pollutants. However, although conventional ion-chromatoraphy has still been the most employed technique in this field, CE provides a higher separation efficiency and analysis speed for the separation of inorganic cations and anions, but a lower detection sensitivity [212].

In order to lower the metal LOD values, various on-capillary pre-concentration techniques were developed, such as sweeping [213], field amplifying stacking [214, 215] and transient isotachophoresis [216]. In addition, fluorescence appeared to be well suited to the sensitive detection of complexes formed between trace metal ions and fluorescent chelating reagents, such as 8-hydroxyquinoline-5-sulphonic acid [212], lumogallion [212, 217], and fluorescein [218]. However, although CE-LIF is known as one of the most sensitive detection systems, metal LOD values were generally not better than about $10^{-8} \mathrm{~mol} \mathrm{~L}^{-1}$ [217]. This relatively low sensitivity, considering the high potential of LIF detection, can be explained by the rather high background noise level produced by addition of a chelating reagent in the carrier buffer solution [217].

Nevertheless, some attempts to solve the low sensitivity problems and to develop simple and fast CE-LIF methods, including CZE for heavy metal ions, $\mathrm{Al}(\mathrm{III})$ and $\mathrm{Ga}(\mathrm{III})[219,220]$, MEKC for mercury ion [221] and CE for selenium and antimony compounds [218], have been reported during the last decade. Some examples of CE-LIF methodologies for the determination of metals are presented in Table 5. It is worthwhile to point out that Saito et al. [219] recently developed an ultrasensitive CZE-LIF method for the determination of paramagnetic and heavy metals ions by combining pre- and on-capillary complexation techniques. By using a novel fluorescent ligand, consisting of an aromatic aminocarboxylate chelating moiety, a strongly emissive fluorescein moiety, and a spacer connecting both molecular parts, the authors were able to achieve extremely low LOD values at the sub-ppt levels and a high resolution of heavy metal complexes [219].

\section{Pharmaceutical compounds}

Although the fluorescence analysis of pharmaceuticals has been predominantly performed by HPLC, their determination can also be carried out by $\mathrm{CE}$. Several CE methods have been used in different applications fields, including the main component analysis, determination of drug-related impurities, chiral separation and trace level determinations of metal ions and inorganic anions [182].

Similarly to the case of PAH CE analysis, the choice of the analytical approach between $\mathrm{CE}$, MEKC, CZE and CEC was made according to the physicochemical properties of pharmaceuticals under study. Therefore, these drugs were generally determined by MEKC or MEEKC methods [208, $222,223]$. In addition, LIF detection combined with MECK was preferably used, because it was more selective and more sensitive than other luminescence detectors [224-226].

Since the majority of pharmaceuticals are constituted by protonated bases in strong acid media, low $\mathrm{pH}$ buffer solutions were applied to the analysis of this fraction of drugs [182]. For example, Hudson et al. [227] utilized a $\mathrm{pH} 2.5$ phosphate buffer to analyze 550 basic pharmaceuticals under the same operation conditions. In contrast, acidic pharmaceuticals could be determined by using higher $\mathrm{pH}$ phosphate or borate buffer solutions ( $\mathrm{pH} 7-10)$ [228-230]. We have given in Table 5 several typical examples of different $\mathrm{CE}$ modes applied to the analysis of pharmaceuticals with LIF detection.

\section{Flow injection analysis (FIA) methods with luminescence detection}

Flow Injection Analysis (FIA) has been applied to the determination of several pollutants in the environment since a number of years [24, 231]. Nowadays, relatively numerous works based on novel forms of this technique, including multisyringe flow injection analysis (MSFIA) [232], se- 
quential injection analysis (SIA) and bead injection analysis (BIA), have continued to be developed according to the principles of classical FIA described for the first time in 1975 by Ruzicka and Hansen [233].

The kinetic aspects of FIA can be further improved by incorporation into the system strategies which rely on controlled kinetic processes, such as absorption and desorption rate, stopped-flow, catalysis, extraction, separation, diffusion of ions or gases through membranes or packed reactors, and enzymatic reactions [231]. Moreover, the use of organized media, such as micelles or CDs, has been reported in various FIA methods to improve the sensitivity of luminescence detection by enhancing the analyte luminescence signal. Table 6 shows various FIA methods developed for the analysis of several environmental pollutants, including PAHs, pesticides, metals and pharmaceuticals.

Table 6

Environmental analysis by FIA methods with luminescence detection

\begin{tabular}{|c|c|c|c|c|c|c|}
\hline Analytes & Matrix & $\begin{array}{l}\text { Separation } \\
\text { mode }\end{array}$ & $\begin{array}{l}\text { Detection } \\
\lambda_{\mathrm{EX}} \lambda_{\mathrm{EM}}(\mathrm{nm})\end{array}$ & $\operatorname{LOD}^{\mathrm{a}}$ & Remarks & Ref. \\
\hline $\mathrm{BaP}^{\mathrm{b}}$ & $\begin{array}{l}\text { Drinking and } \\
\text { waste water }\end{array}$ & FIA & $\begin{array}{l}\text { Fluorescence } \\
392 / 406\end{array}$ & $3.0 \mathrm{ng} \mathrm{L}^{-1}$ & $\begin{array}{l}\text { On-line immobilization of } \mathrm{BaP} \text { on a } \\
\text { non-ionic resin }\end{array}$ & [235] \\
\hline 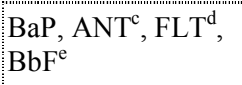 & $\begin{array}{l}\text { Drinking and } \\
\text { mineral water }\end{array}$ & FIA & $\begin{array}{l}\text { Fluorescence } \\
355 / 382\end{array}$ & $1.4-6.4 \mathrm{ng}$ & Amberlite XAD 4 & {$[236]$} \\
\hline $\mathrm{BaP}$ & Tap water & SIA & $\begin{array}{l}\text { Fluorescence } \\
258-275 / 390- \\
430\end{array}$ & $2.5 \mathrm{ng} \mathrm{mL}^{-1}$ & $\begin{array}{l}\text { A C18 microcolumn was used for } \\
\text { extraction }\end{array}$ & {$[238]$} \\
\hline $\begin{array}{l}\alpha \text {-Naphthol, } \\
o \text {-phenylphenol } \\
\text { and thiabendazole }\end{array}$ & $\begin{array}{l}\text { Tap, lake and } \\
\text { river water }\end{array}$ & FIA & $\begin{array}{l}\text { Fluorescence } \\
290 / 325-435\end{array}$ & $\sim \mu \mathrm{g} \mathrm{L}^{-1}$ & C18 silicagel as an active sorbent & {$[239]$} \\
\hline Azoxystrobin & $\begin{array}{l}\text { River, lake and } \\
\text { well water }\end{array}$ & $\mathrm{TR}^{\mathrm{f}}$ & $\begin{array}{l}\text { Fluorescence } \\
340 / 615\end{array}$ & $28 \mathrm{pg} \mathrm{mL}^{-1}$ & $\begin{array}{l}\text { Fluorescein thiocarbamyl } \\
\text { ethylenediamine (EDF) }\end{array}$ & {$[240]$} \\
\hline Asulam & $\begin{array}{l}\text { Irrigation, river, } \\
\text { underground } \\
\text { and bottle water }\end{array}$ & FIA & $\begin{array}{l}\text { Fluorescence } \\
258 / 342\end{array}$ & $5 \mu \mathrm{g} \mathrm{L}^{-1}$ & Buffer $\mathrm{NH}_{4}{ }^{+} / \mathrm{NH}_{3}(\mathrm{pH} 9)$ & {$[241]$} \\
\hline $\begin{array}{l}\text { Linuron, diuron, } \\
\text { isoproturon, } \\
\text { neburon }\end{array}$ & Tap water & FIA-MEPIF & $\begin{array}{l}\text { Indirect } \\
\text { Fluorescence }\end{array}$ & $0.33-0.92 \mathrm{mg}$ & $\begin{array}{l}\text { Sodium dodecyl sulphate (SDS) or } \\
\text { cetyl trimethyl ammonium chloride } \\
\text { (CTAC) }\end{array}$ & {$[241]$} \\
\hline Copper(II) & $\begin{array}{l}\text { Tap and } \\
\text { industrial water }\end{array}$ & FIA & $\begin{array}{l}\text { Fluorescence } \\
300 / 663\end{array}$ & $113 \mu \mathrm{g} \mathrm{L}^{-1}$ & $\begin{array}{l}N \text {-ethyl- } N^{\prime} \text {-methylsulfonylthiourea } \\
\text { (EMT) }\end{array}$ & {$[243]$} \\
\hline $\mathrm{Hg}(\mathrm{II})$ & $\begin{array}{l}\text { Natural water, } \\
\text { rice flour and } \\
\text { pork }\end{array}$ & FIA & $\mathrm{AFS}^{\mathrm{g}}$ & $2-3.6 \mathrm{ng} \mathrm{L}^{-1}$ & $\begin{array}{l}\text { Ammonium diethyl dithiophosphate } \\
\text { and dithizone as complexing agents }\end{array}$ & {$[247]$} \\
\hline $\begin{array}{l}\text { Chromium(III) and } \\
\text { chromium(VI) }\end{array}$ & Natural water & $\mathrm{CFI}^{\mathrm{h}}$ & $C L^{i}$ & $10^{-6} \mathrm{moL} \mathrm{L}^{-1}$ & Luminol- $\mathrm{H}_{2} \mathrm{O}_{2}$ system & {$[249]$} \\
\hline Cobalt(II) & $\begin{array}{l}\text { Natural and } \\
\text { industrial } \\
\text { wastewater }\end{array}$ & FIA and CIA $^{\mathrm{j}}$ & $\mathrm{CL}^{\mathrm{i}}$ & $0.2 \mu \mathrm{g} \mathrm{L}^{-1}$ & Luminol- $\mathrm{H}_{2} \mathrm{O}_{2}-\mathrm{Co}(\mathrm{II})$ system & {$[253]$} \\
\hline $\begin{array}{l}\text { Tricyclic } \\
\text { antidepressants }\end{array}$ & - & FIA & $\begin{array}{l}\text { Fluorescence } \\
265 / 448\end{array}$ & $<0.30 \mathrm{mg} \mathrm{L}^{-1}$ & $\begin{array}{l}\text { 9,10-dimethoxyanthracene-2- } \\
\text { sulphonate (DMAS) }\end{array}$ & {$[260]$} \\
\hline Ibuprofen & - & FIA & $\begin{array}{l}\text { Fluorescence } \\
233 / 287\end{array}$ & $4.5 \mathrm{mg} \mathrm{L}^{-1}$ & $\beta-\mathrm{CD}$ solution & {$[261]$} \\
\hline
\end{tabular}

${ }^{\mathrm{a}} \mathrm{LOD}=$ limit of detection; ${ }^{\mathrm{b}} \mathrm{BaP}=$ benzo $[a]$ pyrene $;{ }^{\mathrm{c}} \mathrm{ANTC}=$ anthracene; ${ }^{\mathrm{d}} \mathrm{FLT}=$ fluoranthene $;{ }^{\mathrm{e}} \mathrm{BbF}=$ benzo $[b]$ fluoranthene; ${ }^{\mathrm{f}} \mathrm{TR}=$ time-resolved fluorescence, ${ }^{\mathrm{g}} \mathrm{AFS}=$ atomic fluorescence spectrometry; ${ }^{\mathrm{h}} \mathrm{CFI}=$ continuous flow injection; ${ }^{\mathrm{i}} \mathrm{CL}=\mathrm{chemilumi}-$ nescence $;{ }^{\mathrm{j}} \mathrm{CIA}=$ continuous injection analysis 
As already mentioned, fluorescence spectroscopy is a versatile analytical tool, regarded as a simple, fast and very sensitive method. However, it is moderately selective, and one of the main difficulties can arise from the multi-component analysis due to spectral overlapping of structurallysimilar components. As a result, the majority of papers concerning the use of FIA techniques with fluorescence detection have been developed for a single analyte, or for mixtures of few constituents (rarely more than three). Other luminescence detection systems, such as phosphorescence and chemiluminescence (CL) have been widely applied to the determination of pollutants in different environmental matrices, although they have generally encountered the same shortcomings as fluorescence detectors.

\section{Polycyclic aromatic hydrocarbons (PAHs)}

Unfortunately, many PAHs exhibit similar luminescence properties, and the lack of selectivity is typical in flow-based luminescence detection methods. However, for FIA methods, fluorescence and phosphorescence detection offer advantages over CL because of their good response to minor spectral changes [234]. Thus, the typical procedure to determine PAHs in environmental matrices by such techniques is based on on-line pre-concentration of the analytes onto solid supports, followed by measurement of their natural fluorescence [ 235 -238]. The comparison between five types of support materials for solid fluorescence sensing of PAHs showed that non-ionic resins were good supports [237].

In a very comprehensive article, FernándezSánchez et al. [236], developed an original methodology for the determination of benzo[a]pyrene, anthracene, fluoranthene and benzo $[b]$ fluoranthene by FIA and fluorescence detection in tap and mineral waters. The authors used Amberlite XAD 4 resin, packed into the flow cell, to retain the PAHs before their detection at $\lambda_{\text {ex }}$ and $\lambda_{\text {em }}$ values of 355 and $382 \mathrm{~nm}$, respectively, and LOD values in the range of 1.4 to $6.4 \mathrm{ppb}$ were obtained [236]. Table 6 provides the analytical performance of some FIA methodologies applied to the determination of PAHs in water samples.

\section{Pesticides}

Among the different techniques used for the analysis of pesticides, FIA systems have been shown to meet the requirements of environmental and agricultural analysis in terms of automation, monitoring, micro-sampling and sample handling [239]. However, the main deficiency of FIA comes up when trying to perform a multi-component analysis, especially when multi-sensing devices such as UV/VIS diode-array or FT-IR are employed as detection techniques.

Despite all, several groups have applied this technique for the analysis of a large number of pesticides (Table 5). For example, DominguezVidal et al. [239] developed a FIA system with fluorescence detection, using C18 silica gel as an active sorbent substrate in the flow cell for the determination of a mixture of three pesticides, namely $\alpha$-naphthol, $o$-phenylphenol and thiabendazole. The authors used a $20 \%$ methanol/ $80 \%$ water $(\mathrm{v} / \mathrm{v})$ mixture as carrier solution, obtaining LOD values of a few $\mu \mathrm{g} \mathrm{L} \mathrm{L}^{-1}$, root mean square error of predictions (RMSEPs) of $1.86 \%, 3.34 \%$ and $0.50 \%$, respectively, and a mean recovery of $103 \%$ in the analysis of environmental water samples.

Moreover, much lower LOD values were reported in other papers by utilizing different FIA modes. For instance, Furzer et al. [240] found a LOD of $28 \mathrm{pg} \mathrm{mL}^{-1}$ for the determination of azoxystrobin, a fungicide, by using time-resolved fluorescence (TRF) - FIA. The authors concluded that their methodology was less time-consuming and approximately 100-fold more sensitive than GC. Also, Súbová et al. [241] developed a FIA methodology with fluorescence detection for the determination of the pesticide asulam, and they achieved a LOD of $5 \mu \mathrm{g} \mathrm{L}^{-1}$, with a RSD of $1 \%$.

In order to improve the sensitivity of FIA and to reduce the consumption of toxic and expensive organic solvents, the Aaron group [242] described a new FIA micellar-enhanced photochemicallyinduced fluorescence (FIA-MEPIF) method for the determination of four phenyl-urea herbicides residues, namely isoproturon, neburon, linuron and diuron. The authors converted these herbicides by UV-irradiation into strongly fluorescent photoproducts in buffered aqueous solutions containing surfactants (SDS) or CTAC), and then, determined them by the optimized methodology. They reported satisfactory LOD values $(0.33-0.92 \mathrm{mg} / \mathrm{L})$, 
and RSD values (1.3-11\%). Various examples of FIA methods for the pesticide analysis are presented in Table 6.

\section{Metals}

In the case the analysis of metals by FIArelated techniques with luminescence detection, the main problem is the large number of interferences from other common metal ions, because of the poor selectivity of these techiques [234]. For this reason, the determination of heavy metals or transition metals by FIA is closely linked to the development of efficient extraction materials or suitable ligands that are able to act like a "filter", isolating the analyte from all other similar metallic ions possibly present in the matrix.

For instance, the analysis of $\mathrm{Cu}$ (II) by FIA in aqueous matrices was mainly conducted by using such chelating agents capable to efficiently extract the metal ion and eliminate possible interferences. Generally, these ligands were located in the flow cell, before the fluorescence detector, and, then, the enhancement or inhibition of fluorescence intensity resulting from complexation was measured. Among various chelating agents used for $\mathrm{Cu}$ (II) determination, $N$-ethyl- $N$ '-methylsulfonylthiourea (EMT) [243], calcein [244], and zincon (along with porphyrin) [245] were most frequently used. These chelating agents could be immobilized by employing cellulose anion-exchange particles embedded in a hydrophilic hydrogel [244] or PVCmembranes [245]. To much lesser extent, CL methods have also been utilized for $\mathrm{Cu}$ (II) detection. For example, Meseguer-Lloret et al. [246] developed an automatic method based on a coproporphyrin $\mathrm{I}-\mathrm{Cu}^{2+} / \mathrm{TCPO} / \mathrm{H}_{2} \mathrm{O}_{2} \mathrm{CL}$ reaction for that purpose and they obtained consistent results.

Mercury $\left(\mathrm{Hg}^{2+}\right)$, another heavy metal of great environmental interest, has been investigated in recent papers using these methodologies. Wu et al. [247] developed a novel FIA method, based on chemical vapor generation atomic fluorescence spectrometry (AFS), for the determination of inorganic mercury and methylmercury, using ammonium diethyl dithiophosphate and dithizone as complexing agents, respectively, and found LOD values of $3.6 \mathrm{ng} \mathrm{L}^{-1}$ for $\mathrm{Hg}^{2+}$ and $2.0 \mathrm{ng} \mathrm{L}^{-1}$ for $\mathrm{CH}_{3} \mathrm{Hg}^{+}$. Also, Serra et al. [248] reported a new multisyringe FIA system for mercury determination with AFS, utilizing a cold vapour technique assembling. The authors obtained a LOD of $0.002 \mu \mathrm{g} \mathrm{L}^{-1}$, with a RSD value inferior to $2 \%$.

FIA methodologies with $\mathrm{CL}$ detection, based on the luminol- $\mathrm{H}_{2} \mathrm{O}_{2}$ system [249-253], the $\mathrm{K}_{2} \mathrm{MnO}_{4^{-}}$ luminol system [254], the lucigenin $-\mathrm{H}_{2} \mathrm{O}_{2}-\mathrm{KOH}$ system [255], and even the pirogalol- $\mathrm{H}_{2} \mathrm{O}_{2}-\mathrm{NaOH}$ reaction system [256], have also been applied for the determination of other heavy metals such as $\mathrm{Cr}(\mathrm{III}), \mathrm{Cr}(\mathrm{VI}), \mathrm{Ni}(\mathrm{II}), \mathrm{Co}(\mathrm{II}), \mathrm{As}(\mathrm{III}), \mathrm{As}(\mathrm{V})$ or $\mathrm{Ag}(\mathrm{I})$. The use of CL detection was facilitated because of the natural catalytic effect of metal ions on the CL reaction [249-253].

Also, it is worthwhile to mention the role of organized media to improve the determination of metallic ions in environmental samples by FIA. The cloud point extraction (CPE) technique was used as an on-line and off-line pre-concentration step for metallic ions, involving neutral complexation of the metal with suitable chelating agents, before FIA determination [257-259]. By utilizing this CPE-FIA approach, an enhancement of the CL or fluorescence signal was achieved, which permitted to reach better LOD values [24]. In Table 6, some examples of CPE-FIA methods for the determination of metallic ions are highlighted.

\section{Pharmaceutical compounds}

Since thirty-five years [233], FIA has become a versatile instrumental tool that has significantly contributed to the development of automation in the pharmaceutical analysis. Due to their inherent advantages, such as an excellent reagent economy and a great capacity of sampling frequency, close to $100 \mathrm{~h}^{-1}$, FIA techniques have had a huge importance in the quality control of drugs as bulk substances, which have allowed one to develop a number of related analytical methodologies (Table 6). In addition, FIA represents a method of choice in the fields of pharmacological drug testing and drug discovery, due to its capability of collecting automated analytical data with a high sampling frequency. Thus, although FIA studies in these areas have opened up dramatically the development of this technique, the multi-component analysis still remains the major challenge. From this point of view, liquid chromatography related techniques, especially those using mass spectrometry detection, seem to be more appropriate.

However, several authors have employed FIA techniques for the simultaneous determination of 
various analytes. For example, Acedo-Valenzuela et al. [260] have developed a FIA method with in situ solvent extraction and fluorimetric detection, for the determination of several tricyclic antidepressants (TCAs), namely imipramine, desipramine, amitriptyline, nortriptyline, clomipramine and doxepine. The authors used 9,10-dimethoxyanthracene-2-sulphonate (DMAS) to form ion pairs which were injected in an acid medium and, then, extracted with dichloromethane. The LOD values were lower than $0.30 \mathrm{mg} \mathrm{L}^{-1}$ [260].

As already indicated, many pharmaceuticals do not exhibit native fluorescence, but they can be transformed into fluorescent compounds by using derivatization procedures based on either chemical reactions with reagents, such as luminol, lucigenil, rhodamine $6 \mathrm{G}$, etc., or photochemical reactions (PIF). Moreover, it is well documented that the fluorescence and PIF methods used in organized media, such as micelles with various surfactants and CDs, can produce a large improvement of sensitivity [24, 28, 29]. For example, Lista et al. [261] reported a fluorimetric FIA method in which the native fluorescence of ibuprofen was considerably enhanced upon formation of a host-guest complex of the analyte with $\beta-\mathrm{CD}$. Thus, the authors obtained a LOD of $4.5 \mathrm{mg} . \mathrm{L}^{-1}$, with a RSD of $1.2 \%$ and a sample throughput of $240 \mathrm{~h}^{-1}$.

\section{Analytical interest of organized media}

As already mentioned, the use of organized media such as micelles and CDs generally enhances the luminescence signal of analytes in dynamic systems, including HPLC, CE and FIA methods, and, as a consequence, increases their analytical sensitivity and lowers the LOD values [24]. In some cases, the formation of inclusion complexes with CDs or the compartimentalization in micelles may even induce the emission of molecules of analytes which normally do not exhibit luminescence. In addition, the extraction techniques utilized in combination with the dynamic systems can be significantly improved by replacing the extraction organic solvents with aqueous organized media. Indeed, most extraction techniques described in the previous paragraphs on dynamic systems required organic solvents, either in large amounts (for Soxhlet, liquid-liquid extraction, etc.), or in lesser volumes (in the case of SPE, SPME, etc.). These solvents present the drawback to be toxic, expensive and to pollute the environ- ment. Therefore, the aqueous organized media, namely micelles and CDs, can be applied as a satisfactory alternative to organic solvents for extraction, since they are much less toxic, easier tohandle, cheaper and environmentally-friendly. Another advantage of micellar media, is the formation of aggregates by the surfactants, above the critical micellar concentration (CMC), which increases their capacity to extract organic analytes.

All these interesting properties of organized media, have been exploited to develop methods that can provide selectivity for extraction by complexation as well as sensitivity resulting from enhanced luminescence emission. Generally, lower LOD values have been obtained when using these organized media in separation techniques such as HPLC, capillary electrophoresis or planar chromatography [262].

Recently, Santana-Rodriguez et al. [263] have reported a number of studies showing the interest of using organized systems combined with chromatographic techniques and luminescence detection in the environmental analysis. For example, extraction processes based on ionic surfactants, such as sodium dodecylsulfonate (SDoS), SDS, sodium octanesulfonate (SOS) or sodium dodecylbenzenesulfonic acid (SDBSA), were described in the case of PAHs [263]. Also, solid phase microextraction with micellar desorption (SPME-MD) coupled to HPLC with fluorescence detection was utilized for the determination of fluoroquinolones in seawater, groundwater and wastewater samples. LOD values were in the range of 0.01 to $0.2 \mathrm{~g}$ $\mathrm{mL}^{-1}$, and the recoveries were between $81 \%$ and $116 \%$. These results were compared with those obtained by using an organic solvent, and a major chromatographic signal was observed when micellar solution was used as a desorbing agent [264]. This can be attributed to a better desorption of the analytes retained in the fiber due to their higher affinity toward the surfactant. In addition, an enhancement of the fluorescence signal was obtained because of an increase of the molecular rigidity in the micellar medium [25].

Another relatively new methodology, the headspace single drop microextraction (HSSDME) was employed by $\mathrm{Wu}$ et al. [265] for the determination of PAHs in lake water. A $\beta-C D$ saturated aqueous solution was used not only as an extraction solvent for HS-SDME, but also as a reagent to enhance the fluorescence signal of PAHs in HPLC-FD. The headspace mode was suitable 
for the extraction of volatile and semi-volatile organic compounds. The obtained enrichment factors were eighteen- to fifty three-fold, and the LOD values were in the range of 0.004 to $0.247 \mathrm{ng} \mathrm{mL}^{-1}$ [265]. The comparison of fluorescence intensities of PAHs in the absence and presence of $0.01 \mathrm{~mol}$ $\mathrm{L}^{-1} \beta-\mathrm{CD}$ showed that the signal was significantly stronger in the presence of this $\mathrm{CD}$. Because of their low formation constants, the PAH : $\beta-C D$ inclusion complexes decomposed immediately after the beginning of the separation process, and PAHs reached the detector as pure species. Under these conditions, the function of $\beta-\mathrm{CD}$ was similar to that of adding $\beta-C D$ to the mobile phase.

Several groups have developed the alreadymentioned cloud point extraction (CPE) methodology, in which a small volume of a surfactant-rich phase allows one to pre-concentrate and extract the analytes in one step, prior to the gas or liquid chromatographic analysis [266-269]. For instance, Eiguren-Fernández et al. [267] applied CPE, with two neutral surfactants (oligoethylene glycol monoalkyl ether and polyoxyethylene-10-cetyl ether), to the HPLC-FD determination of polychlorinated dibenzofurans in sea water, achieving LOD values in the range of 0.5 to $27.5 \mathrm{ng} \mathrm{mL}^{-1}$. In another work, the same group utilized a similar methodology for the extraction of polychlorinated biphenyls, with polyoxyethylene 4-lauryl ether and polyoxyethylene 10-oleyl ether as surfactants [268]. A new CPE approach was reported with the anionic surfactant sodium dodecane sulphonic acid (SDSA) for the extraction and pre-concentration of PAHs, and their determination in water samples (network supply, underground and river waters) [269]. Relative to the neutral surfactants generally used for CPE, SDSA offered two significant advantages, including weak surfactant fluorescence and absorbance signals at the PAH detection wavelengths (because of the absence of an aromatic moiety in the SDSA molecule), and a low chromatographic retention time (owing to the SDSA polar character). These features allowed the sensitive determination of the more polar PAHs without needing a clean-up step to remove the surfactant [269].

There ara several cases of organized media implementation applied to the metal analysis in the environment $[257,270]$. For instance, the differentiation and the selective speciation of chromium traces were carried out through micelle-mediated pre-concentration, coupled with micellar FIAspectrofluorimetry [257]. In this study, Cr(III) yielded in a surfactant solution a hydrophobic complex with 8-hydroxyquinoline (8-HQ), which then was entrapped in situ in the formed micelles. The $\operatorname{Cr}(\mathrm{VI})$ assay was based on its reduction to $\mathrm{Cr}$ (III) by sulfite which subsequently reacted with 8-HQ in a similar way. This method allowed the reliable determination of $\mathrm{Cr}(\mathrm{III})$ and/or $\mathrm{Cr}(\mathrm{VI})$ at levels as low as $0.2 \mu \mathrm{g} \mathrm{L}^{-1}$, in various samples even in those with complex matrix (sea water, pharmaceuticals) [257].

Surfactants were especially convenient, because of their capacity to dissolve and extract different types of organic contaminants present in the environmental solid samples [271-273]. For example, Merino et al. [272] tested the potential of anionic surfactants for the acid induced cloud point extraction (ACPE) and pre-concentration of PAHs from environmental solid samples by investigating their propensity to undergo clouding and liquid-liquid separation at elevated temperatures. Using this methodology, LOD values in the range of 0.1 to $5 \mu \mathrm{g} \mathrm{L}^{-1}$ were achieved for PAHs in soils, sediments and sludges [272]. Another technique that could be utilized with micellar media was the microwave assisted extraction (MAE). The use of microwave energy provided a great extractant capacity for a simple and rapid analysis of a variety of pollutants. For instance, microwave assisted micellar extraction (MAME) was applied to the extraction of polychlorinated dibenzofurans (PCDFs) [271] and polychlorinated biphenyls (PCBs) [273] from marine sediments, using two non-ionic surfactants (oligoethylene glycol monoalkyl ether and polyoxyethylene-10-lauryl ether) as extractants. The LOD values were in the range of 0.42 to 3.06 and of 0.62 to $4.89 \mathrm{ng} \mathrm{mL}^{-1}$, respectively.

Also, the organized media could be employed as sorbent materials. Although the polymeric conventional materials provided higher retention of polar analytes, a reduction of the volume of the organic extract was often necessary to reach higher pre-concentration factors, which was time consuming and resulted in compound losses. On the other hand, the conventional carbon-based sorbents had a great capacity for the pre-concentration of highly polar pesticides, but very high RSD values were observed, as well as irreversible adsorption phenomena. To overcome these problems, the use of surfactant-coated mineral oxide columns was proposed as new sorbents for SPE. For example, Moral et al. [274] investigated the application of SDS-coated alumina to the extraction/pre-concen- 
tration of benzimidazolic fungicides from river and underground waters, obtaining recovery in the ranges of 96 to $105 \%$ and $98-108 \%$, respectively. Besides hydrophobic interactions, attractive electrostatic interactions between the anionic surfactant head-groups and the positively charged nitrogen-groups of analytes played an important role in the retention of these pesticides on the supramolecular sorbent [274].

\section{CONCLUSIONS AND FUTURE TRENDS}

We have shown in this review that a great variety of luminescence analytical methods have been extensively developed for the study and determination of several types of environmental pollutants, including PAHs, organo-chlorinated compounds, pesticides, pharmaceuticals as well as metals.

These analytical studies have been performed, using either stationary luminescence systems (fluorescence and phosphorescence in different modes, luminescent and chemiluminescent (CL) immunosensors, and bioluminescent biosensors), or dynamic systems (various modes of HPLC, CE and FIA) with luminescence or CL detection. However, it is necessary to underline the fact that, in recent years, a larger number of works has concerned mainly the dynamic systems rather than the stationary ones. Indeed, in dynamic systems, a separation method was combined with sensitive luminescence detection, which improved significantly both the selectivity and sensitivity of analytical studies. In addition, these dynamic systems were capable to resolve the complexity of environmental samples due to the great number of pollutants present in a given sample, and, often, their similar molecular structures. Also, important environmental applications can be expected for the use of various organized molecular media, such as micelles, cyclodextrins and calixarenes, in luminescence techniques. It should become possible to adapt these organized supramolecular systems to luminescence studies of relatively new types of pollutants occurring in the environment, including pharmaceuticals and other biomedically-important compounds. Moreover, it should be possible to improve the performances of the simple and inexpensive stationary luminescence methods by means of more efficient, selective and sensitive technologies, including laser induced fluorescence
(LIF), derivative and synchronous luminescence spectra, and chemometrics, etc.

Presently, we can conclude that the trends in the dynamic systems (various modes of HPLC, CE and FIA) with luminescence detection are essentially focused towards two different directions. On the one hand, it will be necessary to improve the separation systems, such as the type of the package in the chromatographic columns, the optimal constitution of the background electrolyte (BGE) in $\mathrm{CE}$, or the development of new FIA-systems by enhancing their kinetic aspects. These trends are already apparent in the scientific literature of the last decade. From this standpoint, the development of separation techniques can be considered as a direct and crucial path to achieve an improvement in both the selectivity and sensitivity of analytical luminescence determination, and this research line can be assumed as an "entity" in constant evolution and development.

On the other hand, the luminescence detectors in dynamic systems will certainly become more sophisticated and sensitive with numerous technical developments. Therefore, the technological improvements and the use of new equipments (such as novel LIF detectors) will increase the sensitivity and selectivity of the luminescence analytical methodologies, improving the limits of detection and making even the performances of these luminescence detectors comparable to those obtained with other, very sensitive detectors, such as the mass spectrometric ones.

Finally, we must make a special mention of the use of organized molecular media in dynamic systems and for extraction techniques, since, besides being able to replace completely the organic solvents in many occasions, these media also offer a cheaper and less toxic alternative than conventional methodologies. In addition, it has been demonstrated in numerous cases that the use of surfactants and cyclodextrins increased the analytical signal of luminescent detectors, improving significantly the sensitivity of analytical determination.

Acknowledgments: Tanausú Vega Morales and Sarah Montesdeoca Esponda thank the Spanish Ministry of Education and the Canary Agency of Investigation, Innovation and Information Society (Goverment of Canary Islands), respectively, for their $\mathrm{PhD}$ student grants. Prof. Dr. Snezhana Efremova Aaron thanks the University of Paris-Est Marne-la-Vallée, Paris, France, for her stay at this university as an invited professor. 


\section{REFERENCES}

[1] C. Baird, Environmental Chemistry, $2^{\text {nd }}$ edition, W. H Freeman and Company, New York, 1999.

[2] F. W. Fifield, P. J. Haines (Eds.), Environmental Analytical Chemistry, Blackie Academic \& Professional, Chapman \& Hall, London, 1997.

[3] L. Baraud, D. Tessier, J.-J. Aaron, J.-P. Quisefit, J. Pinart, A multi-residue method for the characterization and determination of atmosphere pesticides measured at two French, urban and rural sampling sites, Anal. Bioanal. Chem., 377, 1148-1152 (2003).

[4] M. Chevreuil, L'atmosphère, vecteur de micropolluants organiques aux écosystèmes, L'Actualité Chimique, 277-278, 40-48 (2004).

[5] A. Nestorovska-Krsteska, M. Mirčeska, J.-J. Aaron, Z. Zdravkovski, Determination of dimethoate, 2,4dichlorophenoxy acetic acid, mecoprop and linuron pesticides in environmental waters in R. Macedonia by high-performance liquid chromatography, Maced. $J$. Chem. Chem. Engin., 27, 25-33 (2008).

[6] S. Irace-Guigand, J.-J. Aaron, P. Scribe, D. Barcelo, A comparison of the environmental impact of pesticide multi-residues and their occurrence in river waters surveyed by liquid chromatography coupled in tandem with UV diode array detection and mass spectrometry, Chemosphere, 55, 973-981 (2004).

[7] S. G. Schulman (Ed.), Molecular Luminescence Spectroscopy. Methods and Applications, John Wiley and Sons, New York, Part 1, 1985; Part 2, 1988; Part 3, 1993.

[8] M. C. Goldberg (Ed.), Luminescence Applications in Biological, Chemical, Environmental and Hydrological Sciences, American Chemical Society, Washington, 1989.

[9] W. R. G. Baeyens, D. De Keukeleire, K. Korkidis (Eds.), Luminescence Techniques in Chemical and Biochemical Analysis, Marcel Dekker, New York, 1991.

[10] G. Guilbault, Practical Fluorescence, Marcel Dekker, New York, 1990.

[11] A. W. Czarnik (Ed.), Fluorescence Chemosensors for Ion and Molecule Recognition, American Chemical Society, Washington, 1992.

[12] O. S. Wolfbeis (Ed.), Fluorescence Spectroscopy. New Methods and Applications, Springer-Verlag, Berlin, 1993.

[13] B. Valeur, J. C. Brochon (Eds.), New Trends in Fluorescence Spectroscopy. Applications to Chemical and Life Sciences, Springer-Verlag, Berlin, 2001.

[14] B. Valeur, Molecular Fluorescence. Principles and Applications, Wiley-VCH, Weinheim, 2002.

[15] E. Pelizzetti, E. Pramauro, Analytical applications of organized molecular assemblies, Anal. Chim. Acta, 169, 1-29 (1985).

[16] W. L. Hinze, H. N. Singh, Y. Baba, N. G. Harvey, Micellar enhanced fluorimetry, Trends Anal. Chem., 3, 193-199 (1984).

[17] M. E. Díaz García, A. Sanz-Medel, Dye-surfactant interactions: a review, Talanta, 33, 255-264 (1986).
[18] J. J. Santana Rodriguez, The role of organized media in chemiluminescence reactions, in: A. M. GarciaCampana, W. R. G. Baeyens (Eds.) Chemiluminescence in Analytical Chemistry, Marcel Dekker, New York, 2001, pp. $285-319$.

[19] J. M. Lin, M. Yamada, Microheterogenous systems of micelles and microemulsions as reaction media in chemiluminescence analysis, Trends Anal. Chem., 22, 99-107 (2003).

[20] W. L. Hinze, N. Srinivasan, T. K. Smith, S. Igarashi, H. Hoshino, in: I. M. Warner, L. B. McGown (Eds.), Advances in Multidimensional Luminescence, Vol. 1, JAI Press, Tokyo, 1991.

[21] R. von Wandruzka, Luminescence of micellar solutions, Crit. Rev. Anal. Chem., 23, 187-215 (1992).

[22] R. P. Frankewich, K. N. Thimmaiah, W. L. Hinze, Evaluation of the relative effectiveness of different water-soluble $\beta$-cyclodextrin media to function as fluorescence enhancement agents, Anal. Chem., 63, 2924-2933 (1991).

[23] R. A. Femia, S. Scypinski, L. J. Cline Love, Fluorescence characteristics of polychlorinated biphenyl isomers in cyclodextrin media, Environ. Sci. Technol., 19, 155-159 (1985).

[24] J. J. Santana Rodriguez, R. Halko, J. R. Betancort Rodriguez, J.-J. Aaron, Environmental analytical applications of luminescence in organized supramolecular systems, Anal. Bioanal. Chem., 385, 525-545 (2006).

[25] E. Pramauro, E. Pelizzetti, in: S. G. Weber (Ed.), Surfactants in Analytical Chemistry. Applications of Organized Amphiphilic Media, Wilson and Wilson's, Amsterdam (1996).

[26] S. Rubio, A. Gomez-Hens, M. Valcarcel, Analytical applications of synchronous fluorescence spectrometry, Talanta, 33, 633-640 (1986).

[27] J.-J. Aaron, Photochemical fluorometry, in: S. G. Schulman (Ed.), Molecular Luminescence Spectroscopy. Methods and Applications, Part 3. J. Wiley and Sons, New York, 1993, pp. 85-131.

[28] J. J. Aaron, A. Coly, Luminescence methods in pesticide analysis. Applications to the environment, Analysis Eur. JAC, 28, 699-709 (2000).

[29] M. C. Icardo, J. M. Calatayud, Photo-induced luminescence, Crit. Rev. Anal. Chem., 38, 118-130 (2008).

[30] R. J. Hurtubise, Phosphorimetry. Theory, Instrumentation and Application, VCH, New York, 1990.

[31] J. Kuijt, F. Ariese, U. H. T. Brinkman, C Gooijer, Room temperature phosphorescence as a tool in analytical chemistry, Anal. Chim. Acta, 488, 135-171 (2003).

[32] S. A. Bortolato, J. A. Arancibia, G. M. Escandar, A novel application of nylon membranes to the luminescent determination of benzo[ $a]$ pyrene at ultra trace levels in water samples, Anal. Chim. Acta, 613, 218-227 (2008).

[33] J. F. Fernandez-Sanchez, A. Segura Carratero, C. Cruces-Blanco, A. Fernandez -Gutierrez, The development of solid-surface fluorescence characterization of polycyclic aromatic hydrocarbons for potential screening tests in environmental samples, Talanta, 60, 287-293 (2003) 
[34] A. H. Ackerman and R. J. Hurtubise, Methods for coating filter paper for solid-phase micro-extraction with luminescence detection and characterization of the coated filter paper by infrared spectrometry, Anal. Chim. Acta, 474, 77-89 (2002).

[35] J. L. Whitcomb, A. J. Bystol, A. D. Campiglia, Timeresolved laser-induced fluorimetry for screening polycyclic aromatic hydrocarbons on solid-phase extraction membranes, Anal. Chim. Acta, 464, 261-272 (2002).

[36] S. G. Dmitrienko, E. Ya. Gurariv, R. E. Nosov, Yu. A. Zolotov, Solid-phase extraction of polycyclic aromatic hydrocarbons from aqueous samples using polyurethane foams in connection with solid-matrix spectrofluorimetry, Anal. Lett., 34, 425-438 (2001).

[37] O. A. Djachuk, T. I. Gubina, G. V. Melnikov, Adsorption preconcentration in the luminescence determination of polycyclic aromatic hydrocarbons, J. Anal. Chem., 64, 3-7 (2009).

[38] O. A. Djachuk, A. V. Tkachenko, The luminescence of polycyclic aromatic hydrocarbons on modified cellulose by surface-active agent, Progress in Biomedical Optics and Imaging - Proceed. SPIE, 6791, Art $\mathrm{N}^{\circ} 67910 \mathrm{P}(2008)$.

[39] S. Vázquez Troche, I. Marinez Bugallo, M. S. Garcia Falcón, M. A. Lage Yusty, J. Simal Lozano, Constantwavelength synchronous spectrofluorimetry for determination of benzo[a]pyrene, benzo[b]fluoranthene and benzo[k]fluoranthene in presence of 16 EPA PAHs Deutsche Lebensmittel-Rundschau, 99, 96-101 (2003).

[40] A. Andrade Eiroa, S. R. Huckins, E. Vásquez Blanco, P. López Mahia, S. Muniategui Lorenzo, D. Prada Rodriguez, Optimizing resolution in constant-energy synchronous spectrofluorimetry, Appl. Spectrosc., 54, 1534-1538 (2000).

[41] Y. Yan, J.-G. Xu, Z.-G. Lin, Y.-B. Zhao, L.-T. Wang, G.-Z. Chen, Study on total luminescence spectra. Application to three-dimensional synchronous fluorescence spectrometry, Anal. Chim. Acta, 306, 307-312 (1995).

[42] J. J. Santana Rodríguez, Z. Sosa Ferrera, A. Afonso Perera, V. González Diaz, Simultaneous synchronous fluorimetric determination of benzo $[a]$ pyrene and perylene in micellar media, Anal Chim Acta, 255, 107111(1991).

[43] J. J. Santana Rodríguez, Z. Sosa Ferrera, A. Afonso Perera, V. González Diaz, Micellar, enhanced spectrofluorimetric determination of chlorophyll a and chlorophyll b in fresh waters Talanta, 39, 1611-1617 (1992).

[44] J. J. Santana Rodríguez, J. Hernández García, M. M. Bernal, A. Bermejo Martín-Lázaro, Analysis of mixtures of polycyclic aromatic hydrocarbons in sea water by synchronous fluorescence spectrometry in organized, Analyst, 118, 917-921 (1993).

[45] A. Bermejo Martín-Lázaro, J. Hernández García, J. J. Santana Rodríguez, Simultaneous determination of perylene and benzo[ghi]-perylene by synchronous fluorescence using a micellar system, Fresenius J. Anal. Chem., 343, 509-512 (1992).

[47] J. Guiteras, J. L. Beltrán, R. Ferrer, Quantitative multicomponent analysis of five polycyclic aromatic hydro- carbons in water samples, Anal Chim Acta, 361, 233240(1998).

[47] D. Patra, A. K. Mishra, Investigation on simultaneous analysis of multicomponent polycyclic aromatic hydrocarbon mixtures in water samples: a simple synchronous fluorimetric method, Talanta , 55, 143-153 (2001).

[48] J. Amador Hernández, P. L. López de Alba, A. Cladera, J. M. Estela, V. Cerdà, Resolution of a multicomponent polycyclic aromatic hydrocarbon system in micellar media by linear variable angle fluorescence applying distinct chemometric techniques, Analyst, 123, 2235-2242 (1998).

[49] E. Lázaro, M. P. San Andrés, S. Vera, Determination of five polycyclic aromatic hydrocarbons in aqueous micellar media by fluorescence at room temperature, Anal Chim Acta, 413, 159-166 (2000).

[50] S. Rubio Barroso, D. López López, C. Val Ontillera, L. M. Polo Díez, Estudio espectrofluorimetrico de PAHs en medios organizados de $\beta$-Ciclodextrina y PluronicF-68, Quim. Anal., 10, 127-136 (1991).

[51] S. Rubio Barroso, M. N. Kayali, L. M. Polo Díez, Evaluation of some PAHs in particulate air by fluorimetry in ionic surfactants micellar solutions, Quim. Anal., 12, 187-191(1993).

[52] S. Rubio Barroso, M. N. Kayali, L. M. Polo Díez, Fluorimetric study of polycyclic aromatic hydrocarbons in Brij-35 micellar solution. Evaluation of polycyclic aromatic hydrocarbons in air samples, Anal. Chim. Acta, 283, 304-308 (1993).

[53] W. Jin, C. Liu, Luminescence rule of polycyclic aromatic hydrocarbons in micelle-stabilized roomtemperature phosphorescence, Anal. Chem., 65, 863865 (1993)

[54] W. J. Jin, C. S. Liu, Study on Five Polycyclic Aromatic Hydrocarbons by Chemical Deoxygenation MicelleStabilized Room Temperature Phosphorimetry, Microchem. J., 48, 94-103 (1993).

[55] M Algarra, M Hernández, Determination of fluorene in sea-water by room temperature phosphorescence in organised media, Analyst, 123, 2217-2219 (1998).

[56] A. Segura, C. Cruces, M. Sánchez-Polo, J. C. ÁvilaRosón, A. Fernández, Study of different normalmicroemulsion composition by room-temperature phosphorescence to determine benzo $[a]$ pyrene in environmental samples, Anal. Chim. Acta, 474, 91-98 (2002).

[57] S. Debnath, Q. Cheng, T. G. Heddermann, H. J. Byrne, A study of the interaction between single-walled carbon nanotubes and polycyclic aromatic hydrocarbons: Toward structure-property relationships, J. Phys. Chem. C, 112, 10418-10422 (2008).

[58] H. Li, F. Qu, Selective inclusion of polycyclic aromatic hydrocarbons (PAHs) on calixarene coated silica nanospheres englobed with CdTe nanocrystals, J. Mater. Chem., 17, 3536-3544 (2007).

[59] C. Gooijer, I. Kozin, N. H. Velthorst, Shpol'skii spectrometry, a distinct method in environmental analysis, Mikrochim. Acta, 127, 149-182 (1997). 
[60] I. Kozin, C. Gooijer, N. H. Velthorst, J. Hellou, V. Zitko, Isomer-specific detection of PAHs and PAH metabolites in environmental matrices by Shpol'skii luminescence spectroscopy, Chemosphere, 33, 14351447 (1996).

[61] J. W. Hofstraat, U. P. Wild, Constant-Energy Synchronous Scan and Excitation Emission Matrix Shpol'skii Spectroscopy for Characterization of PAHs, J. Fluorescence, 8, 319-325 (1998).

[62] L. Paturel, A.-I. Saber, C. Fachinger, J. Suptil, C. Turnar, A data acquisition and processing software for high-resolution Shpol'skii spectrofluorometry, Polycycl. Arom. Comp., 13, 151-164 (1999).

[63] U. Kirso, N. Irha, L. Paalme, S. Reznikov, A. Matveyev, Levels and origin of PAHs in some big lakes, Polycycl. Arom. Comp., 22, 715-728 (2002).

[64] I. Kozin, C. Gooijer, N. H. Velthorst, Shpol'skii spectroscopy as a tool in environmental analysis for aminoand nitro-substituted polycyclic aromatic hydrocarbons: A critical evaluation, Anal. Chim. Acta, 333, 193-204 (1996).

[65] C. Plaza, B. Xing, J. M. Fernandez, N. Senesi, A. Polo, Binding of polycyclic aromatic hydrocarbons by humic acids formed during composting, Environ. Pollut., 157, 257-263 (2009).

[66] S. B. Hawthorne, R. W. St Germain, N. A. Azzolina, Laser-induced fluorescence coupled with solid-phase microextraction for in situ determination of PAHs in sediment pore water, Environ. Sci, Technol., 42, 80218026 (2008).

[67] R. S. G. Gómez, T. Pandyan, V. E. A. Iris, V. LunaPabello, C. D. De Bazúa, Spectroscopic determination of poly-aromatic compounds in petroleum contaminated soils, Water, Air, Soil Pollut., 158, 137-151 (2004).

[68] N. Hanson, A. Larson, Fixed wavelength fluorescence to detect PAH metabolites in fish bile: Increased statistical power with an alternative dilution method, Environ. Monitor. Assessment, 144, 221-228 (2008).

[69] A. S. Oliveira, M. B. Fernandez, J. C. Moreira, L. V. F. Ferreira, Ground-state diffuse reflectance and laserinduced luminescence on the evaluation of total PAHs in urban air particulate matter from Rio de Janeiro city in Brazil, J. Brazil. Chem. Soc., 13, 245-250 (2002).

[70] J. Hernández García, Z. Sosa Ferrera, A. J. Bermejo Martín-Lázaro, J. J. Santana Rodríguez, Fluorimetric study of PCBs and Aroclors in micellar media. Analytical applications, Anal. Lett., 27, 1355-1382 (1994).

[71] J. Hernández García, Z. Sosa Ferrera, A. J. Bermejo Martín-Lázaro, J. J. Santana Rodríguez, Fluorescent behaviour of polychlorinated dibenzofurans in organized molecular systems. Analytical applications, Mikrochim. Acta, 118, 185-196 (1995).

[72] J. Hernández García, Z. Sosa Ferrera, A. J. Bermejo Martín-Lázaro, J. J. Santana Rodríguez, Determinacion espectrofluoremetrica de 2,8-diclorodibenzofurano usando un medio micelar de polioxietileno-10-laurileter (POLE), Quim. Anal., 13, 96-101 (1994).

[73] J. Hernández García, J. R. Betancort Rodríguez, A. J. Bermejo Martín-Lázaro, J. J. Santana Rodríguez, Sen- sitive spectrofluorimetric determination of $3,3^{\prime}, 4,4^{\prime}$ tetrachlorobiphenyl using a neutral micellar medium, Anal. Chim. Acta, 290, 146-153 (1994).

[74] J. J. Santana Rodríguez, J. Hernández García, Z. Sosa Ferrera, A. J. Bermejo Martín-Lázaro, Spectrofluorometric determination of 4-chlorobiphenyl and Arochlor 1221 using the fluorescence quenching produced by cetylpyridinium bromide micellar medium, Fresenius $J$. Anal. Chem., 354, 221-226 (1996).

[75] J. J. Santana Rodríguez, Z. Sosa Ferrera, J. Hernández García, A. J. Bermejo Martín-Lázaro, Analysis of binary mixtures of 3,3',4,4'-tetrachlorobiphenyl and $2,3,7,8$ - tetrachlorodibenzofuran by derivative synchronous fluorescence spectrometry in organized media, Analyst, 119, 2241-2246 (1994).

[76] J. P. Alarie, T. Vo-Dinh, G. Miller, M. N. Ericson, S. R. Maddox, W. Watts, D. Eastwood, R. Lidberg, M. Dominguez, Development of a battery-operated portable synchronous luminescence spectrofluorometer, Rev. Sci. Instrum., 64, 2541-2546 (1993).

[77] G. J. Hyfantis Jr., W. Watts, T. P. Finnegan, Field applications of a portable luminoscope for hazardous screening, Proceed. SPIE-Intern. Soc. Opt. Engin., 3534, 92-99 (1999).

[78] T. Vo-Dinh, A. Pal, T. Pat, Photoactivated luminescence method for rapid screening of polychlorinated biphenyls, Anal. Chem., 66, 1264-1268 (1994).

[79] P. Jagasia, A. Velasquez, A. Knedlik, T. Vo-Dinh, P. B. Oldham, Enhanced photoactivated luminescence of selected polychlorinated biphenyl congeners and Aroclor mixtures, Microchem. J., 57, 350-360 (1997).

[80] A. Pal, W. Watts, J. Caraway, T. Vo-Dinh, Enhanced room-temperature phosphorescence using sodium lauryl sulfate treated solid substrate, Analysis, 20, 149153(1992).

[81] J. J. Santana Rodríguez, J. Hernández García, Z. Sosa Ferrera, A. Bermejo, Solid surface room-temperature phosphorescence of polychlorinated dibenzofurans enhanced by a surface active agent, Anal. Lett., 28, 24132436 (1995).

[82] J. C. Márquez, M. Hernández, F. García, Enhanced spectrofluorimetric determination of the pesticide warfarin by means of the inclusion complex with $\beta$-cyclodextrin, Analyst, 115, 1003-1005 (1990)

[83] N. L. Pacioni, A. V. Veglia, Determination of carbaryl and carbofuran in fruits and tap water by $\beta$-cyclodextrin enhanced fluorimetric method, Anal. Chim. Acta, 488, 193-202 (2003).

[84] J. H. Ayala, A. M. Afonso, V. González, Spectrofluorimetric determination of carbaryl and 1-naphthol in micellar media, Mikrochim. Acta, 1, 171-179 (1991).

[85] R. M. Maggio, G. N. Piccirilli, G. M. Escandar, Fluorescence enhancement of carbendazim in the presence of cyclodextrins and micellar media: A reappraisal, Appl. Spectrosc., 59, 873-880 (2005).

[86] S. Kunsági-Máté, G. Nagy, L. Kollár, Investigation of the interaction of calixarene (host) and neutral benzotrifluoride (guest) - Comparison of luminescence characteristics of calixarenes with results of model calculations relating to complex formation, Sensors and Actuators, B : Chem., 76, 545-550 (2001). 
[87] S. Kunsági-Máté, G. Nagy, L. Kollár, Host-guest interaction of calixarene molecules with neutral benzotrifluorides - Comparison of luminescence spectral data with results of model calculations relating to complex formation, Anal. Chim. Acta, 428, 301-307 (2001).

[88] H. Li, F. Qu, Synthesis of CdTe quantum dots in solgel-derived composite silica spheres coated with calix[4]arene as luminescent probes for pesticides, Chem. Mater., 19, 4148-4154 (2007).

[89] A. Coly, J. J. Aaron, Cyclodextrin-enhanced fluorescence and photochemically-induced fluorescence determination of five aromatic pesticides in water, Anal. Chim. Acta, 360, 129-141 (1998).

[90] A. Coly, J. J. Aaron, Fluorimetric analysis of pesticides: Methods, recent developments and applications, Talanta, 49, 107-117 (1999).

[91] M. C. Mahedero, A. Muñoz de la Peña, A. Bautista, J. J. Aaron, An investigation of inclusion complexes of cyclodextrins with phenylurea herbicides by photochemically-induced fluorescence. Analytical applications, J. Incl. Phenom. Macro., 42, 61-70 (2002).

[92] A. Coly, J. J. Aaron, Simultaneous determination of binary mixtures of sulfonylurea herbicides in water by first-derivative photochemically induced spectrofluorimetry, J. AOAC Int., 84, 1745-1750 (2001).

[93] A. Coly, J. J. Aaron, Simultaneous determination of sulfonylurea herbicide synthetic binary mixtures by a partial least square method combined with micellarenhanced photochemically-induced fluorescence for application to tap water analysis, Maced. J. Chem. Chem. Engin. ., 27, 33-40 (2009).

[94] E. M. Almanza Lopez, A. M. Garcia-Campana, J. J. Aaron, L. Cuadra Rodriguez, Simultaneous quantification of chlorophenoxyacid herbicides based on timeresolved photochemical derivatization to induce fluorescence in micellar media, Talanta, $\underline{60}, 355-367$ (2003).

[95] M. Mbaye, M. D. Gaye Seye, A. Coly, A. Tine, J. J. Aaron, Usefulness of cyclodextrin media for the determination of $\alpha$-cypermethrin by photochemicallyinduced fluorescence. Analytical applications to natural waters, Anal. Bioanal. Chem., 394, 1089-1098 (2009).

[96] F. García Sánchez, M. Cedazo, J. Lovillo, A. Navas Diaz, Variable-angle synchronous fluorescence spectrometry and rank annihilation methods for mixture resolution, Talanta, 43, 1327-1333 (1996).

[97] G. J. Hyfantis Jr., M. S. Teglas, T. P. Finnegan, P. J. Mulligan, W. Watts, Synchronous scanning luminescence. Method to detect pesticides and explosives, Proceed. SPIE-Intern. Soc. Opt. Engin., 3853, 110 115 (1999).

[98] D. Picon Zamora, M. Martinez Galera, F. A. Garrido Frenich, J. L. Martinez Vidal, Trace determination of carbendazim, fuberidazole and thiabendazole in water by application of multivariate calibration to crosssections of three-dimensional excitation-emission matrix fluorescence, Analyst, 125, 1167-1174 (2000).

[99] A. Segura, C. Cruces, A. Fernández, Determination of the pesticide carbaryl by microemulsion room-tempera- ture phosphorescence in real samples, Anal. Sci., 12, 653-657 (1996).

[100] Y. S. Wei, W. I. Jin, R. H. Zhu, C. S. Liu, S. S. Zhang, Determination of the pesticide carbaryl by chemical deoxygenation micellar-stabilized room temperature phosphorescence, Talanta, 41, 1617-1621 (1994).

[101] A. Segura-Carretero, C. Cruces-Blanco, J. F. Fernandez-Sanchez, B. Canabate-Diaz, A. FernandezGutiérrez, HAI-RTP determination of carbaryl pesticide in different irrigation water samples of South Spain, J. Agric. Food Chem., 48, 4453-4459 (2000).

[102] R. G Machicote,. L. Bruzzone, . Simultaneous determination of carbaryl and 1-naphthol by first-derivative synchronous non-protected room temperature phosphorescence, Anal. Sci., 52, 623-626 (2009).

[103] A. Alvarez-Diaz. , J. M. Costa, R. Pereiro, A. . SanzMedel, . Halogenated molecularly imprinted polymers for selective determination of carbaryl by phosphorescence measurements Anal. Bioanal. Chem., 394, 15691576 (2009).

[104] J. A. Murillo Pulgarín, L. F. García Bermejo, Determination of the pesticide napropamide in soil, pepper, and tomato by micelle-stabilized room-temperature phosphorescence, J. Agric. Food Chem., 50, 1002-1008 (2002).

[105] A. Salinas-Castillo, J. F. Fernandez-Sanchez, A. SeguraCarretero, A. Fernandez-Gutiérrez, Simple determination of herbicide napropamide in water and soil samples by room-temperature phosphorescence, Pest Manag. Sci., 61, 816-820 (2005).

[106] B. C. Diaz, A. S. Carretero, C. C. Blanco, A. F. Gutierrez, Simultaneous determination of the pesticides carbaryl and thiabendazole in environmental samples by a three-dimensional derivative variable-angle and a synchronous room-temperature phosphorescence spectroscopy, Appl. Spectrosc., 57, 1585-1591 (2003).

[107] M. A. González-Martínez, J. Penalva, J. C. RodríguezUrbis, E. Brunet, A. Maquieira, R. Puchades, Immunosensors for pollutants working in organic media. Study of performances of different tracers with luminescent detection, Anal. Bioanal. Chem., 384, 15401547 (2006).

[108] I. M Ciumasu, P. M Krämer, C. M Weber, G Kolb, D. Tiemann, S. Windisch, I. Frese, A. A. Kettrup, A new, versatile field immunosensor for environmental pollutants: Development and proof of principle with TNT, diuron, and atrazine, Biosens. Bioelectron., 21, 354364 (2005).

[109] M. Yu. Rubtsova, J. V. Samsonova, A. M. Egorov, R. D. Schmid, Simultaneous determination of several pesticides with chemiluminescent immunoassay on a multi-spot membrane strip, Food Agric. Immunol., 10, 223-235 (1998).

[110] M. F. Katmeh, G. W. Aherne,, D. Stevenson,_Development and evaluation of a chemiluminescent immunoassay for chlortoluron using a camera luminometer, Analyst, 121, 329-332 (1996).

[111] G. Orellana, D. García-Fresnadillo, M. C. MorenoBondi, Carbamate pesticides sensing with a catalytic biosensor and molecularly engineered luminescent dyes, Afinidad, 64, 257-264 (2007). 
[112] V. S. Nunes-Halldorson, N. L. Duran, Bioluminescent bacteria: lux genes as environmental biosensors, Brazilian J. Microbiol., 34, 91-96 (2003).

[113] S. Girotti, E. N. Ferri, M. G. Fumo, E. Maiolini, Monitoring of environmental pollutants by bioluminescent bacteria, Anal. Chim. Acta, 608, 2-29 (2008).

[114] A. G. Hay, J. F. Rice, B. M. Applegate, N. G. Bright, G. S. Sayler, A bioluminescent whole-cell reporter for detection of 4-dichlorophenoxyacetic acid and 2,4dichlorophenol in soil, Appl. Environ. Microbiol., 66, 4589-4594 (2000).

[115] C. Y. Shao, C. J. Howe, A. J. R. Porter, L. A. Glover, Novel Cyanobacterial Biosensor for detection of herbicides, Appl. Environ. Microbiol., 68, 5026-5033 (2002).

[116] S. Trajkovska, K. Tosheka, J. J. Aaron, F. Spirovski, Z. Zdravkovski Bioluminescence determination of enzyme activity of firefly luciferase in the presence of pesticides, Luminescence, 20, 192-196 (2005).

[117] E. Vetrova, E. Esimbekova, N. Remmel, S. Kotova, N. Beloskov, V. Kratasyuk, I. Gitelson, A bioluminescent signal system: Detection of chemical toxicants in water, Luminescence, 22, 206-214 (2007).

[118] S. Trajkovska, M. Mbaye, M. D. Gaye Seye, J. J. Aaron, M. Chevreuil, H. Blanchoud, Toxicological study of pesticides in the air and precipitations of Paris by means of a bioluminescence method, Anal. Bioanal. Chem., 394, 1099-1106 (2009).

[119] J. L. Ren, J. Zhang, J. Q. Luo, X. K. Pei, Z. X. Jiang, Improved fluorimetric determination of dissolved aluminium by micelle-enhanced lumogallion complex in natural waters, Analyst, 126, 698-702 (2001).

[120] Q. Wie, J. Yang, Y. Zhang, G. Chemg, B. Du, Determination of antimony(III) in environmental water samples in microemulsion system by the fluorescence quenching method, Talanta, 58, 419-426 (2002).

[121] J. J. Aaron, M. Ely, A. Yassar, F. Rodriguez, M. Dieng, J. C. Brochon, E. Guiot, Novel fluorescent oligothiophene-8-hydroxyquinolines for determination of heavy metal ions, Luminescence, 21, 326-328 (2006).

[122] Y. M. Liu, M. R. Fernández de la Campa, M. E. Díaz García, A. Sanz-Medel, Micelle-stabilized liquid roomtemperature phosphorimetry for metals: The micellar reaction of gallium with 7-iodo-hydroxyquinoline-5sulfonic acid and its application to the metal determination, Mikrochim. Acta, 103, 53-64 (1991).

[123] B. San Vicente, J. M. Costa-Fernández, W. L. Jin, R. Pereiro, A. Sanz-Medel, Determination of trace levels of mercury in water samples based on room temperature phosphorescence energy transfer, Anal. Chim. Acta, 455, 179-186 (2002).

[124] B. San Vincente De La Riva, J. M. Costa Fernandez, R. Pereiro, A. Sanz-Medel, Flow through luminescence for heavy metals analysis in sea water, Proceed. SPIE Intern. Soc. Opt. Engin., 3853, 275-287 (1999).

[125] S. M. Tauriainen, M. P. J. Virta, M. T. Karp, M. T., Detecting bioavailable toxic metals and metalloids from natural water samples using luminescent sensor bacteria, Water Research, 34, 2661-2666 (2000).
[126] Y.-J. Fu, W.-L. Chen, Q.-Y. Huang, Construction of two lux-tagged $\mathrm{Hg}^{2+}$-specific biosensors and their luminescence performance, Appl. Microbiol. Biotechnol., 79, 363-370 (2008).

[127] T. Okuda, D. Naoi, M. Tenmoku, S. Tanaka, K. He, Y. Ma, F. Yang, Y. Lei, Y. Jia, D. Zhang, Polycyclic aromatic hydrocarbons (PAHs) in the aerosol in Beijing, China, measured by aminopropylsilane chemicallybonded stationary-phase column chromatography and HPLC/fluorescence detection, Chemosphere, 65, 427435 (2006).

[128] Y. Alnouti, K. Srinivasan, D. Waddell, H. Bi, O. Kavetskaia, A. Gusev, Development and application of a new on-line SPE system combined with LC-MS/MS detection for high throughput direct analysis of pharmaceutical compounds in plasma, J. Chrom. A, 1080, 99-106 (2005).

[129] L. Oliferova, M. Statkus, G. Tsysin, O. Shpigun, Y. Zolotov, On-line solid-phase extraction and HPLC determination of polycyclic aromatic hydrocarbons in water using fluorocarbon polymer sorbents, Anal. Chim. Acta, 538, 35-40 (2005).

[130] J. Li, L. Chen, X. Wang, H. Jin, L. Ding, K. Zhang, H. Zhang, Determination of tetracyclines residues in honey by on-line solid-phase extraction high-performance liquid chromatography, Talanta, 75, 1245-1252 (2008).

[131] K. Mitani, S. Narimatsu, H. Kataoka, Determination of daidzein and genistein in soybean foods by automated on-line in-tube solid-phase microextraction coupled to high-performance liquid chromatography, J. Chrom. A, 986, 169-177 (2003).

[132] S. Wang, W. Huang, G. Fang, J. He, Y. Zhang, On-line coupling of solid-phase extraction to high-performance liquid chromatography for determination of estrogens in environment, Anal. Chim. Acta, 606, 194-201 (2008).

[133] T. Okuda, K. Okamoto, S. Tanaka, Z. Shen, Y. Han, Z. Huo, Measurement and source identification of polycyclic aromatic hydrocarbons (PAHs) in the aerosol in Xi'an, China, by using automated column chromatography and applying positive matrix factorization (PMF), Sci. Total Environ., 408, 1909-1914 (2010).

[134] T. Hien, P. Nam, S. Yasuhiro, K. Takayuki, T. Norimichi, B. Hiroshi, Comparison of particle-phase polycyclic aromatic hydrocarbons and their variability causes in the ambient air in Ho-Chi-Minh City, Vietnam and in Osaka, Japan, during 2005-2006, Sci. Total Environ., 382, 70-81 (2007).

[135] A. Bacaloni, C. Cafaro, L. De Giorgi, R. Ruocco, L. Zoccolillo, Improved analysis of polycyclic aromatic hydrocarbons in atmospheric particulate matter by HPLC fluorescence, Ann. Chim., 94, 751-759 (2004).

[136] O. Delhomme, P. Herckes, M. Millet, Determination of nitro-polycyclic aromatic hydrocarbons in atmospheric aerosols using HPLC fluorescence with a post-column derivatisation technique, Anal. Bioanal. Chem., 389, 1953-1959 (2007).

[137] M. Rynö, L. Rantanen, E. Papaioannou, A. G. Konstandopoulos, T. Koskentalod, K. Savela, Comparison of pressurized fluid extraction, Soxhlet extraction and sonication for the determination of polycyclic aromatic 
hydrocarbons in urban air and diesel exhaust particulate matter, J. Environ. Monit., 8, 488-493 (2006).

[138] C. Schauer, R. Niessner, U. Pöschl, Analysis of nitrated polycyclic aromatic hydrocarbons by liquid chromatography with fluorescence and mass spectrometry detection: air particulate matter, soot, and reaction product studies, Anal. Bioanal. Chem., 378, 725-736 (2004).

[139] A. Šišović, I. Bešlić, K. Šega, V. Vadjić, PAH mass concentrations measured in PM10 particle fraction, Environ. International. 34, 580-584 (2008).

[140] O. Delhomme, E. Rieb, M. Millet, Polycyclic aromatic hydrocarbons analyzed in rainwater collected on two sites in east of France (Strasbourg and Erstein), Polycyclic Aromat. Compd., 28, 472-485 (2008).

[141] M. Bourdat-Deschamps, J. J. Daudin, E. Barriuso, An experimental design approach to optimise the determination of polycyclic aromatic hydrocarbons from rainfall water using stir bar sorptive extraction and high performance liquid chromatography-fluorescence detection, J. Chromatogr. A, 1167 143-153 (2007).

[142] L. Tolun, D. Martens, O. S. Okay, K. W. Schramm, Polycyclic aromatic hydrocarbon contamination in coastal sediments of the Izmit Bay (Marmara Sea): Case studies before and after the Izmit Earthquake, Environ. International, 32, 758-765 (2006).

[143] C. Vane, I. Harrison, A. Kim, Polycyclic aromatic hydrocarbons (PAHs) and polychlorinated biphenyls (PCBs) in sediments from the Mersey Estuary, U. K., Sci. Total Environ., 374, 112-126 (2007).

[144] N. Bihari, M. Fafandel, B. Hamer, B. Kralj-Bilen, PAH content, toxicity and genotoxicity of coastal marine sediments from the Rovinj area, Northern Adriatic, Croatia, Sci. Total Environ., 366, 602-611 (2006).

[145] D. Sanger, A. Holland, G. Scott, Tidal creek and salt marsh sediments in South Carolina Coastal Estuaries: II. Distribution of organic contaminants, Arch. Environ. Contam. Toxicol., 37, 458-471 (1999).

[146] Y. Song, B. Wilke, X. Song, P. Gong, Q. Zhou, G. Yang, Polycyclic aromatic hydrocarbons (PAHs), polychlorinated biphenyls (PCBs) and heavy metals (HMs) as well as their genotoxicity in soil after long-term wastewater irrigation, Chemosphere, 65 1859-1868 (2006).

[147] R. Barra, P. Popp, R. Quiroz, C. Bauer, H. Cid, W. von Tümpling, Persistent toxic substances in soils and waters along an altitudinal gradient in the Laja River Basin, Central Southern Chile, Chemosphere, 58, 905915 (2005).

[148] L. Chrysikou, P. Gemenetzis, A. Kouras, E. Manoli, E. Terzi, C. Samara, Distribution of persistent organic pollutants, polycyclic aromatic hydrocarbons and trace elements in soil and vegetation following a large scale landfill fire in northern Greece, Environ. Intern., 34, 210-225 (2008).

[149] J. Gasperi. S. Garnaud, V. Rocher, R. Moilleron, Priority pollutants in surface waters and settleable particles within a densely urbanised area: case study of Paris (France), Sci. Total Environ., 407, 2900-2908 (2009).

[150] M. Pena, M. Casais, M. Mejuto, R. Cela, Development of an ionic liquid based dispersive liquid-liquid microextraction method for the analysis of polycyclic aro- matic hydrocarbons in water samples, $J$. Chromatogr. A, 1216, 6356-6364 (2009).

[151] E. Escartín, C. Porte, Biomonitoring of PAH pollution in high-altitude mountain lakes through the analysis of fish bile, Environ. Sci. Technol., 33, 406-409 (1999).

[152] H. Schulz, P. Popp, G. Huhn, H. Stärk, G. Schürmann, Biomonitoring of airborne inorganic and organic pollutants by means of pine tree barks. I. Temporal and spatial variations, Sci. Total Environ., 232, 49-58 (1999).

[153] C. Alonso-Alvarez, I. Munilla, M. López-Alonso, A. Velando, Sublethal toxicity of the Prestige oil spill on yellow-legged gulls, Environ. Intern., 33, 773-781 (2007).

[154] L. Fua, X. Liub, J. Hub, X. Zhaob, H. Wangc, X. Wanga, Application of dispersive liquid-liquid microextraction for the analysis of triazophos and carbaryl pesticides in water and fruit juice samples, Anal. Chim. Acta, 632, 289-295 (2009).

[155] R. C. Prados-Rosales, M. C. Herrera, J. L. LuqueGarcía, M. D. Luque de Castro, Study of the feasibility of focused microwave-assisted Soxhlet extraction of Nmethylcarbamates from soil, J. Chromatogr. A, 953, $133-140$ (2002).

[156] H. Li, J. Li, G. Li, J. Jen, Simultaneous determination of airborne carbamates in workplace by high performance liquid chromatography with fluorescence detection, Talanta, 63, 547-553 (2004).

[157] T. Pérez-Ruiz, C. Martínez-Lozano, V. Tomás, J. Martín, High-performance liquid chromatographic assay of phosphate and organophosphorus pesticides using a post-column photochemical reaction and fluorimetric detection, Anal. Chim. Acta, 540, 383-391 (2005).

[158] B. Le Bot, K. Colliaux, D. Pelle, C. Briens, R. Seux, M. Clément, Optimization and performance evaluation of the analysis of glyphosate and AMPA in water by HPLC with fluorescence detection, Chromatographia, 56, 161-164 (2005).

[159] A. López, D. Vega, M. E. Torres, Z. Sosa, J. J. Santana, Solid-phase microextraction of benzimidazole fungicides in environmental liquid samples and HPLCfluorescence determination, Anal. Bioanal. Chem., 387, 1957-1963 (2007).

[160] H. Z. Lian, Y. F. Kang, A. Yasin, S. P. Bi, D. L. Shao, Y. J. Chen, L. M. Dai, L. C. Tia, Determination of aluminium in environmental and biological samples by reversed-phase high-performance liquid chromatography via pre-column complexation with morin, J. Chromatogr. A, 993, 179-185 (2003).

[161] T. Umemuraa, Y. Usamia, S. Aizawaa, K. Tsunodaa, K. Satakeb, Seasonal change in the level and the chemical forms of aluminium in soil solution under a Japanese cedar forest, Sci. Total Environ., 317, 149-157 (2003).

[162] J. L. Santos, I. Aparicio, E. Alonso, M. Callejón, Simultaneous determination of pharmaceutically active compounds in wastewater samples by solid phase extraction and high-performance liquid chromatography with diode array and fluorescence detectors, Anal. Chim. Acta, 550, 116-122 (2005). 
[163] M. Sturini, A. Speltini, L. Pretali, E. Fasani, A. Profumo, Solid-phase extraction and HPLC determination of fluoroquinolones in surface waters, J. Sep. Sci., 32, 3020-3028 (2009).

[164] M. Granados, M. Encabo, R. Compañó, M. D. Prat, Determination of Tetracyclines in Water Samples Using Liquid Chromatography with Fluorimetric Detection, Chromatographia, 61, 471-477 (2005).

[165] J. L. Santos, I. Aparicio, E. Alonso, Occurrence and risk assessment of pharmaceutically active compounds in wastewater treatment plants. A case study: Seville city (Spain), Environ. Intern., 33, 596-601 (2007).

[166] X. Peng, Z. Wang, W. Kuang, J. Tan, K. Li, A preliminary study on the occurrence and behavior of sulfonamides, ofloxacin and chloramphenicol antimicrobials in wastewaters of two sewage treatment plants in Guangzhou, China, Sci. Total Environ., 371, 314-322 (2006).

[167] E. M. Golet, A. C. Alder, A. Hartmann, T. A. Ternes, W. Giger, Trace determination of fluoroquinolone antibacterial agents in urban wastewater by solid-phase extraction and liquid chromatography with fluorescence detection, Anal. Chem., 73, 3632-3638 (2001).

[168] X. Peng, J. Tan, C. Tang, Y. Yu, Z. Wang, Multiresidue determination of fluoroquinolone, sulfonamide, trimethoprim, and chloramphenicol antibiotics in urban waters in China, Environ. Toxicol. Chem., 27, 73-79 (2008).

[169] M. Seifrtová, A. Pena, C. M. Lino, P. Solich, Determination of fluoroquinolone antibiotics in hospital and municipal wastewaters in Coimbra by high performance liquid chromatography using a monolithic column and fluorescence detection, Anal. Bioanal. Chem., 391, 799-805 (2008).

[170] A. V. Herrera-Herrera, J. Hernandez-Borges, M. A. Rodríguez-Delgado, Ionic liquids as mobile phase additives for the high-performance liquid chromatographic analysis of fluoroquinolone antibiotics in water samples, Anal. Bioanal. Chem, 392, 1439-1446 (2008).

[171] A. Pena, D. Chmielova, C. M. Lino, P. Solich, Determination of fluoroquinolone antibiotics in surface waters from Mondego River by high performance liquid chromatography using a monolithic column, J. Sep. Sci., 30, 2924-2928 (2007).

[172] L. Zhao, Y. H. Dong, H. Wang, Residues of veterinary antibiotics in manures from feedlot livestock in eight provinces of China, Sci. Total Environ., 408, 10691075 (2010).

[173] B. J. Robinson, J. Hellou, Biodegradation of endocrine disrupting compounds in harbour seawater and sediments, Sci. Total Environ., 407, 5713-5718 (2009).

[174] P. A. Blackwell, H. C. Holten, H. P Mab, B. HallingSørensen, A. B. A. Boxall, P. Kaya, Ultrasonic extraction of veterinary antibiotics from soils and pig slurry with SPE clean-up and LC-UV and fluorescence detection, Talanta 64, 1058-1064 (2004).

[175] M. Ö. Uslu, A. Yediler, I. A. Balcıoğlu, S. SchulteHostede, Analysis and Sorption Behavior of Fluoroquinolones in Solid Matrices, Water Air Soil Pollut, 190, 55-63 (2008).
[176] M. D. Prat, D. Ramil, R. Compañó, J. A. HernándezArteseros, M. Granados, Determination of flumequine and oxolinic acid in sediments and soils by microwaveassisted extraction and liquid chromatography-fluorescence, Anal. Chim. Acta, 567, 229-235 (2006).

[177] L. K. Sørensen, H. Hansen, Determination of oxolinic acid in marine sediments by HPLC with fluorescence detection, J. Liq. Chromatogr. Relat. Technol., 24, 2469-2476 (2001).

[178] S. Morales-Muñoz, J. L. Luque-García, M. D. Luque de Castro, Continuous microwave-assisted extraction coupled with derivatization and fluorimetric monitoring for the determination of fluoroquinolone antibacterial agents from soil samples, J. Chromatogr. A, 1059, 25-31 (2004).

[179] J. S. Ra, S. Y Oh, B. C. Lee, S. D. Kim, The effect of suspended particles coated by humic acid on the toxicity of pharmaceuticals, estrogens, and phenolic compounds, Environ. Intern., 34, 184-192 (2008).

[180] R. Delépée, H. Pouliquen, H. Le Bris, The bryophyte Fontinalis antipyretica Hedw. bioaccumulates oxytetracycline, flumequine and oxolinic acid in the freshwater environment, Sci. Total Environ., 322, 243- 253 (2004).

[181] F. Tagliaro, G. Manetto, F. Crivellente, F. P. Smith, A brief introduction to capillary electrophoresis, Forensic Sci. Int., 92, 75-88 (1998).

[182] K. D. Altria, Overview of capillary electrophoresis and capillary electrochromatography, J. Chromatogr. A, 856, 443-463 (1999).

[183] P. Puig, F. Borrull, M. Calull, C. Aguilar, Recent advances in coupling solid-phase extraction and capillary electrophoresis (SPE-CE), Trends Anal. Chem., 26, 664-678 (2007).

[184] B. M. Simonet, A. Ríos, M. Valcárcel, Enhancing sensitivity in capillary electrophoresis, Trends Anal. Chem., 22, 605-614 (2003).

[185] S. L. Simpson Jr., J. P. Quirino, S. Terabe, On-line sample preconcentration in capillary electrophoresis. Fundamentals and applications, J. Chromatogr. A, 1184, 504-541 (2008).

[186] J. S. Fritz, The role of organic solvents in the separation of nonionic compounds by capillary electrophoresis, Electrophoresis, 24, 1530-1536 (2003).

[187] M. G. Garguilo, D. H. Thomas , D. S. Anex , D. J. Rakestraw, Laser-induced dispersed fluorescence detection of polycyclic aromatic compounds in soil extracts separated by capillary electrochromatography, $J$. Chromatogr. A, 883, 447-452 (2000).

[188] D. Norton, S. A. Shamsi, Capillary electrochromatography of methylated benzo $[a]$ pyrene isomers. II. Effect of stationary phase tuning, J. Chromatogr. A, 1008, 217-232 (2003).

[189] A. Cantó-Mirapeix, J. M. Herrero-Martínez, C. Mongay-Fernández, E. F. Simó-Alfonso, CEC column behaviour of butyl and lauryl methacrylate monoliths prepared in non-aqueous media, Electrophoresis, 30, 607-615 (2009).

[190] D. A. Stead, R. G. Reid, R. B. Taylor, Capillary electrochromatography of steroids: Increased sensitivity by 
on-line concentration and comparison with highperformance liquid chromatography, J. Chromatogr. A, 798, 259-267 (1998).

[191] L. Geiser, J. L. Veuthey, Non-aqueous capillary electrophoresis 2005-2008, Electrophoresis, 30, 36-49 (2009).

[192] S. J. Kok, I. C. Isberg, C. Gooijer, U. Brinkman, N. H. Velthorst, Ultraviolet laser-induced fluorescence detection strategies in capillary electrophoresis: determination of naphthalene sulphonates in river water, Anal. Chim. Acta, 360, 109-118 (1998).

[193] R. Loos, R. Niessner, Analysis of aromatic sulfonates in water by solid-phase extraction and capillary electrophoresis, J. Chromatogr. A, 822, 291-303 (1998).

[194] D. Martínez, M. J. Cugat, F. Borrull, M. Calull, Solidphase extraction coupling to capillary electrophoresis with emphasis on environmental analysis, J. Chromatogr. A, 902, 65-89 (2000).

[195] R. Ramautar, G. W. Somsen, G. J. de Jong, Recent developments in coupled SPE-CE, Electrophoresis, 27, 4694-4702 (2010).

[196] M. Marlow, R. J. Hurtubise, Liquid-liquid-liquid microextraction for the enrichment of polycyclic aromatic hydrocarbon metabolites investigated with fluorescence spectroscopy and capillary electrophoresis, Anal. Chim. Acta, 526, 41-49 (2004).

[197] P. M. do Rosário, J. M. Nogueira, Combining stir bar sorptive extraction and MEKC for the determination of polynuclear aromatic hydrocarbons in environmental and biological matrices, Electrophoresis, 27, 46944702 (2006).

[198] J. Hernández-Borges, S. Frías-García, A. Cifuentes, M. A. Rodríguez-Delgado, Pesticide analysis by capillary electrophoresis, J. Sep. Sci., 27, 947-963 (2004).

[199] M. Molina, M. Silva, In-capillary derivatization and analysis of amino acids, amino phosphonic acid-herbicides and biogenic amines by capillary electrophoresis with laser-induced fluorescence detection, Electrophoresis, 23, 2333-2340 (2002).

[200] T. Tegeler, Z. El Rassi, Capillary electrophoresis and electrochromatography of pesticides and metabolites, Electrophoresis, 22, 4281-4293 (2001).

[201] Y. Picó, R. Rodríguez, J. Mañes, Capillary electrophoresis for the determination of pesticide residues, Trends Anal. Chem., 22, 133-151 (2003).

[202] Y. Picó, Capillary electrophoresis, environmental applications, Encyclopedia of Analytical Science, 362374 (2005).

[203] M. Asensio-Ramos, Javier Hernández-Borges, L. M. Ravelo-Pérez, M. A. Rodríguez-Delgado, Simultaneous determination of seven pesticides in waters using multiwalled carbon nanotube SPE and NACE, Electrophoresis, 29, 4412-4421 (2008).

[204] E. Rodríguez-Gonzalo, L. Ruano-Miguel, R. CarabiasMartínez, In-capillary microextraction using monolithic polymers: Application to preconcentration of carbamate pesticides prior to their separation by MEKC, Electrophoresis, 30, 1913-1922 (2009).

[205] R. Carabias-Martínez, E. Rodríguez-Gonzalo, J. Domínguez-Alvarez, C. García-Pinto, J. Hernández-Mén- dez, Prediction of the behaviour of organic pollutants using cloud point extraction, J. Chromatogr. A, 1005, 23-34 (2003).

[206] A. Juan-García, Y. Picó, G. Font, Capillary electrophoresis for analyzing pesticides in fruits and vegetables using solid-phase extraction and stir-bar sorptive extraction, J. Chromatogr. A, 1073, 229-236 (2005).

[207] R. Carabias-Martínez, E. Rodríguez-Gonzalo, E. MirandaCruz, J. Domínguez-Álvarez, J. Hernández-Méndez, Sensitive determination of herbicides in food samples by nonaqueous $\mathrm{CE}$ using pressurized liquid extraction, Electrophoresis, 28, 3606-3616 (2007).

[208] M. Silva, Micellar electrokinetic chromatography: Methodological and instrumental advances focused on practical aspects, Electrophoresis, 30, 50-64 (2009).

[209] S. Chen, Y. Xu, Y. Bi, W. Du, B. F. Liu, Analysis of environmental pollutants metabolized from pesticides using capillary electrophoresis with multiphoton-excited fluorescence detection, Talanta, 70, 63-67 (2006).

[210] J. Jiang, C. A. Lucy, Determination of glyphosate using off-line ion exchange preconcentration and capillary electrophoresis-laser induced fluorescence detection, Talanta, 72, 113-118 (2007).

[211] W. Wall, J. Li, Z. El Rassi, Electrically driven microseparation methods for pesticides and metabolites Part VII: Capillary electrophoresis and electrochromatography of derivatized and underivatized phenol pesticidic metabolites. Preconcentration and laser induced fluorescence detection of dilute samples, J. Sep. Sci., 25, 1231-1244 (2002).

[212] R. Zhu, W. T. Kok, Determination of trace metal ions by capillary electrophoresis with fluorescence detection based on post-column complexation with 8-hydroxyquinoline-5-sulphonic acid, Anal. Chim. Acta, 371, 269-277 (1998).

[213] K. Isoo, S. Terabe, Metal complex separation with online sample preconcentration in micellar electrokinetic chromatography, Anal. Sci., 21, 43-47 (2005).

[214] W. Liu, H. K. Lee, Simultaneous analysis of lead, mercury and selenium species by capillary electrophoresis with combined ethylenediaminetetraacetic acid complexation and field-amplified stacking injection, Electrophoresis, 20, 2475-2483 (1999).

[215] Z. Zhu, L. Zhang, A. Marimuthu, Z. Yang, Largevolume sample stacking for analysis of ethylenediaminetetraacetic acid by capillary electrophoresis, Electrophoresis, 23, 2880-2887 (2002).

[216] H. Okamoto, Y. Okamoto, T. Hirokawa, A. R. Timerbaev, Trace ion analysis of sea water by capillary electrophoresis: determination of strontium and lithium pre-concentrated by transient isotachophoresis, Analyst, 128, 1439-1442 (2003).

[217] A. Takatsu, S. Eyama, A. Uchiumi, Determination of Aluminum in Serum by Capillary Zone Electrophoresis with Laser-lnduced Fluorescence Detection, Chromatographia, 40, 125-128 (1995).

[218] S. Y. Chang, H. T. Chiang, Simultaneous determination of selenium and antimony compounds by capillary electrophoresis with indirect fluorescence detection, Electrophoresis, 23, 2913-2917 (2002). 
[219] S. Saito, R. Suzuki, N. Danzaka, A. Hikichi, K. Yoshimoto, M. Maeda, M. Aoyama, Direct fluorometric detection of paramagnetic and heavy metal ions at subamol level using an aromatic polyaminocarboxylate by CZE: Combination of pre- and on-capillary complexation technique, Electrophoresis, 28, 2448-2457 (2007).

[220] S. Saito, J. Shimidzu, K. Yoshimoto, M. Maeda, M. Aoyama, Selective ultratrace detection of $\mathrm{Al}(\mathrm{III})$ and $\mathrm{Ga}(\mathrm{III})$ complexed with a calcein isomer by capillary zone electrophoresis with laser-induced fluorescence detection: Comparison of emissive polyaminocarboxylates as derivatizing ligands, J. Chromatogr. A, 1140, 230-235 (2007).

[221] L. Ma, J. Kang, Determination of mercury ion by MEKC with on-column derivatisation and LIF detection, J. Sep. Sci., 31, 888-892 (2008).

[222] J. M. Lemus-Gallego, J. Perez-Arroyo, Determination of hydrocortisone, polymyxin B and Zn-bacitracin in pharmaceutical preparations by micellar electrokinetic chromatography, Anal. Bioanal. Chem., 375, 617-622 (2003)

[223] A. Macià , F. Borrull, M. Calull, C. Aguilar, Analysis of nonsteroidal anti-inflammatory drugs in water samples using microemulsion electrokinetic capillary chromatography under $\mathrm{pH}$-suppressed electroosmotic flow with an on-column preconcentration technique, Chromatographia, 63, 149-154 (2006).

[224] J. M. Serrano, M. Silva, Trace analysis of aminoglycoside antibiotics in bovine milk by MEKC with LIF detection, Electrophoresis, 27, 4703-4710 (2006).

[225] T. D. Laing, A. J. Marenco, D. M. Moore, G. J. Moore, D. C. Mah, W. E. Lee, Capillary electrophoresis laserinduced fluorescence for screening combinatorial peptide libraries in assays of botulinum neurotoxin A, $J$. Chromatogr. B, 843, 240-246 (2006).

[226] W. Wang, C. Li, Y. Li, Z. Hu, X. Chen, Rapid and ultrasensitive determination of ephedrine and pseudoephedrine derivatizated with 5-(4,6-dichloro-s-triazin2-ylamino) fluorescein by micellar electrokinetic chromatography with laser-induced fluorescence detection, J. Chromatogr. A, 1102, 273-279 (2006).

[227] J. C. Hudson, M. Golin, M. Malcolm, C. F. Whiting, Capillary zone electrophoresis in a comprehensive screen for drugs of forensic interest in whole blood: an update, Can. Soc. Forensic. Sci. J., 31, 1-29 (1998).

[228] A. Musengaa, E. Kenndler, E. Morgantia, F. Rasic, M. A. Raggi, Analysis of the anti-Parkinson drug pramipexole in human urine by capillary electrophoresis with laser-induced fluorescence detection, Anal. Chim. Acta, 626, 89-96 (2008).

[229] A. Musenga, M. Amore, R. Mandrioli, E. Kenndlerc, L. de Martino, M. Augusta Raggi, Determination of duloxetine in human plasma by capillary electrophoresis with laser-induced fluorescence detection, J. Chromatogr. B, 877, 1126-1132 (2009).

[230] M. Hernández, F. Borrull, M. Calull, Analysis of antibiotics in biological samples by capillary electrophoresis, Trends Anal. Chem., 22, 416-427 (2003).
[231] J. Ruzicka, E. H. Hansen, Retro-review of flowinjection analysis, Trends Anal. Chem., 27, 390-393 (2008).

[232] M. A. Segundo, L. M. Magalhaes, Multisyringe flow injection analysis: State-of-the-art and perspectives, Anal. Sci., 22, 3-8 (2006).

[233] J. Ruzicka, E. H. Hansen, Flow injection analyses. Part I. A new concept of fast continuous flow analysis, Anal. Chim. Acta , 78, 145-157 (1975).

[234] X. Wang, M. L. Liu, X. L. Cheng, J. M. Lin, Flowbased luminescence-sensing methods for environmental water analysis, Trends Anal. Chem., 28, 75-87 (2009).

[235] J. F. Fernández-Sánchez, A. S. Carretero, C. CrucesBlanco, A. Fernández-Gutiérrez, Highly sensitive and selective fluorescence optosensor to detect and quantify benzo $[a]$ pyrene in water samples, Anal. Chim. Acta, 506, 1-7 (2004).

[236] J. F. Fernández-Sánchez, A. Segura-Carretero, J. M. Costa-Fernández, N. Bordel, R. Pereiro, C. CrucesBlanco, A. Sanz-Medel, A. Fernández-Gutiérrez, Fluorescence optosensors based on different transducers for the determinativos of polycyclic aromatic hydrocarbons in water, Anal. Bioanal. Chem., 377, 614(2003).

[237] J. F. Fernández-Sánchez, A. S. Carretero, C. CrucesBlanco, A. Fernández-Gutiérrez, The development of solid-surface fluorescence characterization of polycyclic aromatic hydrocarbons for potential screening tests in environmental samples, Talanta, 60, 287-293 (2003).

[238] J. A. Erustes, A. Andrade-Eiroa, A. Cladera, R. Forteza, V. Cerdà, Fast sequential injection determination of benzo $[a]$ pyrene using variable angle fluorescence with on-line solid-phase extraction, Analyst, 126, 451456 (2001).

[239] A. Domínguez-Vidal, P. Ortega-Barrales, A. MolinaDíaz, Environmental water samples analysis of pesticides by means of chemometrics combined with fluorimetric multioptosensing, J. Fluoresc., 17, 271277 (2007).

[240] G. S. Furzer, L. Veldhuis, J. C. Hall, Development and comparison of three diagnostic immunoassay formats for the detection of azoxystrobin, J. Agric. Food Chem., 54, 688-693 (2006).

[241] I. Súbová, A. K. Assandas, M. C. Icardo, J. M. Calatayud, Fluorescence determination of the pesticide asulam by flow injection analysis, Anal. Sci., 22, 21-24 (2006).

[242] S. Irace-Guigand, E. Leverend, M. D. Gaye-Seye, J. J. Aaron, A new on-line micellar-enhanced photochemically-induced fluorescence method for determination of phenylurea herbicide residues in water, Luminescence, 20, 138-142 (2005).

[243] M. Šandor, F. Geistmann, M. Schuster, Luminescent hexanuclear $\mathrm{Cu}(\mathrm{I})$-cluster for the selective determination of copper, Anal. Chim. Acta, 486, 11-19 (2003).

[244] J. Ueberfeld, N. Parthasarathy, H. Zbinden, N. Gisin, J. Buffle, Coupling fiber optics to a permeation liquid membrane for heavy metal sensor development, Anal. Chem., 74, 664-670 (2002). 
[245] C. Cano-Raya, M. D. Fernández-Ramos, L. F. CapitánVallvey, Fluorescence resonance energy transfer disposable sensor for copper(II), Anal. Chim. Acta, 555, 2 (2006) 299.

[246] S. Meseguer-Lloret, P. Campin-Falco, S. Cárdenas, M. Gallego, M. Valcarcel, FI automatic method for the determination of copper(II) based on coproporphyrin I$\mathrm{Cu}(\mathrm{II}) / \mathrm{TCPO} / \mathrm{H}_{2} \mathrm{O}_{2}$ chemiluminescence reaction for the screening of waters, Talanta, 64, 1030-1035 (2004).

[247] H. Wu, Y. Jin, W. Han, Q. Miao, S. Bi, Nonchromatographic speciation analysis of mercury by flow injection on-line preconcentration in combination with chemical vapor generation atomic fluorescence spectrometry, Spectrochim. Acta. Part. B At. Spec., 61, 831-840 (2006).

[248] A. M. Serra, J. M. Estela, V. Cerdà, MSFIA system for mercury determination by cold vapour technique with atomic fluorescence detection, Talanta, 77, 556-560 (2008).

[249] Y. Xu, F. G. Bessoth, J. C. T. Eijkel, A. Manz, On-line monitoring of chromium(III) using a fast micromachined mixer/reactor and chemiluminescence detection, Analyst, 125, 677-683 (2000).

[250] C. Xiao, D. W. King, D. A. Palmer, D. J. Wesolowski, Study of enhancement effects in the chemiluminescence method for $\mathrm{Cr}(\mathrm{III})$ in the $\mathrm{ng}^{-1}$ range, Anal. Chim. Acta, 415, 209-219 (2000).

[251] W. Som-Aum, J. Threeprom, H. F. Li, J. M. Lin, Determination of chromium(III) and total chromium using dual channels on glass chip with chemiluminescence detection, Talanta, 71, 2062-2068 (2007).

[252] A. Economou, A. K. Clark, P. R. Fielden, Determination of $\mathrm{Co}$ (II) by chemiluminescence after in situ electrochemical pre-separation on a flow-through mercury film electrode, Analyst, 126, 109-113 (2001).

[253] L. A. Tortajada-Genaro, P. Campins-Falco, F. BoschReig, Analyser of chromium and/or cobalt, Anal. Chim. Acta, 488, 243-254 (2003).

[254] M. Li, S. H. Lee, Determination of As(III) and As(V) ions by chemiluminescence method, Microchem. J., 80, 237-240 (2005).

[255] L. N. Li, N. B. Li, H. Q. Luo, A new chemiluminescence method for the determination of nickel ion, Spectrochim. Acta, Part A, 64, 391-396 (2006).

[256] V. Cannizzaro, A. R. Bowie, A. Sax, E. P. Achterberg, P. J. Worsfold, Determination of cobalt and iron in estuarine and coastal waters using flow injection with chemiluminescence detection, Analyst, 125, 51-57 (2000).

[257] E. K. Paleologos, C. D. Stalikas, S. M. TzouwaraKarayanni, M. I. Karayannis, Selective speciation of trace chromium through micelle-mediated preconcentration, coupled with micellar flow injection analysisspectrofluorimetry, Anal. Chim. Acta, 436, 49-57 (2001).

[258] E. K. Paleologos, A. G. Vlessidis, M. I. Karayannis, N. P. Evmiridis, On-line sorption preconcentration of metals based on mixed micelle cloud point extraction prior to their determination with micellar chemiluminescence: Application to the determination of chromium at ng $1^{-1}$ levels, Anal. Chim. Acta, 477, 223-231 (2003).
[259] E. K Paleogos, M. A. Koupparis, M. I. Karayannis, P. G. Veltsistas, Nonaqueous catalytic fluorimetric trace analysis of vanadium bases on the pyronine Bhydrogen peroxide reaction and flow injection after cloud point extraction, Anal. Chem., 74, 664-670 (2002).

[260] M. I. Acedo-Valenzuela, T. Galeano-Díaz, N. MoraDíez, A. Silva-Rodríguez, Response surface methodology for the optimisation of flow-injection analysis with in situ solvent extraction and fluorimetric assay of tricyclic antidepressants, Talanta, 66, 952-960 (2005).

[261] A. G. Lista, M. E. Palomeque, B. S. Fernández-Band, A fast fluorimetric flow injection method to determine ibuprofen, J. Braz. Chem. Soc., 17, 1428-1431 (2006).

[262] D. A. Lerner, M. A. Martin, Luminescence in organized media and supramolecular interactions: physicochemical aspects and applications, Analusis, 28, 649$663(2000)$.

[263] J. J. Juan Santana-Rodríguez, Z. Sosa-Ferrera, D. Vega-Moreno, M. E. Torres-Padrón, C. MahugoSantana, Recent trends in the use of organized molecular systems combined with chromatographic techniques in environmental analysis, Anal. Bioanal. Chem., 391, 725-733 (2008).

[264] S. Montesdeoca-Esponda, M. E. Torres-Padrón, Z. SosaFerrera, J. J. Juan Santana-Rodríguez, Solid-phase microextraction with micellar desorption and HPLC-fluorescence detection for the analysis of Fluoroquinolones residues in water samples, Anal. Bioanal. Chem., 394, 927-935 (2009).

[265] Y. Wu, L. Xia, R. Chen, B. Hu, Headspace single drop microextraction combined with HPLC for the determination of trace polycyclic aromatic hydrocarbons in environmental samples, Talanta, 74, 470-477 (2008).

[266] E. K. Paleologos, D. L. Giokas, M. I. Karayannis, Micelle-mediated separation and cloud-point extraction, Trends Anal. Chem., 24, 426-436 (2005).

[267] A. Eiguren-Fernández, Z. Sosa-Ferrera, J. J. SantanaRodríguez, Application of cloud-point methodology to the determination of polychlorinated dibenzofurans in sea water by high-performance liquid chromatography, Analyst, 124, 487-491 (1999).

[268] A. Eiguren-Fernández, Z. Sosa-Ferrera, J. J. SantanaRodríguez, Determination of polychlorinated biphenyls by liquid chromatography following cloud-point extraction, Anal. Chim. Acta., 358, 145-155 (1998).

[269] D. Sicilia, S. Rubio, D. Pérez-Bendito, N. Maniasso, E. A. G. Zagatto, Anionic surfactants in acid media: a new cloud point extraction approach for the determination of polycyclic aromatic hydrocarbons in environmental samples, Anal. Chim. Acta., 392, 29-38 (1999).

[270] E. K. Paleologos, M. A. Koupparis, M. I. Karayannis, P. G. Veltsistas, Nonaqueous catalytic fluorometric trace determination of vanadium based on the pyronine B-hydrogen peroxide reaction and flow injection after cloud point extraction, Anal. Chem., 73, 4428-4433 (2001).

[271] A. Eiguren-Fernández, Z. Sosa-Ferrera, J. J. SantanaRodríguez, Microwave-assisted extraction of organochlorine compounds in marine sediments with organized molecular systems, Chromatographia, 53, 375-379 (2001). 
[272] F. Merino, S. Rubio, D. Pérez-Bendito, Acid-induced cloud point extraction and preconcentration of polycyclic aromatic hydrocarbons from environmental solid samples, J. Chromatogr. A, 962, 1-8 (2002).

[273] A. Eiguren-Fernández, Z. Sosa-Ferrera, J. J. SantanaRodríguez, Application of microwave-assisted extraction using micellar media to the determination of polychlorinated biphenyls in marine sediments, Anal. Chim. Acta., 433, 237-244 (2001).

[274] A. Moral, D. Sicilia, S. Rubio, D. Pérez-Bendito, Sodium dodecyl sulphate-coated alumina for the extraction/preconcentration of benzimidazolic fungicides from natural waters prior to their quantification by liquid chromatography/fluorimetry, Anal. Chim. Acta., 369, 132-138 (2006).

[275] M. Marlow, R. J. Hurtubise, Separation and detection of a benzo $[a]$ pyrene metabolite with capillary electrophoresis in the presence of DNA using laser-induced fluorescence, Talanta, 57, 193-201 (2002).

[276] C. J. Smith, J. Grainer, D. G. Patterson Jr, Separation of polycyclic aromatic hydrocarbon metabolites by $\gamma$ cyclodextrin-modified micellar electrokinetic chromatography with laser-induced fluorescence detection, $J$. Chromatogr. A, 803, 241-247 (1998).
[277] J. Kuijt, C. García-Ruiz, G. J. Stroomberg, M. L. Marina, F. Ariese, U. A. Th. Brinkman, C. Gooijer, Laserinduced fluorescence detection at $266 \mathrm{~nm}$ in capillary electrophoresis Polycyclic aromatic hydrocarbon metabolites in biota, J. Chromatogr. A, 907, 291-299 (2001).

[278] J. H. T. Luong, The combined effect of acetonitrile and urea on the separation of polycyclic aromatic hydrocarbons using sodium dioctyl sulfosuccinate in electrokinetic chromatography, Electrophoresis, 19, 1461-1467 (1998).

[279] W. Wall, Z. El Rassi, Electrically driven microseparation methods for pesticides and metabolites: V. Micellar electrokinetic capillary chromatography of aniline pesticidic metabolites derivatized with fluorescein isothiocyanate and their detection in real water at low levels by laser-induced fluorescence, Electrophoresis, 22, 2312-2319 (2001).

[280] M. Navarrete-Casas, A. Segura-Carretero, C. CrucesBlanco, A. Fernández-Gutiérrez, Potential determination of aminated Pesticides and metabolites by cyclodextrin capillary electrophoresis-laser-induced fluorescence using FITC as labeling, Pest. Manag. Sci., 61,197-203 (2005). 
Copyright of Macedonian Journal of Chemistry \& Chemical Engineering is the property of Society of Chemists $\&$ Technologists of Macedonia and its content may not be copied or emailed to multiple sites or posted to a listserv without the copyright holder's express written permission. However, users may print, download, or email articles for individual use. 